\title{
Beitrag zur Kenntniss der Eiweisskörper der Kuhmilch.
}

Von

\section{Gustar Simon,}

cand. chem. aus Hambüren i. Westfalen.

Aus dem Laboratorium der agric.-chem. Versuchsstation zu Halle a. S.

(Der Redaction zugegangen am 14. Augast 1901.)

Die Eiweisskörper, besonders die in der Milch befindlichen, sind in den letzten Jahrzehnten der Gegenstand zahlreicher Untersuchungen gewesen. Die Ergebnisse jedoch, die aus diesen Arbeiten erzielt wurden, stehen zum Theil in scharfem Widerspruche mit einander. Nicht einmal über die Zahl der Eiweisskörper, darüber, ob die Kuhmilch einen oder mehrere Eiweisskörper besitzt, herrscht Einstimmigkeit. Die Forscher, die der Ansicht sind, es in der Milch mit mehreren von einander verschiedenen Eiweissstoffen zu thun zu haben, führen zwei, drei, ja bis zu acht verschiedene an.

Die Anwesenheit von nur einem Eiweisskörper in der Milch wird hauptsächlich betont von Duclaux, Pfeiffer, Biedert und Peters. Nach Duclaux ${ }^{1}$ ) enthält die Kuhmilch nur Casein, das in drei verschiedenen Formen vorkommt: "als festes, colloidales und gelöstes Casein.» Pfeiffer ${ }^{2}$ ) nimmt ebenfalls nur einen in mehrere Modificationen zerlegbaren Eiweisskörper, "das Casein», an und bezeichnet die vier verschiedenen Modificationen als a-Casein (fällbar durch Säuren und Lab), b-Casein (durch Erhitzen gerinnend), c-Casein (nach Abscheidung des a- und b-Casein in der Milch spontan bei 20-250 durch Lab sich ausscheidend), schliesslich d-Casein (nicht coagulabler, durch Tannin fällbarer Antheil). Diese Pfeiffer'sche Auffassung wird auch von Biedert ${ }^{3}$ ) vertreten.

1) Comptes rendus. 98. 1884.

2) Jahresbericht der Thierchemie. 1884.

3) Die Kinderernährung im Säuglingsalter, citirt nach Schlossmann, Zeitschr. f. physiol. Chem., Bd. XII, S. 204. 
Nach Peters ${ }^{1}$ ) kommt in der Milch nur ein Eiweisskörper vor, den er *Caseinogen* nennt.

Alle diese erwähnten Ansichten sind jedoch zur Genüge von verschiedenen Forschern widerlegt, von denen ich nur Sebelien ${ }^{2}$ ) und Schlossmann ${ }^{3}$ ) erwähnen will. Sebelien fand nämlich zwei wesentliche Punkte, durch die sich Albumin und Casein von einander unterscheiden. Casein enthält, wovon ich mich durch eine Analyse gleichfalls überzeugte, Phosphor; der im Albumin nicht vorkommt, ausserdem zeichnet es sich vor dem Albumin durch einen viel geringeren Schwefelgehalt aus. Schlossmann hebt mit Recht ausdrücklich hervor, dass Körper, die sich in ihrer Zusammensetzung durch Fehlen oder Anwesenheit eines Elementes unterscheiden; unmöglich Modificationen einer und derselben Substanz sein können.

Gegenüber den genannten Autoren, die also nur einen Eiweisskörper in der Milch gelten lassen wollen, glauben hinwiederum andere eine ganze Reihe verschiedener Eiweissstoffe gefunden zu haben. Sehr fruchtbar in der Beziehung waren Danilewsky und Radenhausen. ${ }^{4}$ ) Sie zerlegen das Casein in «Caseoalbumin» und «zwei Protalbstoffe (Alkalialbuminate)*. Auch das Molkeneiweiss sei kein einheitlicher Stoff und wird deshalb von ihnen noch weiter zerlegt; sie unterscheiden «Orroprotein», gelöstes «Stromaalbumin * und "Lacto-syntoProtalbstoffe ; letztere beständen wieder aus drei verschiedenen. Stoffen: «Lactosyntogen", «echtes Pepton» und «Pseudopepton*. Die Arbeiten von Danilewsky und Radenhausen sind von Hammarsten einer kritischen Beleuchtung unterworfen worden und in einer längeren Abhandlung mit Glück widerlegt.s)

1) R. Peters, Untersuchungen über das Lab und die labähnlichen Fermente, von der medic. Facultät preisgekrönte Schrift. Rostock 1894.

2) Hoppe-Seyler, Zeitschr. f. physiol. Chem., Bd. IX, S. 460 u. Bd. XIII, S. 167 u. folg.

3) Hoppe-Seyler, Zeitschr. f. physiol. Chem., Bd. XII, S. 206 u. folg.

4) Petersen, Forschungen auf dem Gebiete der Viehhaltung und ihre Erzeugnisse. Heft 9, 1880: Untersuchungen über die Eiweissstoffe der Milch von Prof. Dr. A. Danilewsky und Dr. P. Radenhausen.

5) Zur Frage, ob das Casein ein einheitlicher Stoff sei, von Olof Hammarsten, Hoppe-Seyler, Zeitschr. f. physiol. Chem, Bd. VII, S. 227 u. folg. 
Wie man aus dem bisher Gesagten ersieht, herrscht also an sich direkt widersprechenden Ansichten kein Mangel. Für diese merkwürdige Erscheinung lässt sich sehr leicht der Grund finden. Einmal erklären sich diese zahlreichen Widersprüche in Beziehung auf Zahl und Zusammensetzung der Eiweissstoffe aus der mehr oder weniger grossen Brauchbarkeit der von den verschiedenen Forschern angewandten Methoden zur Isolirung der einzelnen Eiweisskörper. Dann wieder haben wir in den Eiweissstoffen sehr complicirte, hochmolekulare Verbindungen vor uns, die in Folge der grossen Anzahl von Stoffgruppen, aus denen sie sich zusammensetzen, wenig constant sind und zu Umlagerungen und Zersetzungen schon spontan, vor Allem aber beim Einwirken chemischer Reagentien, physikalischer Einflüsse und in Folge der Thätigkeit von Enzymen, Bacterien etc. neigen, so dass man im Unklaren darüber sein kann, ob man es mit den ursprünglichen, vom Thier gelieferten, unveränderten Eiweissverbindungen oder aber mit Umwandlungs- und Abspaltungsprodukten zu thun hat. Trotz aller dieser Schwierigkeiten, die sich der Erforschung der Eiweissstoffe hindernd entgegen stellen, ist jetzt wohl ohne jeden Zweifel und mit Sicherheit anzunehmen, dass sich in der frischen Milch drei Eiweissverbindungen befinden, und zwar das Casein, das Albumin und das Globulin. Wenn ich mich dieser herrschenden Ansicht auch völlig anschliesse, so lasse ich dabei doch die Frage, ob diese drei genannten Stoffe Einzelindividuen sind oder noch weiter zerlegbar seien, offen. Denn wie auf anderen Gebieten der Chemie das Bestreben herrscht, Stoffe, die bisher unantastbar als Elemente galten, zu zerlegen, und oft mit Erfolg, genau so ist es auch denkbar, diese complicirten Eiweissgebilde noch weiter zu zerlegen; bis jetzt ist es aber noch nicht gelungen! Ob ausser den drei genannten Stoffen auch noch Pepton Bestandtheil der Milch ist, eine Behauptung, die namentlich Schmidt-Mühlheim $^{1}$ ) verficht, (er behauptet, Pepton in jeder untersuchten Milch stets präformirt gefunden zu haben), darüber sind selbst

1) Pflüger, Arch.f. d. gesammte Physiol., Bd.XXVIII, S. 287, 1882. 
Autoritäten auf diesem Gebiete nicht einig, Sebelien, Hofmeister, $\left.{ }^{1}\right)$ Arnold, $\left.{ }^{2}\right)$ Kirchner ${ }^{3}$ etc. Sebelien, ${ }^{4}$ ) dem wir überhaupt bei der Analyse der Milch so manche Förderung verdanken, hat auch über diese specielle Frage eingehende Untersuchungen angestellt und niemals, weder in frischer noch in alter, saurer Milch, von einer ganzen Heerde wie von einzelnen Kühen, zu keiner Zeit der Lactation auch nur Spuren von Pepton nachweisen können. Auf meine eigenen Erfahrungen über diesen Punkt komme ich später zurück.

Bei dem grossen Interesse, das Chemiker und Physiologen von jeher den Eiweisskörpern entgegengebracht haben, ist naturgemäss die Zahl der zur Bestimmung und Isolirung der Eiweissstoffe vorgeschlagenen Methoden eine ausserordentlich hohe. Ueber ihre Brauchbarkeit und Genauigkeit weist die Litteratur die verschiedensten Angaben auf. Ich habe mir nun die Aufgabe gestellt, im Folgenden zunächst die quantitativen Fällungseigenschaften einiger Mittel einer kritischen Beobachtung zu unterziehen.

Grundsätzlich habe ich bei allen folgenden Untersuchungen die gewichtsanalytische Bestimmung der Eiweissverbindungen vermieden. Wahrscheinlich sind nämlich, wie auch Sebelien ${ }^{5}$ ) angibt, die Mengenverhältnisse, in denen die Reagentien sich mit den Eiweisskörpern verbinden, keineswegs constant, so dass die Feststellung des Gewichts des Niederschlags zu grossen Ungenauigkeiten führen würde. Die Eiweisskörper rein darzustellen, also von ihrem Fällungsmittel völlig zu trennen, ist sehr schwierig, vielfach unmöglich, so dass dann das Wägen Fehler im Gefolge haben würde. Schliesslich treten bei den hohen Temperaturen, denen die Eiweisskọrper, um sie zu trocknen, von den verschiedensten Forschern unterworfen werden $\left(125^{\circ}\right.$ C. $)$, so leicht Zersetzungen und Umwandlungen ein, dass auch hierdurch Fehler bedingt sind.

1) Hoppe-Seyler, Zeitschr. f. physiol. Chem., Bd. II, S. 288.

2) Jahresbericht der Thierchemie, 1881, S. 167.

3). Beitrag zur Kenntniss der Kuhmilch etc. Dresden 1877, S. 42.

4) Hoppe-Seyler, Zeitschr. f. physiol. Chem., Bd. XIII, S. 153.

5) Hoppe-Seyler, Zeitschr. f. physiol. Chem., Bd. XIII, S. 158. 
Von diesen Erwägungen geleitet, habe ich nach Sebelien's Vorschlage (oben) stets nur den Stickstoffgehalt der Eiweissniederschläge und der Filtrate mittelst der Kjeldahl'schen Methode festgestellt. Die vorher angeführten, bei der Gewichtsanalyse leicht eintretenden Fehler sind bei dieser Methode völlig ausgeschlossen, so dass die Genauigkeit der Resultate in keiner Weise gefährdet ist. Unbeschadet ihrer Genauigkeit bietet dann diese Methode als wesentlichen Vortheil die Möglichkeit einer schnellen und bequemen Ausführung einer grösseren Anzahl von Analysen resp. Untersuchungen. Bei der Wahl der Kjeldahl'schen Stickstoffbestimmungsmethode kam selbstverständlich eine ganze Gruppe von Fällungsreagentien bei meiner Prüfung von vornherein in Wegfall (z. B. Nitrate, Ammonium-, Cyanverbindungen, überhaupt alle solcheVerbindungen, die Stickstoff im Moleküle enthalten). Von den noch übrigen Methoden habe ich nur die in der Fachlitteratur bekanntesten in den Bereich meiner Untersuchungen gezogen. Die Reihenfolge, in der die Prüfung der Fällungsmittel erfolgen musste, war von selbst gegeben: Zunächst hatte ich mein Augenmerk auf die Verbindungen zu richten, die im Stande sind, die Gesammteiweisskörper der Milch niederzuschlagen, an zweiter Stelle mussten sich jene anschliessen, die eine theilweise Fällung bewirken und eine Trennung und Isolirung der einzelnen Stoffe ermöglichen.

\section{Theil.}

Methoden zur Bestimmung des Gesammteiweisses.

\section{Methode: Fällung mit Gerbsäurelösung.}

Unter den Verbindungen, die die Eigenschaft haben sollen, die gesammten Eiweissstoffe der Milch quantitativ abzuscheiden, ist die bekannteste die Gerbsäure. Zuerst von Almén empfohlen, ${ }^{1}$ ) wurde sie dann von verschiedenen Forschern mehr oder weniger eingehend auf ihre Fällungsfähigkeit hin untersucht. Ich nenne hier Liborius, ${ }^{2}$ ) Girgensohn ${ }^{3}$ ) und

1) Upsala lakare förenings förhandlingar, 1870.

2) Beiträge zur quantitativen Eiweissbestimmung. Diss. Dorpat 1871.

3) Beitrag zur Albuminometrie und zur Kenntniss der Tanninverbindungen der Albuminate, Diss. Dorpat 1872. 
Taraszkewicz. ${ }^{1}$ ) Die Versuche der Genannten, eine maassanalytische Bestimmungsmethode mit Gerbsäure zu finden (als Titerflüssigkeit benutzten sie eine Lösung, die 20 g Tannin, $400 \mathrm{ccm}$. 85\% igen Alkohol und 37,5 ccm. Eisessig im Liter enthält), mussten alle scheitern, da es sich herausstellte, dass das Tannin sich nicht constant mit denselben Gewichtseinheiten an das Eiweissmolekül anlagere, sondern bald mehr, bald weniger Tannin zur Abscheidung der Eiweissstoffe verbraucht wurde. Taraszkewicz beobachtete z. B., dass zwei Parallelbestimmungen in derselben Milch zur Fällung gleicher Eiweissmengen zwar ein gleiches Quantum Tannin erforderten; dieselbe Tanninmenge schlug aber in einer anderen Milch mehr, in einer anderen weniger Eiweiss nieder. Die maassanalytischen Methoden mussten deshalb verlassen werden, und T aras zk ewicz versuchte gewichtsanalytisch zum Ziele zu kommen, und zwar mit Erfolg. Es war nämlich möglich, aus dem fett- und gerbsäurehaltigen Eiweissniederschlage das Fett mit Petroläther und die Gerbsäure mit Alkohol rein auszuwaschen, so dass das reine Eiweiss gewogen werden konnte. Die Manipulationen zur Entfernung des Fettes und der Gerbsäure, des Trocknens und Wägens etc. fallen bei der Bestimmung des Stickstoffs; wie Eingangs erwähnt, fort, und ich hatte also mein Augenmerk nur darauf zu richten, ob in dem Gerbsäureniederschlage wirklich alles Eiweiss enthalten uar und beim Auswaschen darin verblieb.

Mit reiner Gerbsäure allein erreichte ich, wie ein Vorversuch ergab, eine quantitative Ausfällung nicht, und ich verwandte deshalb eine Mischung, die von Almén ${ }^{2}$ ) empfohlen wurde und so zusammengesetzt ist: $4 \mathrm{~g}$ Gerbsäure, $8 \mathrm{ccm}$. 25\% \% ige Essigsäure, $190 \mathrm{ccm}$. 40-50\% iger Alkohol. Diese Mischung habe ich bei allen hier angeführten Versuchen angewandt, und wenn ich später der Kürze halber nur von Gerbsäure oder Tannin spreche, so ist darunter immer nur die Almén'sche Gerbsäurelösung zu verstehen. Die

1) Einige Methoden z. Werthbestimmung der Milch. Diss. Dorpat 1873.

2) Citirt nach Sebelien, Zeitschr. f. physiol. Chem., Bd. XIII, S. 143, Anmerkung. 
Eiweissbestimmung wurde dann in folgender Weise ausgeführt: 10. ccm. Kuhmilch, deren Gewicht jedesmal ausdrücklich festgestellt wurde, wurden nach Verdünnung mit $100 \mathrm{ccm}$. destillirten Wassers mit einem Ueberschuss der Gerbsäuremischung (15 ccm. genügten in normaler frischer Milch immer) versetzt. Dann wurde mit einem Glasstabe kräftig umgerührt und einige Stunden stehen gelassen. Der Niederschlag setzte sich in kleinen Flocken gut $\mathrm{ab}$, so dass die überstehende Flüssigkeitsschicht völlig klar war. Es wurde decantirt und schliesslich der Niederschlag aufs Filter gebracht und mit kaltem Wasser ausgewaschen. Das Filtriren ging verhältnissmässig schnell von Statten, wenn nur die Vorsicht beobachtet wurde, den Niederschlag rechtzeitig von den Filterwandungen abzuspritzen, so dass er sich daran nicht festsetzen und die Poren des Filters verstopfen konnte. Lässt man diese Vorsicht ausser Acht, so setzt sich der Niederschlag fest an und stellt eine für Wasser wenig durchlässige, zusammenhängende Schicht dar, die das Auswaschen stark verzögert. Das Filtrat war immer klar und zeigte auf Zusatz von Gerbsäurelösung oder von Phosphorwolframsäure auch nach längerem Stehen nicht die geringste Trübung. Im Filtrat hatte nun noch eine Prüfung auf Stickstoff zu erfolgen. Zu dem Zweck wurde dasselbe in Hoffmeister'schen Glasschälchen auf dem Wasserbade eingeengt und der Rückstand mit den zertrümmerten Schälchen in die Stickstoffaufschliessungskölbchen gebracht und die Stickstoffbestimmung darin ausgeführt. Die Verwendung der Hoffmeister'schen Schälchen hat vor dem Eindampfen in Porzellanschalen oder Bechergläsern den grossen Vorzug, dass man bei der Ueberführung in die Zersetzungskolben die Substanz nicht mit Wasser nachzuspülen braucht, wobei man zuviel Flüssigkeit bekommen würde, die wieder verdampft werden müsste, und dass jeder, auch der geringste Substanzverlust ausgeschlossen bleibt.

Die Gerbsäure soll nur dann gute Resultate liefern, ${ }^{1}$ ) wenn genügend Salze in der Milch vorhanden sind. Parallel-

1) Sebelien, 1. c. S. 144 . 
versuche theils mit, theils ohne Zusatz von gesättigter Magnesiumsulfat- oder Kochsalzlösung zeigten übereinstimmende Werthe; woraus zu schliessen ist, dass normale Milch genügende Salzmengen besitzt, dass durch Gerbsäure die Eiweissstoffe nach oben beschriebener Methode quantitativ abgeschieden werden. Zum Beweise für diese Behauptung lasse ich hier einige Beispiele folgen. Beiläufig sei bemerkt, dass die Milch, die ich bei meinen sämmtlichen Versuchen verarbeitete, entweder von der Strasse aufgekauft oder dem Viehstall des landwirthschaftlichen Universitätsinstituts entnommen war, in beiden Fällen also nicht die Milch einer einzelnen Kuh, sondern Sammelmilch von mehreren Kühen darstellte. Die Wahrscheinlichkeit, normale Milch zu haben, war so grösser, als wenn ich beispielsweise ein Gemelk einer einzelnen Kuh analysirt hätte. Von den hier folgenden Proben sind $a, b$ und $c$ mit je $2 \mathrm{ccm}$. kalkgesättigter $\mathrm{MgSO}_{4}$-Lösung versetzt und dann wie sonst behandelt, $\mathrm{d}$, $\mathrm{e}$ und $\mathrm{f}$ sind ohne diesen Zusatz untersucht.

$$
\begin{array}{llc}
\mathrm{a}=0,5206 \% \mathrm{~N} & \mathrm{~d}=0,5206 \% \mathrm{~N} & \pm 0 \% \mathrm{~N} \\
\mathrm{~b}=0,5181 \% & \mathrm{e}=0,5181 \%, & \pm 0 \% \\
\mathrm{c}=0,4775 \% & \mathrm{f}=0,4754 \% & -0,0021 \% \mathrm{~N} .
\end{array}
$$

Die Differenzen sind also, wo überhaupt vorhanden, so gering, dass man sie vernachlässigen kann.

Auch blieb die Uebereinstimmung der Resultate dieselbe, ob ich die Probe mit $50 \mathrm{ccm}$. oder mit $100 \mathrm{ccm}$. Wasser vor der Fällung versetzte. Da aber der Niederschlag bei einer Verdünnung mit $100 \mathrm{ccm}$. Wasser sich besser absetzte und das Filtriren nicht länger dauerte, so habe ich später die Analyse stets nach Verdünnung mit der zehnfachen Menge Wasser ausgeführt. Die Proben $a, b, c, d$ sind mit $50 \mathrm{ccm}$., $\mathrm{e}, \mathrm{f}, \mathrm{g}, \mathrm{h}$ mit $100 \mathrm{ccm}$. Wasser verdünnt:

$$
\begin{aligned}
& a=0,5456 \% \mathrm{~N} \\
& \mathrm{e}=0,5414 \% \mathrm{~N} \\
& \mathrm{~b}=0,5181 \% \text { } \\
& \mathrm{f}=0,5181 \% \text {, } \\
& -0,0042 \% \mathrm{~N} \\
& \mathrm{c}=0,4754 \% \text { ， } \\
& \mathrm{g}=0,4734 \% \text {, } \\
& \mathrm{d}=0,4990 \% \text { ， } \\
& \mathrm{h}=0,4990 \% \\
& \pm .0 \% \mathrm{~N} \\
& =0,0020 \% \mathrm{~N} \\
& \pm 0 \% \mathrm{~N} \text {. }
\end{aligned}
$$

Ein Einfluss der verschiedenen Behandlung der Milch auf die Resultate lässt sich auch hier nicht constatiren. 
Ausser der Stickstoffbestimmung des mit Gerbsäure erzielten Niederschlages und des Filtrates wurde stets in einer besonderen Probe eine direkte Bestimmung des gesammten in der Milch befindlichen Stickstoffs vorgenommen; indem in die Kjeldahlkölbchen unmittelbar $10 \mathrm{ccm}$. Milch, deren Gewicht natürlich festgestellt wurde, hineinpipettirt und bestimmt wurden. Hierdurch hatte ich stets eine schnell zu erlangende und nicht gut $\mathrm{zu}$ entbehrende Kontrolle für die Brauchbarkeit der gewonnenen Zahlen. Falls richtig gearbeitet ist, darf die Summe des Niederschlagstickstoffs und des Filtratstickstoffs nicht erheblich unter oder über dem direkt ermittelten Gesammtstickstoff bleiben. Kleine Differenzen werden sich selbstverständlich auch bei peinlichster, sorgfältigster Arbeit nicht vermeiden lassen, wenn sie nur innerhalb der zulässigen Fehlergrenze bleiben. Dass diese Grenze nicht überschritten ist, beweisen die in angehängter Tabelle I aufgeführten Zahlen. Die Schwankungen betragen nur ein Geringes über $0,01 \% \mathrm{~N}$, in einem einzigen Falle, den ich vielleicht ebensogut hätte ausscheiden können, 0,02\% N. Dass der durch Summiren des Eiweissstickstoffes und Filtratstickstoffes erhaltene Stickstoff, mit einer einzigen Ausnahme, immer um ein Geringes höher ist, als der aus der Gesammtstickstoffbestimmung gefundene, lässt sich leicht erklären, einmal dadurch, dass der Eiweissniederschlag auf offenem Filter in der gewöhnlich $\mathrm{NH}_{3}$-haltigen Laboratoriumsluft leicht Spuren von Stickstoff aufnehmen kann, dann auch daraus, dass Fällungsmittel und Filter geringe Spuren Stickstoff enthielten, wovon eine blinde Bestimmung mich überzeugte.

Diese Stickstoffspuren waren allerdings so geringfügig, dass ich sie nicht ausdrücklich mit in Rechnung gebracht habe. Wie vorhin erwähnt, war nie in der vom Eiweissniederschlag abfiltrirten klaren Flüssigkeit, weder auf weiteren Zusatz von Gerbsäure, noch auch von Phosphorwolframsäure, selbst wenn das Filtrat eingeengt wurde, die geringste Trübung zu bemerken. Und doch zeigte sich das Filtrat bei der Stickstoffbestimmung immer, ohne Ausnahme, als stickstoffhaltig. 
Die Anwesenheit dieses Stickstoffes im Filtrate kann nur auf drei Ursachen zurückgeführt werden. Entweder waren die Gerbsäure und Phosphorwolframsäure nicht im Stande, die Eiweisskörper absolut quantitativ zu entfernen, und man hätte es also mit der Fällung entgangenem Eiweissstickstoff $z u$ thun. Sebelien $^{1}$ ) hat nun aber in den Fällen, in denen er reine Eiweisslösungen verwandte, das Eiweiss mit Gerbsäure so vollständig niedergeschlagen, dass die Filtrate völlig stickstofffrei waren, und damit bewiesen; dass keine Spur Eiweiss der Gerbsäurefällung entgeht. Der im Filtrat bei mir vorhandene Stickstoff war demnach, da ein Grund, an 'Sebelien's Beweisführungen zu zweifeln, nicht. vorlag, kein eiweissartiger. Zweitens konnte der von mir im Filtrat gefundene Stickstoff von dem angewandten Fällungsmittel herrühren. Blinde Bestimmungen, die mit grösseren Mengen Almén'scher Lösung und auch mit den anderen später verwandten Reagentien angestellt wurden, ergaben, dass diese völlig stickstofffrei waren oder nur ganz ausserordentlich geringe Spuren enthielten, so dass sie garnicht in Betracht kamen. Es blieb also nur eine dritte Erklärung übrig, dass sich ausser den eigentlichen Eiweisskörpern noch andere stickstoffhaltige Verbindungen in der Milch befinden, sogenannte Extractivstoffe. Und in der That ist auch von verschiedenen Forschern eine ganze Reihe von nicht eiweissartigen stickstoffhaltigen Körpern in der Kuhmilch entdeckt worden. So wies Hoppe-Seyler das Lecithin $^{2}$ ) und das Leucin $^{8}$ ) nach, Schmidt-Mühlheim ${ }^{4}$ ) das Hypoxanthin, von Lefort ${ }^{5}$ ) den Harnstoff, Th. Weyl ${ }^{6}$ ) das Kreatin, Commaille ? das Kreatinin, Musso das Schwefelcyanoder Rhodannatrium. ${ }^{8}$ )

1) Hoppe-Seyler, Zeitschr. f. physiol. Chem., Bd. XIII, S. 146.

2) Hoppe-Seiler, Zeitschr. f. physiol. Chem., 1881, S. 275.

3) Arch. f. pathol. Anatomie u. Physiologie, Bd. 17, S. 437.

4) Pflüger's Arch., Bd. 30, S. 383.

5) Jahreshericht der Chemie, 1866, S. 747.

6) Bericht der deutschen chemischen Gesellschaft, Bd.11, S. 2176.

7) Jahresbericht der Chemie, 1868, S. 828.

8) Jahresbericht der Thierchemie, Jahrg. 1877, S. 168. 
Schlossmann ${ }^{1}$ ) behauptet, die Extractivstoffe seien noch eine «terra incognita», und für ihr «obligatorisches Vorhandensein in absolut frischer Milch sei ein unanfechtbarer Beweis noch nicht gebracht worden. Er begründet diese Ansicht damit, dass er bei seinen Untersuchungen, sei es, dass er die gesammten Eiweissstoffe mit Gerbsäure, sei es, dass er sie nach dem von Munk modificirten und mit der Stutzer'schen Cu-Methode combinirten Ritthausen'schen Verfahren fällte, sei es, dass er die Eiweissstoffe Casein und Albumin einzeln entfernte, häufig das Schlussfiltrat stickst offfrei fand, in anderen Fällen aber stickstoffhaltig, «doch war das die Ausnahme». Er legt es nahe, dass im letzten Filtrat befindlicher Stickstoff leicht von dem verwendeten Fällungsmittel herrühren könne. Die Gerbsäure könne, wie bei ihrer Provenienz leicht erklärlich, mit stickstoffhaltigen Bestandtheilen verunreinigt sein. Da dieser Einwand, wie die in der Gerbsäure ausgeführte, oben erwähnte Stickstoffbestimmung bewiesen hat, bei meinen Versuchen keine Berechtigung hat, so glaube auch ich annehmen $\mathrm{zu}$ müssen, dass der stets vorhandene Reststickstoff auf die Extractivstoffe zurückzuführen ist. Mögen nun auch nicht alle eben aufgezählten Extractivkörper in frischer Milch vorkommen, eigene Erfahrungen darüber fehlen mir, so werden doch einige von ihnen so stark vertreten sein, dass dadurch die Höhe des im letzten Filtrate vorhandenen Stickstoffes ihre Erklärung findet. Die Menge des Extractivstickstoffes ist durchaus nicht constant, sondern sie ist verhältnissmässig erheblichen Schwankungen unterworfen. SchmidtMühlheim fand in dem Restfiltrat, und Sebelien beobachtete dasselbe, $\left.{ }^{2}\right)$ im Allgemeinen $40-50 \mathrm{mg}$ Stickstoff für $100 \mathrm{ccm}$. Milch, eine Erfahrung, die durch meine Zahlen (siehe Tabelle I) vollständig bestätigt wird. Aus der Tabelle geht aber weiter hervor, dass der Stickstoff bis auf und unter $30 \mathrm{mg}$ in derselben

1) Hoppe-Seyler's Zeitschrift für physiol. Chemie, Bd. XXII. S. 200. (Diese letzteren Litteraturangaben sind theilweise, wo ich das Original nicht in Händen gehabt habe, nach «Stohmann Milch- und Molkereiprodukte 1898 Seite 84, citirt.)

2) Hoppe-Seyler's Zeitschrift für physiol. Chemie, Bd. XIII, S. 156. 
Menge Milch sinken kann, die niedrigste Zahl ist 24,5 mg, und ich möchte auch die Erklärung Sebelien's (seine Zahlen gehen bis auf $30 \mathrm{mg}$ zurück), dass diese niedrigen Werthe nicht etwa auf ungenügendes Auswaschen des Gerbsäureniederschlages zurückzuführen seien, $\cdot z$ der meinigen machen. Die'im zweiten Theile dieser Arbeit ausgeführten Analysen von Colostrum bestätigen ferner die Behauptung Sebelien's, dass das Colostrum in $100 \mathrm{ccm}$. bis $\mathrm{zu} 80 \mathrm{mg}$ nicht eiweissartigen Stickstoff enthalten kann. (Tabelle IV.)

Will man also den stets im Filtrat noch vorhandenen Stickstoff auf Rechnung nicht eiweissartiger Verbindungen, der Extractivstoffe, setzen, wozu man nach den angeführten Thatsachen ohne Zweifel veranlasst ist, so muss man zu dem Schlusse kommen, dass man in der Gerbsäure, angewandt in der Almén'schen Mischung, ein Mittel besitzt, die Gesammteiweissstoffe der Milch scharf und quantitativ auszufällen. Hieraus geht aber auch hervor, dass wir bei vergleichenden Untersuchungen in den mit Gerbsäure erhaltenen Zahlen einen Maassstab für die Genauigkeit und Brauchbarkeit der nach anderen Methoden gefundenen Zahlen besitzen. Aber nicht erst bei der Vergleichung der Resultate, schon bei der Ausführung der Fällung der Eiweisskörper mit einem anderen Eiweissreagens, können wir vermittelst der Gerbsäure einen Schluss auf den Grad der Vollständigkeit der Abscheidung machen. Bringt nämlich die Gerbsäure in den Filtraten, die von mit anderen Mitteln erzeugten Niederschlägen herrühren, eine stickstoffhaltige Fällung oder Trübung hervor, so ist eben das Eiweiss nicht völlig niedergeschlagen worden. Man braucht also mit Gerbsäure nur die Probe zu machen. Andererseits muss man sich aber vor der Folgerung hüten, dann eine Fällung für quantitativ zu halten, wenn die Prüfung des Filtrates mit Gerbsäure negativ verläuft. Es wäre nämlich denkbar, dass das in der Lösung vorhandene, zuerst angewandte Eiweissreagens die fällende Wirkung der Gerbsäure, auch bei noch vorhandenem Eiweissrest, hemmt und schliesslich aufhebt. Man muss dann schon den Stickstoff des Filtrates bestimmen und kann aus der Höhe des Extractivstickstoffes auf die quanti- 
tativen Eigenschaften des zu prüfenden Mittels schliessen. Diese Handhabung ist denn auch bei den weiteren vergleichenden Untersuchungen nie unterlassen worden.

\section{Methode: Fällung mit Phosphorwolframsäure.}

Als ebenso bequem und leicht in ihrer Anwendung, wie genau und scharf in ihren Ergebnissen im Vergleich mit der Gerbsäure, hat sich in zweiter Linie die Phosphorwolframsäure erwiesen. Wiederum ist es Sebelien (l. c.), der uns in aller Kürze über die Fällungseigenschaften dieser Säure berichtet und die Vorschrift zur Bereitung der Lösung, mit der auch ich meine Versuche angestellt habe, angibt: «1 Theil kryst. Phosphorwolframsäure wird in fünf Theilen Wasser unter $\mathrm{Zu}$ satz von $2 \%$ concentrirter Schwefelsäure gelöst». Dieser $\mathrm{Zu}$ satz von Schwefelsäure ist unbedingt erforderlich, da die Phosphorwolframsäure nur in salzsaurer oder schwefelsaurer Lösung quantitativ fällt. Ueber die genauere Ausführung der Methode, vor Allem über die zu verwendende Säuremenge, fand ich keine Angaben. Ich verfuhr deshalb analog mit der Gerbsäuremethode.

$10 \mathrm{ccm}$. Milch wurden mit $100 \mathrm{ccm}$. Wasser verdünnt und in der Kälte unter Umrühren mit Phosphorwolframsäurelösung versetzt. Der Niederschlag setzte sich nach einigem Stehen feinflockig ab und konnte leicht filtrirt und mit kaltem Wasser ausgewaschen werden. Das Auswaschen war genügend, wenn die abtropfende Flüssigkeit keine Schwefelsäure mehr aufwies. Ueber die zur Fällung erforderliche Menge des Säurezusatzes gaben einige Versuche, deren Ergebnisse hier folgen mögen, Aufschluss. Die Proben a und b erhielten je $5 \mathrm{ccm}$, c und $d$ je 3 ccm., e, f, g und $h$ je $2 \mathrm{ccm}$. Phosphorwolframsäurelösung.

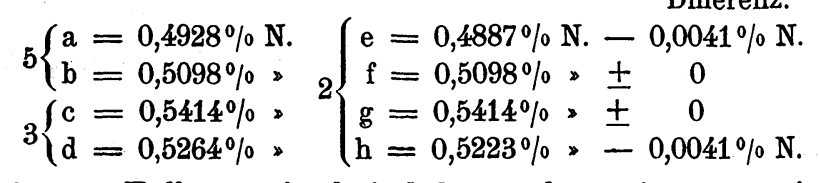

2 cem. Fällungsmittel sind demnach zu einer quantitativen Abscheidung völlig ausreichend, aber auch ein Ueberschuss, 3 und $5 \mathrm{ccm}$., verschlechtert die Resultate in keiner Weise. 
Der Phosphorwolframsäureniederschlag enthält denselben Stickstoffgehalt, wie der in Kontrollproben mit Gerbsäure hervorgerufene. Das Filtrat ist absolut klar und bleibt es auf Zusatz von Phosphorwolframsäure und auch von Gerbsäure. Die Bestimmung des im Filtrat noch befindlichen Stickstoffs stimmt. überein mit dem Extractivstoffe der Kontrollproben. Der grösste Unterschied zwischen beiden Methoden beträgt bei Gesammteiweissstickstoff 0,0068\% N, bei Extractivstickstoff 0,0041\% N, liegt also innerhalb der unvermeidlichen (erlaubten) Fehlergrenze (siehe Tabelle I).

\section{Methode: Fällung mit Trichloressigsäure.}

Ein Referat einer Arbeit von Dr. Fr. Obermayer «Ueber die Anwendung der Trichloressigsäure in der physiologischchemischen Analyse, Wiener medic. Jahrbücher 1888, Seite 375, welches ich in der Zeitschrift für analytische Chemie, Band XXIX, Seite 114, las, enthält die Angabe: «Trichloressigsäure fällt echte Eiweissstoffe in Gestalt von in Säuren und Salzen, sowie beim Erhitzen unlöslichen Flocken.» Ferner: «Um eine quantitative Ausfällung von Eiweiss mit Trichloressigsäure zu erzielen, bedarf es eines Ueberschusses derselben. Nach wiederholtem Waschen mit säurehaltigem Wasser und sehr sorgfältiger Extraction mit Alkohol und Aether bleibt das Eiweiss zurück, das nun getrocknet und gewogen wird. In der Milchanalyse kann die Trichloressigsäure zur Gesammtbestimmung der Eiweisskörper nur bei der Kuhmilch benutzt werden, da sich das Casein der Frauenmilch im Ueberschuss der Säure zum Theil wieder löst.» Das Original der Obermayer'schen Veröffentlichung (die med. Jahrbücher) war mir zu der Zeit, als ich meine Versuche anstellte, nicht zugänglich, und ich war deshalb, da dies aus dem Referat nicht hervorging, über die nähere Ausführung der Methode, vor Allem über die passende Concentration der zu verwendenden Trichloressigsäure, im Unklaren. Später gelangte ich in den Besitz der Obermayer'schen Originalarbeit, konnte aus ihr aber auch nur mit Wahrscheinlichkeit entnehmen, dass er eine Trichloressigsäure in der Concentration von 2 : 1 verwandt hat. 
Eine Lösung von 1 Theil krystall. Trichloressigsäure in zwei Theilen Wasser schien mir eine durchaus genügende Concentration $\mathrm{zu}$ besitzen, und ich verfuhr nach einigen Versuchen, die eine energisch gerinnende Wirkung der Säure zeigten, folgendermassen: $10 \mathrm{ccm}$. Milch wurden nach Verdünnung mit $100 \mathrm{ccm}$. Wasser mit Trichloressigsäure unter lebhaftem Umrühren versetzt. Schon auf Zusatz einiger Tropfen trat eine Gerinnung der Eiweissstoffe ein, um aber einen Ueberschuss an Säure im Gemisch zu haben, wurden im Ganzen $5 \mathrm{ccm}$. hinzugefügt. Das Coagulum setzte sich in feinen weissen Flocken ab, ohne dass die überstehende Flüssigkeit sich völlig geklärt hätte. Das Filtriren und Auswaschen mit trichloressigsäurehaltigem Wasser nahm nur kurze Zeit in Anspruch. Stets erhielt ich jedoch ein trübes Filtrat, in dem Gerbsäure eine erneute Fällung hervorrief. Die Stickstoffbestimmung des Trichloressigsäureniederschlages ergab gegenüber der Gerbsäure- und Phosphorwolframsäuremethode zu niedrige Werthe, und zwar um so viel, als in dem im Filtrat mit Gerbsäure erzeugten Niederschlag gefunden. wurde. Ein Beispiel möge zum Beweis dieser Thatsache genügen:

Gerbsäure :

Trichloressigsäure:

Gesammt-Eiweiss N. - $0,7083 \%$ N. $0,6450 \%$ N. $0,0645 \%, *)$

Extractiv-N $0,0413 \%$ क

Summa . . . . 0, 0,7496\% N. $0,7508 \%$ N.

*) Mit Gerbsäure im Filtrat gefällt.

Auch bei Vermehrung des Trichloressigsäurezusatzes trat ein merkhar günstigeres Resultat nicht ein. Da ich annehmen musste, dass die Concentration der Säure noch keine genügende wäre, so suchte ich diese dadurch $\mathrm{zu}$ erhöhen, dass ich $\mathrm{zu}$ zwei Proben unverdünnter Milch $5 \mathrm{ccm}$. Trichloressigsäure (1:2) hinzufügte. Gleichzeitig wurden zwei andere Proben mit $50 \mathrm{ccm}$. Wasser verdünnt und wie vorher mit $5 \mathrm{ccm}$. Trichloressigsäure gefällt. Der Erfolg war ein überraschender:

Während es nämlich sonst bei Eiweissfällungen in der Milch ein unbedingtes Erfor derniss ist, die zu analysirenden Proben stets mit einigen Volumen Wasser zu verdünnen, 
wenn man überhaupt quantitative Eiweissabscheidungen er. zielen will, gelangte ich dagegen wider Erwarten mit der Trichloressigsäure in unverdünnter Milch zu besseren Resultaten. Die Filtrate waren jetzt völlig klar und blieben es auch auf weiteren Zusatz von Trichloressigsäure. Gerbsäure oder Phosphorwolframsäure riefen aber stets, oft allerdings erst nach längerem Stehen, eine geringe Opalescenz hervor. Die Resultate stimmten mit den nach der Gerbsäuremethode erhaltenen ganz gut überein, und Verluste waren durch die Zahlen nicht zu constatiren. Es konnten demnach nur Spuren von Eiweiss der so vorgenommenen Fällung entgangen sein. Einige Beispiele mögen die Ergebnisse der Analysen in verdünnter und unverdünnter Milch im Vergleich mit der Gerbsäuremethode erläutern:

1.

Trichloressigsäure: Gerbsäure: unverdünte und verdünnte Probe.

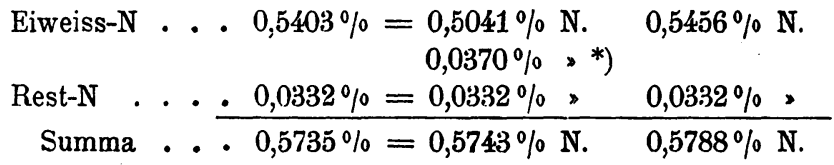

2.

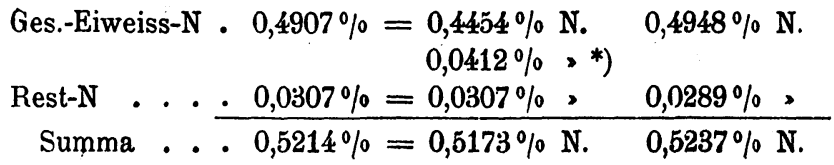

3.

Ges.-Eiweiss . $0,5185 \%=0,4749 \%$ N. $0,5185 \%$ N. $0,0518 \%$,*)

Rest-N $\cdots 0,0373 \%=0,0331 \%$ \% $0,0332 \%$,

Summa . . $0,5558 \%=0,5598 \%$ N. $0,5517 \%$ N.

*) Im Filtrat mit Gerbsäure gefällt.

Da ich in der unverdünnten Milch mit Trichloressigsäure so gute Resultate erhielt, der Beweis also erbracht war, dass die Trichloressigsäure überhaupt die Eiweissstoffe völlig zu fällen vermochte, so versuchte ich auch in der verdünnten Milch ein gleiches Ergebniss durch Steigerung des Säurezusatzes $\mathrm{zu}$ erhalten. Es wurden nebeneinander angesetzt: 
2 Proben unverdünnt mit $5 \mathrm{ccm}$., 2 Proben verdünnt mit $10 \mathrm{ccm}$. Trichloressigsäure und als Kontrollversuche für beide 2 Proben mit Gerbsäure. Das Ergebniss war folgendes: Die Filtrate der vier Trichloressigsäurefällungen waren alle klar und blieben klar auf weiteren Zusatz desselben Fällungsmittels. Setzte ich aber eine kleine Menge Gerbsäure zu, so trat bei allen eine völlig gleichmässige, geringe Opalescenz' ein. Bei anderen, genau so ausgeführten Versuchen konnte ich dieselben Beobachtungen wiederholen. Die Filtrate waren immer klar, zeigten aber auf Zusatz von Gerbsäure - die Phosphorwolframsäure verhielt sich ebenso - eine oft erst nach längerem Stehen wahrnehmbare Opalescenz. Da die Resultate, wie einige gleich anzuführende Beispiele zeigen werden, gut mit den Kontrollversuchen übereinstimmten, so muss man zu dem Schluss kommen, dass die Gerbsäure und die Phosphorwolframsäure selbst so geringe Spuren von Eiweiss nachzuweisen vermögen, dass es mit der Kjeldahl'schen Methode nicht mehr möglich ist, sie zu bestimmen.

1.

Trichloressigsäure:

Gerbsäure:

unverdünnt $5 \mathrm{ccm}$. verdünnt $10 \mathrm{ccm}$.

Ges.-Eiweiss . $0,4775 \% \mathrm{~N}=0,4754 \% \mathrm{~N}=0,4775 \% \mathrm{~N}$.
Rest $\cdot .0,0329 \%=0,0329 \%,=0,0288 \%$
Summa $. .0,5104 \% \mathrm{~N}=0,5083 \% \mathrm{~N} .=0,5063 \% \mathrm{~N}$.

2.

Ges.-Eiweiss . $0,4948 \% \mathrm{~N}=0,4948 \% \mathrm{~N} .=0,4990 \% \mathrm{~N}$.

Rest ....0,0359\% $=0,0359 \%$ \% $=0,0371 \%$.

Summa . 0,5307\% N $=0,5307 \% \mathrm{~N}=0,5361 \% \mathrm{~N}$.

3.

Ges.-Eiweiss . $0,5016 \% \mathrm{~N}=0,5016 \% \mathrm{~N} .=0,5030 \% \mathrm{~N}$.

Gerbs.-Ndschlag. $\left.0,0082 \%{ }^{*}\right)=0,0082 \%{ }^{*}$ )

Rest $\ldots .0,0326 \%=0,0326 \%$ \% $=0,0407 \%$,

Summa . $0,5424 \% \mathrm{~N}=0,5424 \% \mathrm{~N} .=0,5437 \% \mathrm{~N}$.

*) Hier war mit Gerbsäure im Filtrat ein noch filtrirbarer Niederschlag erzeugt.

Später habe ich die Concentration der Trichloressigsäure auf 1:1 erhöht, ohne dass jedoch das Ergebniss bei der Bestimmung ein anderes geworden wäre. 
Da nun, wie aus dem Gesagten erhellt, die Trichloressigsäure mit unverdünnter Milch vorzügliche Resultate liefert, so wird man zweckmässig bei Eiweissbestimmungen nach dieser Methode die Ausführung in unverdünnter Milch der in verdünnter Milch vorziehen, da einmal eine Operation, das Verdünnen, erspart wird, und dann auch das Filtriren und Auswaschen weniger Zeit beansprucht.

\section{Methode: Fällung mit Kupfersulfat (nach Ritthausen).}

Die Salze fast aller schweren Metalle haben die Eigenschaft, mit Eiweiss unlösliche Verbindungen einzugehen, und die Litteratur zählt von ihnen eine ganze Reihe auf, die sich als quantitative Fällungsmittel für Eiweiss erwiesen und bewährt haben sollen, z. B. Kupfersulfat und -acetat, Eisenchlorid und -acetat, Quecksilberchlorid, basisches und neutrales Bleiacetat, Zinksulfat und endlich Salze von Platin, Cobalt und vielen anderen Metallen. Von diesen vielen Salzen habe ich nur das Kupfersulfat in den Bereich meiner Untersuchungen gezogen, weil es mir nach den vielen Litteraturangaben als das zuverlässigste und am leichtesten zu handhabende Eiweissreagens erschien. Eine sehr gute und brauchbare Methode mit diesem Kupfersulfat hat Ritthausen ${ }^{1}$ ) ausgearbeitet und empfohlen: « $10 \mathrm{ccm}$. Milch werden mit der. zwanzigfachen Menge Wasser verdünnt, mit $5 \mathrm{ccm}$. Kupfersulfatlösung versetzt, und dann wird so viel verdünnte, der Kupfersulfatlösung äquivalente Natronlauge (10,2 $\mathrm{g}$ auf 1 Liter) hinzugefügt, dass das Gemisch neutrale, eher ein wenig saure als alkalische Reaction zeigt.» Ritthausen schreißt vor, eine Kupfersulfatiôsung zu verwenden, die $63,5 \mathrm{~g}$ reines krystallisirtes $\mathrm{CuSO}_{4}$ im Liter enthält. Fleischmann ${ }^{2}$ ) gibt $69,28 \mathrm{~g} \mathrm{CuSO}_{4}$ an und $\mathrm{Munk}^{3}$ ) endlich spricht von $103,9 \mathrm{~g}$ reinen Kupfervitriols im Wasser $\mathrm{zu}$ einem Liter gelöst (105,9 $\mathrm{g}$ würden demselben Aequivalent wie $63,5 \mathrm{~g}$ entsprechen, ohne Krystallwasser gelöst). Ich

1) Journal für praktische Chemie [2], B்d. 15, S. 329.

2) Lehrbuch der Milchwirthschaft, If. Auflage, 1898, S. 122.

3) Archiv für pathol. Anatomie u. Physiologie, Bd. 134, S. 514, Jahrg. 1893. 
habe mich an Ritthausen's Vorschrift gehalten und $63,5 \mathrm{~g}$ zum Liter gelöst. Bei neutraler Reaction setzt sich der Niederschlag gut $a b$, und das Filtrat enthält kein gelöstes Kupfer mehr. Nach dem Absetzen wird filtrirt und mit kaltem Wasser nachgewaschen. Die weiteren von Ritthausen zur Ausführung der Gewichtsanalyse vorgenommenen Operationen, wie Entfetten, Trocknen, Veraschen, $\mathrm{W}$ ägen etc. kommen selbstverständlich bei der Stickstoffbestimmung des Kupfereiweissniederschlages nach Kjeldahl nicht in Betracht. Auch der Fehler, der der gewichtsanalytischen Bestimmung, wie Stenberg ${ }^{1}$ ) nachwies, anhaftet, insofern, als das $\mathrm{Cu}(\mathrm{OH})_{2}$ bei $125^{\circ}$ nicht alles Wasser abgibt, sondern erst beim Glühen, und die Zahlen für Eiweiss in Folge dessen $\mathrm{zu}$ hoch ausfallen, wird umgangen, und man kommt mit der Kjeldahl'schen Stickstoffsbestimmungsweise bedeutend schneller zum Ziel. Das Filtrat des leicht filtrirbaren Niederschlages war immer völlig klar und erfuhr durch Gerbsäure keinerlei Trübung; da auch der Stickstoffgehalt, sowohl des Eiweissniederschlages als auch des Filtrates, in der sonst vorhandenen Höhe sich hielt, so war das ein Beweis für die Genauigkeit und Vollständigkeit, mit der sich nach dem Ritthausen'schen Verfahren die Eiweissstoffe aus der Milch entfernen lassen. Einige Zahlen mögen hierfür als Beleg dienen.

1.

Ritthausen: Gerbsäure :

Eiweiss . . $0,4419 \% \mathrm{~N}=0,4419 \% \mathrm{~N}$.

Rest.... 0,0317\% > $=0,0295 \%$,

Summa $\ldots .0,4736.0 \% \mathrm{~N}=0,47140,6 \mathrm{~N}$.

2.

Ges.-Eiweiss ․ 0,5981\% N $=0,5981 \% \mathrm{~N}$.

Rest . . . 0 0,0489\%, $=0,0467 \%$,

Summa . . $0,6470 \% \mathrm{~N}=0,6448 \% \mathrm{~N}$.

3.

Ges.-Eiweiss - $0,4946 \% \mathrm{~N}=0,4922 \% \mathrm{~N}$.

Rest . . . 0 0,0272\% s $=0,0317 \%$ o

Summa . $0,5218 \% \mathrm{~N}=0,5239 \% \mathrm{~N}$.

1) Nordisk medicinsk Arkiv, 1882. 
Eine bessere Uebereinstimmung in den Resultaten zweier verschiedener Methoden, als sich aus den obigen Beispielen ergibt, ist kaum denkbar und das Ritthausen'sche Verfahren ist, was Genauigkeit anbetrifft, dem Gerbsäureverfahren völlig gleich zu stellen, nur bietet seine Ausführung eine Schwierigkeit, und zwar liegt diese darin, dass es oft nicht leicht ist, genau das richtige Maass beim Natronlaugezusatz einzuhalten, nicht $\mathrm{zu}$ wenig und nicht zu viel. Bei alkalischer Reaction des Gemisches bleiben nämlich Theile des Eiweisses, Caseinkupfer, in Lösung und entgehen der Fällung, auch erfolgt kein gutes Absetzen des Niederschlages. Bei stark saurer Reaction erfolgt zwar ein schnelles Absetzen, aber es können dadurch, dass viel überschüssiges Kupfer gelöst bleibt, Ungenauigkeiten entstehen, indem dann nicht alles Eiweiss ausgefällt wird, ein geringer Säureüberschuss beeinträchtigt dagegen die Genauigkeit der Bestimmung nicht. Zur Erleichterung des Neutralisirens ist der sehr zweckmässige Vorschlag gemacht worden, Phenolphtalein als Indicator zu der verdünnten Milch hinzuzufügen. Man lässt bis zum eben bemerkbaren Farbenumschlage die verdünnte Natronlauge tropfenweise zufliessen. Trotzdem dann durch Lackmus noch keine Alkalität nachweisbar ist, erfolgt kein gutes Absetzen; fügt man nun aber nach Pfeiffer's Vorschlag ${ }^{1}$ ) einige Tropfen sehr stark verdünnter Salzsäure hinzu, so tritt ein rasches, vollständiges Absetzen ein. Ritthausen fand im Filtrat als Reststickstoff nur 0,02\% N. Da die Kupfersulfatlösung nicht im Stande ist, irgend einen der stickstoffhaltigen Extractivstoffe abzuscheiden, so erscheint mir dieser Refund ein etwas zu miedriger zu seir. Bei meinem zahlreichen Analysenmaterial, ganz gleich, nach welcher Methode ich arbeitete, habe ich Schwankungen im Extractivstoffgehalt bis zu dieser niedrigen Grenze niemals beobachtet (cf. Tabelle I-III).

1) Analyse der Milch, S. 29, citirt nach Stohmann, Milch und Molkereiprodukte, S. 279. 


\section{Methode: Fällung mit Alaun und Kupferoxydhydratbrei (nach M u n k).}

So gute Werthe die Ritthausen'sche Methode auch zu liefern vermag, so sind andererseits die Schwierigkeiten, die das unbedingt auszuführende Neutralisiren doch offenbar mit sich bringt, nicht $\mathrm{zu}$ unterschätzen. Munk ist es nun gelungen, ${ }^{1}$ ) durch eine Modification der Kupfermethode den zeitraubenden Alkalizusatz zu umgehen und zwar dadurch, dass er das Verfahren zur Bestimmung der Eiweisskörper von Stutzer mit dem von Ritthausen combinirte.

Stutzer schlug zur quantitativen Bestimmung des ProteinStickstoffs vor, $\left.{ }^{2}\right)$ die zu untersuchende Substanz mit $100 \mathrm{ccm}$. Wasser zu übergiessen, bis zum Sieden zu erhitzen und mit einigen Cubikcentimetern aufgeschlämmten Kupferoxydhydratbreies von bekanntem Gehalt zu versetzen, dann in dem abfiltrirten, gewaschenen und getrockneten Niederschlage den Stickstoff $\mathrm{zu}$ bestimmen. Das Kupferoxydhydrat wird so bereitet: $100 \mathrm{~g}$ Kupfersulfat werden in 5 Litern Wasser gelöst und mit 2,5 g Glycerin versetzt. Aus dieser Lösung wird durch Zusatz von verdünnter Natronlauge, bis die Flüssigkeit alkalisch reagirt, das Kupfer als 0xydhydrat ausgefällt. Letzteres wird abfiltrirt, alsdann durch Anreiben mit Wasser, welches im Liter $5 \mathrm{~g}$ Glycerin enthält, aufgeschlämmt. Durch wiederholtes Decantiren und Filtriren entfernt man die letzten Spuren von Alkali. Der Filterrückstand wird mit Wasser, dem man $10 \%$ Glycerin zugesetzt hat, verrieben und bis zu einer Verdünnung gebracht, dass derselbe eine gleichmässige, mit einer Pipette aufsaugbare Masse bildet. Dieselbe wird in gut verschlossenen Flaschen und im Dunkeln aufbewahrt. Den Gehalt der breiigen Masse an $\mathrm{Cu}(\mathrm{OH})_{2}$ bestimmt man durch Eindunsten eines abgemessenen Volumens und Glühen des Rückstandes. Kamen in den zu untersuchenden Substanzen phosphorsaure Alkalien vor, wie das ja auch in der Milch der Fall ist, so verhinderte Stutzer die in der Wärme mit $\mathrm{Cu}(\mathrm{OH})_{2}$ leicht eintretende Bildung von phosphorsaurem Kupfer

1) Virchow's Archiv, Bd. 134, S. 515 u. f.

2) Journal für Landwirthschaft, Jahrg. 1881, S. 473 u. f. 
und freiem eiweisslösenden Alkali durch Hinzufügung eines $\mathrm{Cu}$ bikcentimeters Essigsäure. Munk schloss die ${ }^{1}$ ) Möglichkeit dieser Bildung durch Zusatz einiger Tropfen Alaunlösung aus, wobei sich das phosphorsaure Alkali zu Alaumphosphat umsetzt, das in keiner Weise auf das Kupferoxydhydrat einwirkt. Die Bestimmung des Eiweissstickstoffes in der Milch gestaltet sich dann in dieser neuen Form so: «10 ccm. Milch werden in einem $250 \mathrm{ccm}$. fassenden Becherglase mit Wasser auf $100 \mathrm{ccm}$. verdünnt, erhitzt, zuerst 1-2 ccm. Alaunlösung, dann, wenn die Flüssigkeit eben ins Sieden geräth, $5 \mathrm{ccm}$. von dem aufgeschwemmten Kupferoxydhydratbrei hinzugefügt und einige Minuten im Sieden erhalten. Der zumeist feinflockige Niederschlag, welcher sich, sobald die Mischung vom Feuer genommen wird, schnell absetzt, wird noch warm abfiltrirt, auf dem Filter mit warmem Wasser ausgewaschen und sammt Filter noch feucht nach Kjeldahl verbrannt.» Die Genauigkeit der nach diesem Munk'schen modificirten Verfahren erhaltenen Resultate war bei meinen Versuchen eine ebenso grosse, wie bei den bisher beschriebenen Methoden. In den stets klar vom Kupferniederschlag abgetropften Filtraten war durch Gerbsäure oder Phosphorwolframsäure nie eine Spur Eiweiss nachzuweisen. Nur in einigen Fällen erhielt ich in den Filtraten durch Gerbsäure einen Niederschlag, als ich nämlich die Milch versuchsweise freiwillig hatte gerinnen lassen und darin, ohne vorher zu neutralisiren, die Munk'sche Eiweissbestimmung vorgenommen hatte. Waren die Analysen der Vorschrift entsprechend in frischer Milch ausgeführt, so ergaben sich vorzüglich mit anderen Methoden übereinstimmende Resultate, wie einige hier folgende Beispiele darthun; eine grössere Anzahl von Analysen weist die angehängte Tabelle I auf.

1.

Munck: Gerbsäure: Gesammt-N direkt ermittelt:

Ges.-Eiweiss-N $.=0,5445 \% \mathrm{~N}=0,5486 \% \mathrm{~N}$

Rest-N . . . =0,0331 \% , =0,0352 $\%$ \%

Summa $.=0,5776 \% \mathrm{~N}=0,5838 \% \mathrm{~N}=0,5795 \% \mathrm{~N}$.

1) Virchow's Archiv, Bd. 134, S. 515 u. f. 
2.

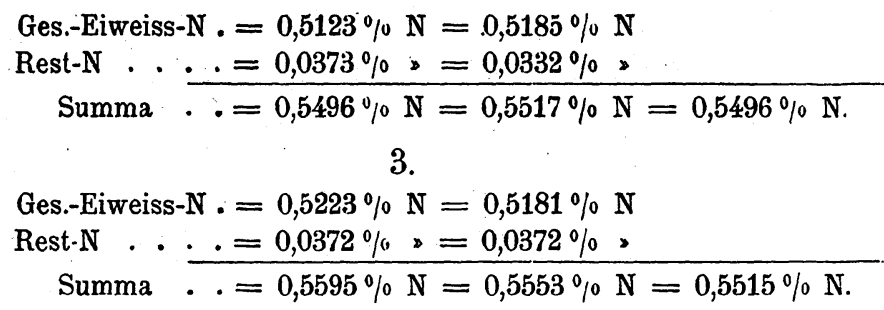

Ist es Munk nun auch gelungen, die eine Schwierigkeit. der Ritthausen'schen Methode völlig zu umgehen, so haftet. seinem modificirten Verfahren doch immer noch ein anderer Uebelstand an. Wenn man nämlich der Vorschrift entsprechend das Gemisch von Milch, Alaun und Kupferoxydhydratbrei einige Minuten im Sieden erhält, so ist ein Spritzen des kochenden Gemenges nicht $\mathrm{zu}$ vermeiden. Schützen die genügend hohen Wände des Becherglases auch vor etwaigen Verlusten durch Wegspritzen, so ist doch unter Umständen ein Verlust noch in anderer Weise zu befürchten. Die hochgespritzten Theilchen des Eiweisskupfers setzen sich nämlich während des Siedens so fest an den Wandungen des Glasgefässes an, dass eine völlige Entfernung derselben auf mechanischem Wege, auch mit heissem Wasser, nur äusserst schwierig zu ermöglichen ist, jedenfalls erfordert sie zum Mindesten sehr viel Geduld. Ob diese Methode also bei derselben analytischen Genauigkeit einen Vorzug vor der Ritthausen'schen verdient, möge dahingestellt bleiben.

\section{Methode: Fällung mit Metaphosphorsäure.}

Bekannt wegen ihrer die Eiweissstoffe coagulirenden Eigenschaft ist die Metaphosphorsäure; es ist dies ja ein charakteristisches Unterscheidungsmerkmal für. sie von der Orthophosphorsäure. Es lag nun nahe, zu untersuchen, wie weit diese Coagulationsfähigkeit gehe. Ich greife hier auf eine Arbeit von Denigès ${ }^{1}$ ) zurück, die zwar nicht speciell über

1) Journ. de Pharm., Nr. 27, S. 413 u. f.; Zeitschr. f. analytische Chemie, Bd. 35, S. 103. 
Eiweisskörper handelt, in der er aber beschreibt, wie er, um für seine Milchzuckerbestimmungen eiweissfreie Lösungen zu erhalten, die Eiweisskörper mit Metaphosphorsäure entfernt.

Er bringt zu dem Zwecke $10 \mathrm{ccm}$. Milch in ein $100 \mathrm{ccm}$.Kölbchen, fügt $2,5 \mathrm{ccm}$. einer $5 \%$ igen Lösung von metaphosphorsaurem Natrium hinzu, verdünnt mit $70 \mathrm{ccm}$. Wasser, schüttelt um, versetzt mit $5 \mathrm{ccm}$. Salzsäure (1 Theil conc. HCl auf 5 Theile Wasser), füllt bis zur Marke auf, schüttelt von Neuem durch, filtrirt und verwendet das eiweissfreie Filtrat zur Milchzuckerbestimmung. Nach dieser Vorschrift richtete ich mich, verwandte allerdings nicht ein $100 \mathrm{ccm}$.-Kölbchen, da sich aus demselben das Eiweiss beim Filtriren schlecht hätte entfernen lassen, sondern ein offenes Becherglas, und stellte eine innige Vermengung des Gemisches durch kräftiges Umrühren mit einem Glasstabe her. Auf Salzsäurezugabe schied sich in dem Gemisch sofort ein feinflockiger Niederschlag ab, der sich allmählich zu Boden setzte. Die Filtrate waren meistens nicht völlig klar, sondern zeigten eine Opalescenz oder geringe Trübung. Nochmaliges Filtriren bewirkte ein etwas klareres Filtrat. Gerbsäure oder Phosphorwolframsäure erzeugten in dem Filtrat stets noch eine geringe Trübung, die sich nach einigem Stehen als geringfügiger Niederschlag zu Boden setzte und abfiltrirt werden konnte. Eine in demselben vorgenommene Stickstoffbestimmung ergab einen Stickstoffgehalt und zwar in der Höhe, um welche der erste mit Metaphosphorsäure erregte Eiweissniederschlag hinter der correspondirenden Gerbsäureeiweissbestimmung zurückgeblieben war. Es ergaben beispielsweise einige Versuche folgende Zahlen:

1.

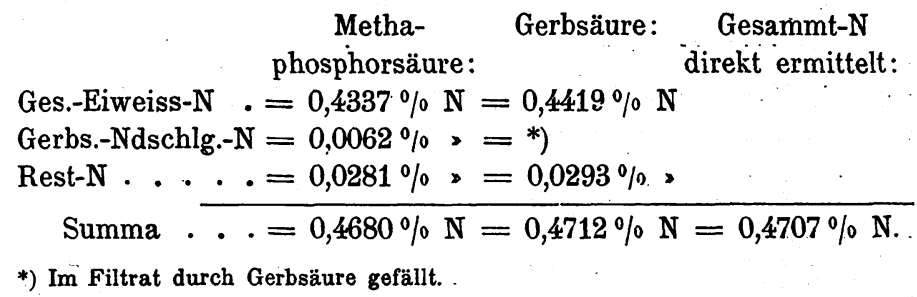


2.

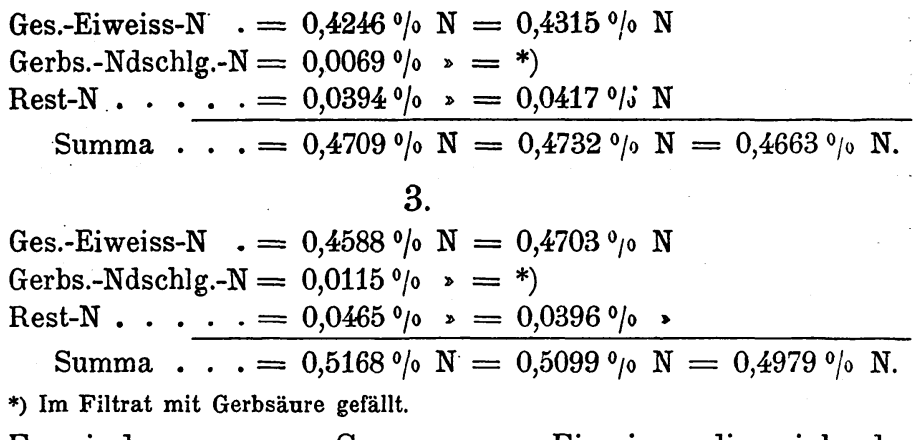

Es sind zwar nur Spuren von Eiweiss, die sich der Fällung mit Metaphosphorsäure entziehen, und in der Praxis wird diese geringe Ungenauigkeit kaum eine Rolle spielen. Da aber mit Gerbsäure schon qualitativ Eiweissspuren, die nicht mitgefällt sind, im Filtrat sich nachweisen lassen, so kann man die Methode mit metaphosphorsaurem Natrium kaum eine quantitative nennen.

\section{Methode: Fällung mit Asaprol.}

Ein ähnliches Ergebniss, wie mit der Metaphosphorsäure, erhielt ich bei Eiweissbestimmungen mit Asaprol. Asaprol ist der Handelsname für das Calciumsalz der $\beta$-Naphtholmonosulfosäure $\mathrm{C}_{10} \mathrm{H}_{6} \mathrm{OHSO}_{3} \mathrm{H}$. Ich fand dieses Reagens zufällig in einem mir bekannten «Hülfsbuch für Nahrungsmittelchemiker von A. Bujard und E. Baier, II. Aufl., 1900, S. 118," bei der Beschreibung von Milchzuckerbestimmungen erwähnt und beschloss, da es für die Zuckerbestimmungen völlig eiweissfreie Lösungen liefern sollte, es speciell für Eiweissbestimmungen zu verwenden. Die Vorschrift für die Verwendung des Asaprols wird in dem Hülfsbuch ${ }^{1}$ ) so angegeben: "10 $\mathrm{ccm}$. Milch und $15 \mathrm{ccm}$. Asaprolreagens (in folgender Weise bereitet: $15 \mathrm{~g}$ Asaprol und $15 \mathrm{~g}$ [gepulverte] krystallisirte Citronensäure löst man in $500 \mathrm{ccm}$. Wasser und filtrirt dann die Lösung) gibt man in ein Messkölbchen von $100 \mathrm{ccm}$. Inhalt und füllt die Mischung bis zur Marke, darnach schüttelt man kräftig durch,

1) Nach Riegler, Zeitschr. f. analyt. Chemie, 1898, S. 24 . 
erwärmt bis auf etwa $60^{\circ}$ C. und filtrirt. Von dem Filtrate, welches wasserklar und vollständig eiweissfrei ist etc. etc.» Aus demselben Grunde, wie bei der Metaphosphorsäuremethode, wurde die Bestimmung nicht in einem Kölbchen, sondern in einem Becherglase ausgeführt. Die Eiweissstoffe schieden sich in feinen Flocken $\mathrm{ab}$ und liessen sich nach dem Absetzen gut filtriren und mit kaltem Wasser auswaschen. Die Filtrate waren ausnahmslos vollständig wasserklar, fingen aber auf $\mathrm{Zu}$ satz von Gerbsäure oder Phosphorwolframsäure stets an zu opalisiren. Beim Stehen über Nacht setzte sich ein geringer Niederschlag ab, der abfiltrirt und nach Kjeldahl verbrannt wurde. Er erwies sich immer, wenn auch in geringerem Maasse, als stickstoffhaltig, wie aus den angeführten Beispielen hervorgeht.

1.

Asaprol: Gerbsäure: Gesammt-N direkt ermittelt:

Ges.-Eiweiss-N $\quad .=0,5172 \% \mathrm{~N}=0,5172 \% \mathrm{~N}$

Gerbs.-Ndschlg.-N $=0,0066 \%$ *)

Rest-N. . . = =0,0377\% $,=0,0377 \%$,

Summa ... $=0,5615 \% \mathrm{~N}=0,5549 \% \mathrm{~N}=0,5594=\mathrm{N}$.

2.

Ges.-Eiweisr- $\mathrm{N} .=0,4870 \% \mathrm{~N}=0,4922 \% \mathrm{~N}$

Gerbs.-Ndschlg.-N $=0,0044 \%, *$ )

Rest-N . . . . =0,0272\%, =0,0317\% ,

Summa $\ldots=0,5186 \% \mathrm{~N}=0,5239 \% \mathrm{~N}=0,5077 \% \mathrm{~N}$.

3.

Ges.-Eiweiss- $\mathrm{N} .=0,4955 \% \mathrm{~N}=0,5021 \% \mathrm{~N}$

Gerbs.-Ndschlg.-N=0,0088\%,*)

Rest-N . . . = =0,0351\%, =0,0351\% ,

Summa . . =0,5394\% $\mathrm{N}=0,5372 \% \mathrm{~N}=0,5328 \% \mathrm{~N}$.

*) Im Filtrat mit Gerbsäure gefällt.

Die Unterschiede zwischen beiden Methoden sind äusserst klein, auch ist die im Filtrat mit Gerbsäure nachweisbare Spur von Eiweiss so geringfügig, dass man sie beinahe vernachlässigen könnte. Das Asaprol ist also der Gerbsäure in Bezug auf Schärfe zwar nicht gleichzustellen, es ist aber ein für die Praxis genügende Genauigkeit bietendes Eiweissreagens.

Stellen wir nun eine vergleichende Betrachtung aller bis- 
her beschriebenen Methoden an, so müssen wir zu dem Schlusse kommen, dass wir in allen genannten, bis auf die Metaphosphorsäure (und das Asaprolreagens) vorzügliche, quantitativ fällende Eiweissreagentien haben. Als besonders scharf haben sich die Almén'sche Gerbsäure und die Phosphorwolframsäure erwiesen, beide bieten bei der Ausführung keinerlei Schwierigkeiten und Unbequemlichkeiten; ein geringer Ueberschuss schadet der Genauigkeit durchaus nicht. Der grösste Unterschied, der sich bei Parallelversuchen mit beiden Mitteln ergeben hat, beträgt nur $0,0068 \% \mathrm{~N}$, im Mittel $0,0028 \% \mathrm{~N}$, eine Differenz, die vollkommen innerhalb der zulässigen Fehlergrenze liegt. Die Ritthausen'sche und die von Munk combinirte Ritthausen-Stutzer'sche Kupfermethode stehen den beiden genannten, was Genauigkeit der Ergebnisse anbelangt, zwar in keiner Weise nach, aber einmal erfordert deren Ausführung grössere technische Fertigkeiten, dann aber auch mehr Zeit, so dass sie für Serienbestimmungen nicht so gut geeignet sind. Die Trichloressigsäure liefert in der von mir beschriebenen Ausführung brauchbare Zahlen, aber der Umstand, dass in dem Filtrat durch Gerbsäure oder Phosphorwolframsäure Spuren von Eiweiss nachzuweisen sind, wenn auch nicht in der Stärke, wie bei dem Metaphosphorsäureverfahren, verringert ihren Werth für Eiweissbestimmungen. Man wird sie hauptsächlich dann anwenden, wenn man das Filtrat zur Milchzuckerbestimmung benutzen will.

Aus der Uebereinstimmung der mit Gerbsäure und Phosphorwolframsäure erhaltenen Ergebnisse könnte man, da Gerbsäure im Ueberschuss das Pepton nicht, Phosphorwolframsäure dasselbe aber vollständig fällt, den Schluss ziehen, dass Pepton kein ständiger Begleiter der echten Eiweissstoffe der Kuhmilch sei, wenigstens nicht eine erhebliche Menge erreiche; aber ich versuchte doch auf anderem Wege darüber Aufklärung zu erhalten. Am entschiedensten vertritt Schmidt-Mühlheim,1) wie oben bereits erwähnt, die Ansicht, dass Pepton stets in der Milch vorhanden sei. Er behauptet, dass die von den

1) Archiv f. Physiologie, Bd. 28, S. 287. 
anderen zum Nachweis des Peptons angewandten Methoden nicht zuverlässig seien, da sie theilweise das Pepton mit den Eiweissstoffen fällen, und führt eine Methode an, bei der dieser Uebelstand vermieden werde. Und zwar verdünnt er ein Volumen Milch mit einem Volumen Wasser, sättigt diese Mischung vollständig mit Kochsalz, fügt zwei Volumen einer Lösung hinzu, die auf ein Volumen Eisessig fünf Völumen gesättigte Kochsalzlösung enthält, filtrirt den Niederschlag ab und wäscht mit der Eisessigkochsalzlösung aus. Die Eiweissstoffe seien dann so vollständig gefällt, dass Ferrocyankalium im Filtrate keine Spur von Trübung gebe, Pepton bleibe dagegen ungefällt und werde mit Phosphorwolframsäure im Filtrate nachgewiesen. Schmidt-Mühlheim hat so in frischer Milch $0,08-0,19 \%$, in gestandener $0,33 \%$ Pepton gefunden. Bei Wiederholung dieses Versuches erhielt ich mit Phosphorwolframsäure eine Trübung, die abfiltrirt, nach Kjeldahl verbrannt wurde und sich in geringem Maasse als stickstoffhaltig erwies. Dogiel $^{1}$ ) behauptet, dass der negative Ausfall der Ferrocyankaliumprobe bei Schmidt-Mühlheim nicht beweiskräftig sei, da bei Gegenwart von viel Salz kleine Mengen von Eiweiss durch Ferrocyankalium nicht gefällt und dann selbstverständlich durch Phosphorwolframsäure nachgewiesen würden. Die Trübung durch letztere zeige also kein Pepton an, sondern Eiweiss. Da ich nicht entscheiden konnte, ob die durch Phosphorwolframsäure hervorgerufene Fällung von Eiweiss oder Pepton herrühre, versuchte ich noch eine andere Methode zum Peptonnachweis, wie Sebelien ${ }^{y}$ ) sie beschreibt. Danach werden $50 \mathrm{ccm}$. Milch bei Zimmertemperatur mit festem gepulverten Ammoniumsulfat vollständig gesättigt und nach erzielter Sättigung filtrirt. Das zur Hälfte mit Wasser verdünnte Filtrat wird mit einigen Tropfen Gerbsäure versetzt (Phosphorwolframsäure kann nicht verwendet werden, da sie mit dem Ammoniumsulfat einen dicken, weissen Niederschlag gibt). Pepton gibt sich dann durch eintretende Fällung, die im Ueberschuss wieder

1) Hoppe-Seyler, Zeitschr. f. physiol. Chem., Bd. IX, S. 601.

2) Hoppe-Seyler, Zeitschr. f. physiol. Chem., Bd. XIII, S. 1 ว̆2. 
löslich wird, kund. Einige Tropfen Gerbsäure erzeugten bei mir keinen Niederschlag, erst als ich mehr hinzufügte, nahm die Mischung eine dunkle Farbe an und schied einen röthlich gefärbten Niederschlag $a b$, der sich im Ueberschuss nicht löste und jedenfalls von einer Zersetzung der Gerbsäure herrührte, also als eine Reaction auf Pepton nicht anzusehen war. Nach Heinsius ${ }^{1}$ ) ist übrigens Ammoniumsulfat zu diesem Nachweis überhaupt nicht geeignet, da dasselbe nicht nur die echten Eiweissstoffe, sondern auch Pepton vollständig fällt.

Aus diesem Grunde schlug ich noch einen anderen Weg ein, indem ich nach dem Vorschlage von Zuntz ${ }^{2}$ ) die Eiweissstoffe durch Aussalzen mit gepulvertem Zinksulfat entfernte. Angewandt wurden $100 \mathrm{ccm}$. Milch zum Peptonnachweis. In der vom Zinksulfatniederschlage abfiltrirten Lösung riefen Gerbsäure wie Phosphorwolframsäure eine schwache Trübung hervor, die durch einen Ueberschuss von Gerbsäure nicht verschwand. Bei der Stickstoffbestimmung wurde ein so schwacher Antheil Stickstoff gefunden, nämlich 0,0004\% dass ich denselben eher als eine Verunreinigung, als vom Pepton herrührend, ansehen möchte. $\mathrm{Nach}$ alledem komme ich zu dem Schluss, dass frische Milch kein Pepton, wenigstens nicht in nachweisbaren Mengen enthält.

\section{Theil.}

\section{Trennung der Eiweisskörper.}

Die Zahl der zur fractionirten Bestimmung der Eiweisskörper der Milch vorgeschlagenen Methoden ist bei Weitem nicht so gross, wie die der für Abscheidung des Gesammteiweisses bekannt gewordenen. Die grösste Rolle unter den das Eiweiss nur theilweise fällenden Stoffen spielt in der Technik das das Casein bei der Käsefabrikation abscheidende Labferment. Es ist aber allgemein bekannt, dass das Lab nicht im Stande ist, alles Casein zur Gerinnung zu bringen; ich habe deshalb bei meinen

1) Archiv. f. Physiologie, Bd. 34, S. 330.

2) Hoppe-Seyler, Zeitschr. f. physiol. Chem., Bd. XXVII, S. 220. 
Betrachtungen vom Lab absehen zu dürfen geglaubt und es nicht in den Bereich meiner Untersuchungen gezogen:

Frenzel und Weyl schlugen vor, ${ }^{1}$ ) das Casein vom Albumin in auf das Vierfache verdünnter Milch mit verdünnter Schwefelsäure $\left(1 \mathrm{ccm}\right.$. conc. $\mathrm{H}_{2} \mathrm{SO}_{4}$ vom spec. Gewicht 1,84 auf 1 Liter Wasser) zu trennen. Sie geben aber selbst an, dass die so erhaltenen Zahlen niedriger als bei der Trennung mit Essigsäure ausfallen, und dass das Casein in einem kleinen Ueberschuss der Schwefelsäure sich stärker löst, als im Ueberschuss von Essigsäure. Aus diesem Grunde habe ich auch diese Methode, nachdem einige Vorversuche die Angaben jener beiden bestätigt hatten, nicht weiter berücksichtigt.

\section{Methode: Trennung von Casein und Albumin mit verdünnter Essigsäure (nach Hoppe-Seyler).}

Die älteste und bekannteste Methode, Casein und Albumin der Kuhmilch von einander zu trennen, ist die von HoppeSeyler ausgearbeitete mit Essigsäure und Kohlensäure. ${ }^{2}$ )

"Man verdünnt $10 \mathrm{ccm}$. Milch mit Wasser, bis das Volumen der Flüssigkeit $200 \mathrm{ccm}$. beträgt, fügt hierzu sehr verdünnte Essigsäure $(1: 100)$ in einzelnen Tropfen, bis sich eben ein flockiger Niederschlag zeigt, leitet während einer halben Stunde einen Strom von Kohlensäure durch die Flüssigkeit und lässt dieselbe dann 12 Stunden ruhig stehen. Es ist zweckmässig, drei solcher Proben auf dieselbe Weise zu behandeln und von diesen diejenige für die weitere Behándlung $\mathrm{zu}$ wählen, in welcher die Flüssigkeit vollkommen klar geworden ist. Das Casein setzt sich mit dem Fette als faserig-flockiger Niederschlag zu Boden. Man filtrirt zunächst die klare Flüssigkeit, sammelt dann mit zurückgegossenen Theilen des Filtrates den Niederschlag auf dem Filter und wäscht mit Wasser aus. Im Filtrate befinden sich Albumin, Milchzucker und etwas ge10̈stes Casein.» Das Albumin bestimmte Hoppe-Seyler, indem er das vom Casein befreite essigsaure Filtrat einige

1) Hoppe-Seyler, Zeitschr. f. physiol. Chem., Bd. IX, S. 246.

2) Handbuch der physiol.-chem. Analyse, 5. Aufl.; 1893, S. 462. 
eine schwache Opalescenz, die ja auf noch anwesendes Casein schliessen lässt, so filtrirt man noch einmal, und man wird dann fast immer ein klares, caseinfreies Filtrat vor sich haben. Im Uebrigen setzt man zweckmässig, wie ja auch Hoppe-Seyler empfiehlt, drei Bestimmungen nebeneinander an und sieht dann die als die richtigere an, bei der das Filtrat keine Opalescenz aufwies. Die Zahlen, die mit der Essigsäuremethode sich ergaben, stimmten bei meinen Versuchen, wie später angeführte Beispiele zeigen werden, gut mit den nach einer anderen Methode (Kalialaun) gewonnenen überein. Die hier angeführten Zahlen mögen die absoluten Mengen von Casein und Albumin angeben und ausserdem beweisen, dass die mit Essigsäure- und Gerbsäurefällung einzeln erhaltenen Eiweissstoffe, Casein und Albumin, in ihrer Summe sich decken mit dem mittelst Gerbsäure bestimmten Gesammteiweiss, worin eine Garantie für die Richtigkeit der fractionirten Bestimmungsweise liegt.

1.

Essigsäure Hoppe-Seyler Casein . . 0,3515\% N

Albumin . . 0,0822\% *

Ges.-Eiweiss aus der Summa $0,4337 \% \mathrm{~N} \quad 0,4419 \% \mathrm{~N}$.

2.

Casein . . 0,3635\% N

Albumin . . 0,0672\%

Summa $0,4307 \% \mathrm{~N} \quad 0,4261 \% \mathrm{~N}$.

3.

Casein . . 0,4580\% N

Albumin . . 0,1378\% ,

Summa $0,5958 \% \mathrm{~N} \quad 0,5981 \% \mathrm{~N}$.

Frenzel und Weyl behaupten, ${ }^{1}$ ) «dass eingeleitete Kohlensäure die Caseinmenge in keiner Weise beeinflusse, vielmehr nur die Form der Ausscheidung modificire; die Caseinflocken seien bei Anwendung von Kohlensäure feinflockiger, als ohne dieselbe.» Jedenfalls wird aber durch die Anwendung

1) Hoppe-Seyler, Zeitschr. f. physiol. Chem., Bd. IX, S. 251.

Hoppe-Seyler's Zeitschrift f. physiol. Chemie. XXXIII. 
von Kohlensäure die verdünnte Milch in so lebhafte Bewegung gesetzt und mit dem Fällungsmittel in so innige Berührung gebracht, dass dadurch ein besseres Zusammenballen und $\mathrm{Ab}$ setzen der sonst suspendirt bleibenden Caseintheilchen bewirkt wird. Der Niederschlag lässt sich besser filtriren, das Filtrat ist klar, während dasselbe ohne Anwendung von Kohlensäure trotz wiederholten Zurückgiessens immer trüb bleibt, in Folge des durchs Filter mit durchfliessenden Caseins. Auf diese Weise wird indirekt auch die Menge des abgeschiedenen Caseins entgegen der Behauptung von Frenzel und Weyl beeinflusst. Ein ohne Einleiten von Kohlensäure ausgeführter Versuch lieferte bedeutend weniger Casein im Vergleich mit einer Caseinbestimmung nach Schlossmann.

Caseinbestimmung:

mit Essigsäure ohne $\mathrm{CO}_{2}$-Einleitung

Casein-N . . 0,3212\% N

Albumin- $\mathrm{N} . .0,1284 \%$,

Summa $0,4496^{\circ} / 0 \mathrm{~N}$ mit Alaun (Schlossmann) $0,3625 \% \mathrm{~N}$ $0,1192 \%$

Die Hoppe-Seyler'sche Methode ist nach diesen Ergebnissen als eine zur Trennung von Casein und Albumin gut geeignete anzusehen, wenn man das Albumin mit Gerbsäure niederschlägt; sie war bis vor Kurzem (1897) die schärfste der bekannten Methoden und musste den weitest gehenden Ansprüchen in jeder Beziehung völlig genügen, so lange man keine bessere kannte.

\section{Methode: Caseinbestimmung mit Kaliumalaun (nach Schlossmann).}

Schlossmann gebührt das Verdienst, eine andere Methode gefunden zu haben, die in den Ergebnissen mindestens von gleicher Genauigkeit ist, in ihrer Ausführung aber wesentliche Vortheile bietet, da sie einmal das zeitraubende Einleiten der Kohlensäure überflüssig macht, und zweitens auch nicht so grosse Flüssigkeitsmengen, die zu filtriren oft mühsam ist, benöthigt. Das ist die Trennung von Casein und Albumin mit Kaliumalaun, ${ }^{1}$ ) deren nähere Ausführung Schlossmann so beschreibt: "Man nimmt $10 \mathrm{ccm}$. Milch (Frauen-, Kuh-, Ziegen-,

1) Hoppe-Seyler, Zeitschr. f. physiol. Chem., Bd. XXII, S. 213. 
Schweine-, Eselsmilch) und verdünnt mit 3-5 Theilen Wasser, erwärmt vorsichtig über kleiner Flamme oder besser auf dem Wasserbade unter Kontrolle des Thermometers auf $40^{\circ}$, setzt alsdann $1 \mathrm{ccm}$. einer concentrirten Lösung von Kalialaun zu und wartet unter Umrühren ab, ob eine mittelflockige Coagulation und rasches Absetzen der Coagula erfolgt; ist letzteres noch nicht der Fall, so wird so lange mit dem Zusatz von $1 / 2 \mathrm{ccm}$. der erwähnten Lösung fortgefahren, bis der Moment der genügenden Coagulation und Abscheidung eintritt. Es muss selbstverständlich immer vor erneutem Alaunzusatz einen Augenblick gezögert werden ( $1 / 2$ Minute), um zu diesem Absetzen Zeit zu lassen; die Temperatur ist dabei constant auf $40^{\circ} \mathrm{C}$. zu halten. Ein kleiner Ueberschuss der Alaunlösung · schadet sicher nicht. Nach Vollendung der Abscheidung, die bei Kuh-, Ziegen-, Schweine- und Eselsmilch grossflockig bis mittelflockig, bei Frauenmilch feinflockig ist, lässt man einige Minuten stehen und filtrirt dann. Die Abscheidung des Frauenmilchcaseins erleichtert man durch Zusatz von etwas Chlornatrium in Substanz während des Erwärmens, die Filtration durch Hinzufügen von Kaliumphosphat, das mechanisch die feinen Caseinflocken auf dem Filter zurückhält und ihr Durchpassiren hindert. Nachdem das Filtrat wasserklar geworden ist, wozu es bisweilen des 2-3maligen Rückgiessens, das aber immer in kurzer Zeit wieder durchfiltrirt, bedarf, und einige Male mit Wasser nachgewaschen ist, kann das Filter im Soxhletapparat entfettet werden; auf diese Weise wird das Fett quantitativ erhalten, da dasselbe dem Niederschlage anhaftet. Das entfettete Filter wird nach Kjeldahl verbrannt und der so gefundene Stickstoff auf Casein umgerechnet und als solcher in Ansatz gebracht. Das Filtrat wird mit $10 \mathrm{ccm}$. Tanninlösung versetzt, der entstehende voluminöse Niederschlag abfiltrirt und nach dreimaligem Waschen mit frischem Wasser ebenfalls nach Kjeldahl verbrannt. Der gefundene Stickstoff wird als Stickstoff des löslichen Eiweisses aufgefasst (Albumin und Globulin) und entsprechend umgerechnet.» Man stösst bei Anwendung dieser Methode auf keinerlei Schwierigkeiten, der richtige Alaunzusatz ist leicht $\mathrm{zu}$ treffen, zumal da ein kleiner Ueberschuss keine 
nachtheilige Wirkung ausübt. War das Filtrat einmal nicht ganz klar durch das Filter gelaufen, so genügte immer schon ein einmaliges Zurückgiessen, um ein klares Filtrat zu erhalten und jede Spur von Casein auf dem Filter zurückzuhalten. Verschiedene Milchsorten scheinen sich in der Beziehung übrigens nicht gleichmässig zu verhalten. Bei meinen später beschriebenen Versuchen konnte ich nämlich die Beobachtung machen, dass beim Alaunzusatz zu der Milch von Kuh 643 das Filtrat stets oder doch nur mit geringen Ausnahmen ein nochmaliges Filtriren erforderte, während bei Kuh 636 stets nach erstmaligen Passiren durchs Filter eine völlig klare Flüssigkeit erzielt wurde. In beiden Fällen wurde so verfahren, dass ich nicht etwa ein gleiches Quantum von Alaunlösung zu gleichen Gewichtsmengen Milch zusetzte, sondern dass ich durch tropfenweise erfolgenden Alaunzusatz den Augenblick zu treffen suchte, in dem das Casein sich schön zusammenballte und leicht absetzte. Meistens war an der über dem abgesetzten Gerinnsel stehenden klaren oder mehr oder weniger opalescirenden Flüssigkeitsschicht schon zu erkennen, ob das Filtrat klar oder trübe durchlaufen würde. War dieses verschiedene Verhalten der Milch auf das Alter der Thiere, von denen die Milch stammte, auf die Zeit der Lactation, auf Fütterung oder auf verschiedene Eigenschaften des producirenden Organismus zurückzuführen, das wage ich nicht zu entscheiden, behaupte aber, dass die Behandlungsweise der Milch bei Ausführung der Analyse die Ursache nicht war.

In einer und derselben Probe Milch die Fettbestimmung durch Aetherextraction des Caseinfettniederschlages und in dem erschöpften Niederschlage die Stickstoffbestimmung vorzunehmen, wie Schlossmann empfiehlt, halte ich für unzweckmässig. Man kommt mit Stickstoff- und Fettbestimmung eher zum Ziel, wenn man den feuchten Caseinniederschlag nach Kjeldahl verbrennt und das Fett in einer gesonderten Probe für sich bestimmt. Ausser den schon erwähnten Vorzügen vor der Essigsäuremethode bietet das Schlossmann'sche Verfahren noch den Vortheil, dass man auch bei der Be- 
stimmung des Albumins mit Gerbsäure bedeutend schneller fertig wird, weil der voluminöse Niederschlag sich aus der geringen hier vorhandenen Flüssigkeitsmenge leichter filtriren lässt. Auch ist der Umstand nicht zu unterschätzen, dass diese Bestimmungsweise, ebenso wie für Kuhmilch, auch für Frauenmilch etc. anwendbar ist.

Was nun die Genauigkeit der Resultate betrifft, so ist diese Methode als eine sehr scharfe und exacte anzusehen. Vergleichende Versuche mit der Hoppe-Seyler'schen Methode gaben für Casein wie für Albumin übereinstimmende Zahlen. Aber auch daraus, dass die Summe des Casein- und Albuminstickstoffs sich deckt mit dem nach einer anderen Methode ermittelten Gesammteiweissstickstoff oder dass Casein-, Albumin- und Extractivstickstoff gleich ist dem direkt ermittelten Gesammtstickstoff der Milch, scheint doch die Genauigkeit dieser Methode genügend hervorzugehen.

Einige Belegbeispiele seien hier angeführt:

1.

\begin{tabular}{|c|c|c|c|c|}
\hline & $\underset{\% / 0}{\text { Alaun }}$ & $\begin{array}{c}\text { Essigsäure } \\
\% \% \mathrm{~N}\end{array}$ & $\begin{array}{l}\text { Ges.-Eiweiss } \\
\% \text { N m. Gerbs. }\end{array}$ & $\begin{array}{l}\text { Ges.-Stickstoff } \\
\% \text { N direkt }\end{array}$ \\
\hline Casein- $N$ & 0,3494 & 0,3515 & - & - \\
\hline Albumin-N . . & 0,0966 & 0,0822 & - & 一 \\
\hline Extractiv-N . . & 0,0295 & 0,0295 & 0,0295 & - \\
\hline Ges.-Eiweiss-N & 0,4460 & 0,4337 & 0,4419 & - \\
\hline Ges.-Stickstoff-N & 0,4755 & 0,4632 & 0,4714 & 0,4707 \\
\hline
\end{tabular}

2.

\begin{tabular}{lcccc} 
Casein-N . . & 0,3612 & 0,3635 & - & - \\
Albumin-N . & 0,0764 & 0,0672 & - & - \\
Extractiv-N . & 0,0278 & 0,0278 & 0,0278 & - \\
\cline { 2 - 5 } Ges.-Eiweiss-N & 0,4376 & 0,4307 & 0,4261 & - \\
\cline { 2 - 5 } Ges.-Stickstoff . & 0,4654 & 0,4585 & 0,4539 & 0,4585
\end{tabular}

3.

\begin{tabular}{lcccc} 
Casein-N . . & 0,3921 & 0,3899 & - & - \\
Albumin-N . & 0,1285 & 0,1307 & - & - \\
Extractiv-N . & 0,0332 & 0,0332 & 0,0332 & - \\
\cline { 2 - 5 } Ges.-Eiweiss-N & 0,5206 & 0,5206 & 0,5185 & - \\
\cline { 2 - 5 } Ges.-Stickstoff . & 0,5538 & 0,5538 & 0,5517 & 0,5595
\end{tabular}




\section{Methode: Caseinbestimmung mit Magnesiumsulfat.}

Zum ersten Male wurde von Mitscherlich ${ }^{1}$ ) im Jahre 1874.das Magnesiumsulfat zur Trennung des Caseins von Albumin angewandt. Nach ihm sind dann von verschiedenen Forschern Untersuchungen mit diesem Salze angestellt, z. B. von Tolmatscheff, $\left.{ }^{2}\right)$ Makris; ${ }^{3}$ ) Hoppe-Seyler. ${ }^{4}$ ) Sebelien schlägt vor, das Magnesiumsulfat als einen halbflüssigen Krystallbrei zu verwenden, da dieser sich in der Milch besser löse, als das trockene, gepulverte Salz. Er verdünnt $10 \mathrm{ccm}$. Milch mit $20 \mathrm{ccm}$. gesättigter $\mathrm{MgSO}_{4}$-Lösung und trägt soviel von dem Krystallbrei in die Milch ein, als sich lösen will. Man lässt dann, um eine vollständige Sättigung mit dem Salz zu erreichen, ca. 24 Stunden stehen, filtrirt dann ab und wäscht mit gesättigter $\mathrm{MgSO}_{4}$-Lösung aus. Das Albumin fällt man in dem mit Wasser verdünnten Filtrat mit Gerbsäure. Ob man das Sättigen bei gewöhnlicher Zimmertemperatur oder bei $30^{\circ}$, wie Neumeister nach Hammarsten's Methode ${ }^{5}$ ) vorschlug, sich vollziehen lässt, hat auf die Höhe der Resultate, wie einige Versuche zeigten, keinen Einfluss; bei $30^{\circ}$ geht die Sättigung nur schneller von Statten. Das Filtriren des ausgesalzenen Niederschlages ist äusserst langwierig und beansprucht sehr viel Zeit.

Die Anwendung der Saugpumpe führt auch nicht eher zum Ziel, im Gegentheil geht die Filtration ohne Saugpumpe immer noch schneller vor sich. Ein grosser Druck lässt sich nämlich, da man befürchten muss, das Filter zu zerreissen, mit der Pumpe nicht ausüben; setzt man vollends, um ein Durchreissen des Filters zu verhüten, einen Conus unter dasselbe und lässt die Saugpumpe ihren vollen Druck ausüben, so kommt man mit dem Filtriren garnicht zu Ende, das Salz

1) Makris, die Eiweisskörper der Kuh- u. Menschenmilch, 1876, S. 20.

2) Hoppe-Seyler, Med.-chem. Untersuchungen, Bd. II, 1867.

3) Makris, Die Eiweisskörper der Kuh- und Menschenmilch, 1876.

4) Handbuch der physiol.-chem. Analysen, 4. u. 5. Auflage.

5) Zeitschr. f. Biologie, Bd. 23, S. 399, Jahrg. 1887.

Diese ebengenannten Litteraturangaben sind citirt nach Sebelien, Zeitschr. f. physiol. Chem., Bd. XIII, S. 160. 
krystallisirt auf dem Filter aus, bevor die Flüssigkeit abgelaufen ist.

Auch das zwecks Albuminfällung mit Gerbsäure versetzte verdünnte Filtrat lässt sich schwer filtriren, da das Albumin in der in Folge des hohen Salzgehaltes specifisch so schweren Flüssigkeit sich nicht vollständig zu Boden setzt, sondern darin suspendirt bleibt, sodass also ein Decantiren nicht möglich ist und beim Aufgiessen sofort erhebliche Theile des voluminösen Albumintannats aufs Filter gerathen und die Poren desselben verstopfen. Bei der Leichtigkeit, mit der die Trennung mit Schlossmann's Alaunlösung zu bewerkstelligen ist, wird man das Aussalzen des Caseins nie vornehmen, wenn nicht eine besondere Veranlassung dazu gegeben ist, z. B. die Absicht vorliegt, die Methode nachzuprüfen oder das Albumin ohne Globulin getrennt zu erhalten.

Einige Versuche seien hier aufgeführt, die über die Höhe der mit $\mathrm{MgSO}_{4}$ erhaltenen Zahlen, verglichen mit den nach Schlossmann gewonnenen, Aufschluss geben.

1.

\begin{tabular}{|c|c|c|c|c|}
\hline $1+c$ & $\begin{array}{c}\mathrm{MgSO}_{0,4824 \% \mathrm{~N}}\end{array}$ & $\begin{array}{c}\text { Alaun } \\
0,4543 \% \mathrm{~N}\end{array}$ & Gerbsäure & $\begin{array}{r}\mathrm{MgSO}_{4}>\text { Alaun } \\
0,0381 \% \mathrm{~N}\end{array}$ \\
\hline & $0,1156 \%$ & $0,1422 \%$ & - & $0,0266 \%$. \\
\hline Ges.-Eiwe & $\% \mathrm{~N}$ & $0,5965 \% \mathrm{~N}$ & $59810 \mathrm{~m} \mathrm{~N}$ & - \\
\hline
\end{tabular}

2.

Casein (+ Globulin) $0,4352 \% \mathrm{~N} \quad 0,3930 \% \mathrm{~N} \quad-\quad>0,0422 \% \mathrm{~N}$ Albumin .... 0,0977\% $0,1354 \%>\quad-\quad<0,0377 \%$, Summa: Ges.-Eiweiss 0,5329\% N $0,5284 \% \mathrm{~N} \quad 0,5374 \% \mathrm{~N} \quad-$ 3.

Casein (+ Globulin) $0,4254 \% \mathrm{~N} \quad 0,3921 \% \mathrm{~N} \quad->0,0333 \% \mathrm{~N}$ Albumin . . . . 0,1063\% $0,1285 \%>\quad-\quad 0,0222 \%$, Summa: Ges.-Eiweiss 0,5317\% N $0,5206 \% \mathrm{~N} \quad 0,5185 \% \mathrm{~N}$

Die Zahlen der mit Magnesiumsulfat ausgeführten Bestimmungen zeigen durchgehends für Casein einen höheren, für Albumin einen entsprechend niedrigeren Betrag, als die nach Schlossmann. Bisher habe ich bei Besprechung der die einzelnen Eiweissstoffe fällenden Reagentien einen, oben als 
stets in der Milch vorkommenden Körper erwähnten Eiweissstoff gänzlich ausser Acht gelassen, das «Globulin». In einer Abhandlung, «Zur Frage, ob das Casein ein einheitlicher Stoff sei, ${ }^{1}$ ) die Hammarsten zur Widerlegung der Eingangs genannten Arbeit von Danilewsky und Radenhausen veröffentlichte, sagt er, "wenn auch alles Casein ausgefällt sei, enthalte das Filtrat neben Albumin noch eine mit $\mathrm{MgSO}_{4}$ fällbare Substanz, die kein Serumalbumin sei. Nach einigen Reactionen $\mathrm{zu}$ urtheilen, scheine sie ein Globulin $\mathrm{zu}$ sein.» Den Beweis für die von ihm hier ausgesprochene Vermuthung erbrachte auf seine Veranlassung später Sebelien. ${ }^{2}$ ) Das $\mathrm{MgSO}_{4}$ ist demnach also im Stande, nicht nur das Casein, sondern auch das Globulin vollständig aus den Lösungen auszusalzen. Hiermit ist die Erklärung für den mit $\mathrm{MgSO}_{4}$ gefundenen höheren Gehalt an Casein und niedrigeren an Albumin gegeben. Das Kalialaun fällt nur das Casein aus und die Gerbsäure vereinigt in ihrem Niederschlage im Filtrate den ganzen Rest an Eiweiss, d. i. Globulin und Albumin. Streng genommen, hätte ich also, wo bisher von Albumin gesprochen wurde, an dessen Stelle Albumin + Globulin anführen müssen.

Das Mehr an Stickstoff, das ich mit $\mathrm{MgSO}_{4}$ gegenüber dem Kalialaun stets fand, war durchaus nicht constant, sondern vielmehr erheblichen Schwankungen unterworfen. Im geringsten Falle betrug es $0,0204 \%$ Stickstoff und im höchsten $0,0638 \% \mathrm{~N}$, wie ein Blick auf die Tabelle II lehrt. Man könnte nun geneigt sein, diese Schwankungen auf ein mehr oder weniger vollständiges Auswaschen des $\mathrm{MgSO}_{4}$-Niederschlages zurückzuführen, denn die Schwierigkeiten, die das Auswaschen mit der gesättigten $\mathrm{MgSO}_{4}$-Lösung bei dem überaus langwierigen Filtriren verursacht, sind so gross, dass dieser Einwand nicht so ohne Weiteres von der Hand $\mathrm{zu}$ weisen ist. Ich musste mich deshalb auf andere Weise davon überzeugen, ob der Globulingehalt constant oder thatsächlich so grossen Schwankungen unterworfen sei. Diese Absicht konnte ich auf

1) Hoppe-Seyler, Zeitschr. f. physiol. Chem., Bd. VII, S. 250.

2) Hoppe-Seyler, Zeitschr. f. physiol. Chem., Bd. IX, S. 445. 
zwei verschiedenen Wegen durchführen, entweder konnte ich das Casein aus der Milch mit $\mathrm{NaCl}$ aussalzen, wie Sebelien es that und dann aus dem Filtrat das Globulin mit $\mathrm{MgSO}_{4}$, oder aber ich konnte nach dem Entfernen des Caseins mit Alaun in dem Filtrat das Aussalzen mit $\mathrm{MgSO}_{4}$ vornehmen. Die Schwierigkeiten, die das Filtriren salzgesättigter viscöser Gemische bereitet (bei dem NaGl kommt auch noch der Umstand hinzu, dass es leicht über den Trichterrand kriecht), lassen jeden, zumal wenn er die Wahl zwischen verschiedenen Methoden hat, auf das Aussalzen gern verzichten. Ich zog deshalb den letzteren Weg vor, zumal das Filtrat bei der Entfernung des Caseins mit Alaun nicht sehr verdünnt und in Folge der Abwesenheit des Fettes auch nicht viscös ist. Zum Sättigen verwandte ich jetzt das $\mathrm{MgSO}_{4}$ nicht als Krystallbrei, sondern in gepulverter, trockener Form und setzte es im Ueberschuss zu. Das Gemenge hatte nach dem Sättigen ein trübes milchiges Aussehen von ausgeschiedenem Globulin. Die Trübung wurde abfiltrirt, mit gesättigter $\mathrm{MgSO}_{4}$-Lösung ausgewaschen und nach $\mathrm{Kjeldahl} \mathrm{verbrannt.} \mathrm{Das} \mathrm{Albumin} \mathrm{wurde}$ nicht in dem salzgesättigten Filtrat, sondern in einer anderen Probe im Filtrat von dem mit Kalialaun erzeugten Caseinniederschlage bestimmt mit Gerbsäure, also als Albumin + Globulin. Um das reine Albumin zu erhalten, braucht man den Globulinstickstoffgehalt von dem mit Gerbsäure im Filtrat gefundenen nur abzuziehen. Folgende Zahlen wurden bei den so ausgeführten Bestimmungen erhalten:

1.

Casein-N . . . 0 0,4791\%.

Casein-N . . . 0,4791\%.

Albumin + Globulin-N . 0,1913\%.

Globulin-N . . . 0 0 0 0 $0512 \%$.

Albumin-N . . 0, 0,1401\%.

Summa: Ges.-Eiweiss-N . $\overline{0,6704 \%}$ Summa:Ges.-Eiweiss-N $\overline{0,6704 \%}$. Gesammt-Eiweissstickstoff mit Gerbsäure ermittelt . . 0,6692 ${ }^{\circ} j$.

2.

Casein-N . . . . . 0,3795\%. Casein-N . . . 0,3795\%.

Albumin + Globulin-N . 0,1398\%. Globulin-N . . . 0,0488\%.

Summa :Ges.-Eiweiss-N . $\overline{0,5193 \%}$ Summa:Ges.-Eiweiss- $\frac{0,0910 \%}{0,5193 \%}$.

Gesammt-Eiweissstickstoff mit Gerbsäure ermittelt . . 0,5172\%. 
3.

Casein-N . . . . 0 0,3921\%.

Casein-N . . . 0 0,3921\%.

Albumin + Globulin-N . 0,1285\%. Globulin-N . . . 0,0288\%.

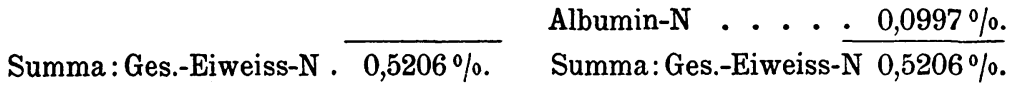
Gesammt-Eiweissstickstoff mit Gerbsäure ermittelt . . 0,5185\%.

4.

Casein-N . . . . 0 0,3680\% Casein-N . . . 0,3680\%.

Albumin + Globulin-N . 0,1108\%. Globulin-N . . . 0 0,0430\%.

Albumin-N . . 0,0678\%.

Summa: Ges.-Eiweiss-N..$\overline{0,4788 \%}$. Summa: Ges.-Eiweiss-N $0,4788 \%$. Gesammt-Eiweissstickstoff mit Gerbsäure ermittelt . . 0 0,4922\%.

Aus diesen durch direkte Bestimmung ermittelten Zahlen geht hervor, dass der Globulingehalt keine constante Grösse ist, sondern weiten Schwankungen unterworfen ist. Auch darf man daraus wohl folgern, dass das mit $\mathrm{MgSO}_{4}$ erhaltene Mehr thatsächlich dem Globulin anzurechnen und nicht etwa auf mechanisch im Casein zurückgehaltenes Albumin zurückzuführen ist. Die absolute Höhe des Globulingehaltes ist aber so gering (sie beträgt im Mittel nicht einmal 0,05\% Stickstoff), dass man bei Milchuntersuchungen, wenn es sich nicht um speciell wissenschaftliche Ziele handelt, von seiner ausdrücklichen Bestimmung ruhig absehen und ihn mit zum Albumin rechnen kann.

\section{Methode: Bestimmung des Caseins auf mechanischem Wege mittelst Thonteller (nach Lehmann).}

In den Eiweisskörpern haben wir so complicirte, wenig beständige Gebilde vor uns, dass man annehmen muss, dass sie durch jeden Eingriff mit chemischen Reagentien ihren ursprünglichen Zusammenhang aufgeben und in neue, von den ursprünglichen total verschiedene Formen sich umwandeln können. Mit dieser Möglichkeit haben die Forscher schon lange gerechnet, und $Z_{a h n^{1}}$ ) versuchte zuerst eine Trennung des Caseins und Albumins ohne chemischen Eingriff durchzuführen, indem er einen Thoncylinder in ein Gefäss, das er

1) Pflüger's Archiv, 1869, II. Theil, S. 598. 
mit Milch füllte, stellte und dann den Cylinder mit einer Luftpumpe evacuirte. Hierbei stellte sich heraus, dass wohl das Albumin durch die Poren filtrirte, das Casein aber zurückblieb. Später hat Herrmann ${ }^{1}$ ) sich die Eigenschaft des Thons, das Casein zurückzuhalten, zu Nutze gemacht, doch wandte er keinen Thoncylinder, sondern pulverisirten Thon an. Lehmann $\left.{ }^{2}\right)$ kam nun auf den Gedanken zurück, mittelst porösen Thons die Eiweisskörper auf Grund ihres verschiedenen physikalischen Verhaltens von einander zu scheiden und versuchte dieses Verfahren zu einer quantitativen Bestimmungsweise auszuarbeiten. $\mathrm{Zu}$ diesem $\mathrm{Zwecke}$ brachte er eine bestimmte Gewichtsmenge Milch in zusammenhängender, dünner Schicht auf Thonplatten, liess die flüssigen, gelösten Bestandtheile von der porösen Masse völlig aufsaugen und schabte den ungelösten Rückstand in Lamellen ab und behauptete, so das gesammte Casein frei von anderen Stoffen als den anorganischen Salzen, unverändert, wie es in frischer. Milch vorkommt, vor sich zu haben und nannte es "genuines Gasein". Wollte ich die Lehmann'schen Versuche wiederholen, so war es natürlich erste Voraussetzung, dass ich womöglich ein ganz gleiches Thonmaterial wie Lehmann benutzte. Ist nämlich die Porosität eine zu grosse, sind die Poren grösser als die einzelnen Caseinfettkügelchen, so werden sie, ebenso wie das Serum, auch noch Casein aufnehmen, welches dann durch Abschaben nicht wieder zu gewinnen ist. Ist andererseits die Porosität eine $\mathrm{zu}$ geringe, so wird das Serum nicht völlig aufgenommen werden. Die von Hempel ${ }^{3}$ ) bei Veröffentlichung der Lehmann'schen Arbeit als Lieferantin des passenden stets gleichmässigen Thonmaterials angegebene Steingutfabrik von Villeroy und Boch in Dresden, von der Lehmann seine Thonteller bezogen hatte, stellt in Folge des geringen Bedarfs diese Waare nicht fabrikmässig, weil unter diesen Umständen zu knstspielig, dar, und es war mir zunächst nicht möglich, solche Thonmasse geliefert zu bekommen. Zufällig wurde später

1) Pflüger's Archiv, XXVI, S. 442.

2) Annalen der Chemie u. Pharm., 1877, S. 189.

3) Pflüger's Archiv, Bd. 56, 1894. 
nochmals ein grösserer Posten hergestellt, und ich gelangte so in den Besitz genau derselben gleichmässig verfertigten Teller, wie sie Lehmann zur Verfügung gestanden hatten. Die Thonplatten haben einen Durchmesser von ca. $18 \mathrm{~cm}$., sind schwach concav, auf ihrer oberen Fläche mit Achat polirt, damit man das zurückbleibende Caseinfettgemisch vollständig davon abheben kann. Lehmann hat für die Benutzung dieser Teller folgende Vorschrift gegeben:

"Die Thonplatten werden, nachdem sie einige Zeit auf oder über $100^{\circ}$ erhitzt und wieder abgekühlt sind, bei schräger Haltung mit einem dünnen Strahl kalten Wassers schnell übergossen und auf ein verhältnissmässig weites Glasgefäss gesetzt, dessen Boden mit einer dünnen Schicht concentrirter Schwefelsäure bedeckt ist. Die Milch wird mit dem gleichen Volumen Wasser verdünnt, vorsichtig und in vollem Zusammenhang auf den mittleren Theil der Platte aufgetragen (2 mm. dick) und, um Verdampfung zu vermeiden, mit einem glattrandigen Glasschälchen bedeckt. Das Serum von $10 \mathrm{ccm}$. verdünnter Milch wird schon nach Verlauf von 1-2 Stunden derartig von der Platte aufgesaugt, dass man den Rückstand mit einem scharfen Hornspatel gut abnehmen kann.» Die weiteren Vorschriften Lehmann's - er untersuchte das Casein gewichtsanalytisch kamen für mich nicht in Betracht, da ich behufs Stickstoffbestimmung die Lamellen sofort in ein Kjeldahlkölbchen gab. Denn nicht die physikalischen und chemischen Eigenschaften und die Zusammensetzung des genuinen Caseins veranlassten mich, Lehmann's Versuche zu wiederholen, sondern mir kam es nur darauf an, den nach Lehmann's Methode resultirenden Stickstoffgehalt in Bezug auf seine absolute Höhe mit dem nach anderen Methoden erhältlichen Stickstoff $\mathrm{zu}$ vergleichen. Lehmann fand bei vergleichenden Versuchen gegenüber Hoppe-Seyler's Verfahren stets mehr Casein und zwar, wie er meint, um so viel mehr, als nach jener Methode durch Auswaschen des mit Essigsäure erregten Niederschlages wieder löslich wird. Das Wenigste, um das seine Zahlen die nach Hoppe-Seyler erhaltenen übertreffen, ist 0,06\% Casein, das Höchste $0,62 \%$, oder im Mittel von sechs angeführten Be- 
stimmungen 0,298\% Casein, oder auf Stickstoff umgerechnet durch Division mit dem Factor 6,37 $=0,046 \%$ Stickstoff. Das ist bei einer einzelnen Bestimmung eine ziemlich grosse Differenz. Um nun zu unterscheiden, welche Zahlen die richtigen seien, hat Lehmann einerseits den Gesammtstickstoff der Milch, andererseits den Casein-, Albumin- und Reststickstoff besonders bestimmt. Die Summe von Casein- (HoppeSeyler), Albumin- und Reststickstoff und andererseits die Summe von Casein- (Lehmann), Albumin- und Reststickstoff müssen sowohl beide untereinander, als auch mit dem direkt ermittelten Gesammtstickstoff ungefähr übereinstimmen. Die Resultate, die Lehmann fand - in einem Falle beträgt die Differenz der Summe der Hoppe-Seyler'schen Bestimmung gegen die Gesammtstickstoff bestimmung nicht weniger als 0,118\% Stickstoff - , hält er für ganz befriedigende bei beiden Methoden. Nebenbei sei erwähnt, dass die von Lehmann angeführten Zahlen für Albuminstickstoff mein Bedenken erregen wegen ihrer Niedrigkeit. In zwei Fällen wird der Albuminstickstoff sogar vom Reststickstoff an Höhe übertroffen. Offenbar ist es Lehmann nicht gelungen, nach der Hoppe-Seyler'schen Methode durch Kochen das Albumin vollständig zu coaguliren, sodass er einen Theil desselben als Reststickstoff mit angegeben hat. Für die Beurtheilung seiner Methode spielt dies übrigens keine Rolle, da hier nur die Summe des Caseinstickstoffs und des nach Ausscheidung des Caseins noch vorhandenen Stickstoffes, gleichgültig in welcher Form, mit der Summe des direkt ermittelten Stickstoffs zu vergleichen ist.

Die Zahlen, die Lehmann angibt, stammen schon aus dem Jahre 1877 und mögen bei den damals gebräuchlichen Methoden seine Befriedigung gefunden haben. Heute aber, wo die Kjeldahl'sche Stickstoff bestimmungsmethode sich so leicht und scharf ausführen lässt, muss man aus jenen Zahlen direkt auf die Unzulänglichkeit einer der beiden Methoden schliessen. Die von mir angestellten Versuche mit den Thontellern verliefen genau in derselben Weise, wie Lehmann beschrieben hatte. In 1/2-2 Stunden war das Serum soweit aufgesaugt, dass keine Spur eines Flüssigkeitsspiegels 
im Centrum der aufgetragenen Milchmasse mehr sichtbar war; das Abheben des Rückstandes ging mit einem Spatel bequem vor sich, ob quantitativ, war natürlich nicht $\mathrm{zu}$ sehen, beobachtet wurde indess ein sichtbarer Rückstand nicht.

Ueber den Werth und die Brauchbarkeit des Lehmannschen Verfahrens für Caseinbestimmungen bin ich jedoch zu einer anderen Ansicht gelangt. Zunächst hatte ich vermuthet, dass die Resultate niedriger ausfallen würden, verglichen mit den nach Schlossmann und Hoppe-Seyler erhaltenen Zahlen, da ich annehmen zu müssen glaubte, dass stets Bruchtheile von Casein, auch bei einer möglichst geringen Porosität, in den Poren des Thontellers zurückgehalten werden würden, das Abheben der Lamellen also nicht quantitativ durchzuführen sei. Um so mehr war ich erstaunt, als ich beträchtlich höhere Zahlen erhielt, und meine Aufmerksamkeit lenkte sich auf eine Wahrnehmung, die Schlossmann bei Besprechung der Lehmann'schen Methode ${ }^{1}$ ) erwähnt, "es gehe aus der Lehmannschen Arbeit nicht hervor, ob sich das Globulin zum Casein oder zum Albumin halte, er glaubt aber (eigene Versuche hat er nicht angestellt), dass es sich eher dem Albumin ähnlich verhalte und durch den Thon mit durchfiltrire». Später «hält er die von Lehmann gegebenen Mittelwerthe, wohl was ihr relatives Verhältniss zu einander betrifft, für völlig correcte, nicht aber ihre absolute Höhe. Ein Durchschnittsgehalt von 1,7\% Proteinsubstanz in Frauenmilch dürfte, wenn man den Stickstoff, den man durch direkte Bestimmung aus der Milch erhält, berücksichtigt, als zu hoch gegriffen erscheinen ». Trotzdem kommt er aber zu dem Schluss, «dass ein Zweifel darüber nicht bestehen kann, dass die Verwendung von Thonseparatoren, besonders in der von Lehmann empfohlenen Form, eine exacte Fractionirung der Eiweissstoffe der Milch - wenigstens des Caseins einerseits, des Albumins und Globulins andererseits - gestattet .

Die in dem zweiten Satze enthaltene Ansicht Schlossmann's über die absolute Höhe der von Lehmann ange-

1) Hoppe-Seyler, Zeitschr. f. physiol. Chemie, Bd.XXII, S. 211 u. ff. 
gebenen Zahl für Frauenmilch, die von mir selbst gefundenen Werthe für Kuhmilch, ausserdem die Angabe Lehmann's, er erhalte um so viel mehr Casein, als beim Auswaschen des Essigsäureniederschlages (nach Hoppe-Seyler) löslich werde, brachte mich dazu, an der Thatsache, dass das Globulin zum Albumin gehe, zu zweifeln und vielmehr anzunehmen, dass es neben dem Casein auf der Thonplatte zurückbleibe. Zur Zeit, als Lehmann seine Versuche anstellte, hatte Sebelien das Globulin noch nicht isolirt und Lehmann konnte die Anwesenheit dieses Körpers neben Casein und Albumin nicht vermuthen. Es hatte deshalb seine Berechtigung, wenn er sagte, er erhalte auf dem Thonteller den Theil des Caseins auch noch, der bei dem Essigsäureverfahren löslich werde. Wir wissen nun aber, dass es das Globulin ist, das bei der Trennung der Eiweisskörper mit Essigsäure oder auch mit Alaun in Lösung geht oder bleibt und durch Gerbsäure mit dem Albumin zusammen gefällt wird. Deshalb lag meine Vermuthung, dass die höheren Zahlen durch den Globulingehalt verursacht würden, nicht fern und veranlasste mich, neben den Lehmann'schen Thontelleranalysen noch Kontrollbestimmungen zur Feststellung des Casein- und Globulinstickstoffs mittelst $\mathrm{MgSO}_{4}$-Brei anzustellen. Ich erwartete nun, Uebereinstimmung beider Methoden zu finden. Das Ergebniss war jedoch folgendes:

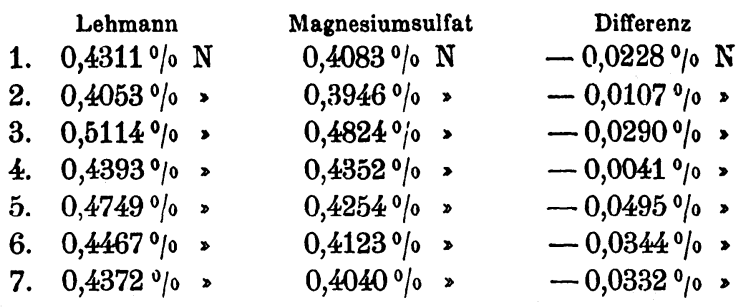

In allen Fällen ist der Stickstoffgehalt nach Lehmann höher, als der mit Magnesiumsulfat gefundene, und zwar ist die Differenz bald grösser, bald weniger gross. Diese Thatsache überraschte mich nicht wenig. Hätte die $\mathrm{MgSO}_{4}$-Methode durchweg um ein Geringes höhere Zahlen geliefert, als die Lehmann'sche, so hätte ich das daraus er- 
klären zu müssen geglaubt, dass beim Auswaschen des $\mathrm{MgSO}_{4}$ Niederschlages mit der stark concentrirten Salzlösung noch Reste des löslichen Albumin- oder Extractivstickstoffes zurückgehalten worden wären. So aber war das Verhältniss gerade umgekehrt. Die richtige Erklärung für diese Erscheinung glaube ich geben zu können. Auf dem Thonteller befinden sich zunächst Casein und Globulin, die Gründe für diese Behauptung habe ich oben aufgezählt. Dass der nun noch verbleibende Rest in einem dritten Körper seinen Ursprung haben könnte, der ebenso wie das Casein und vermuthlich auch das Globulin nicht in gelöstem, sondern gequollenem Zustande in der Milch vorhanden wäre, und der nach Entziehung seines Quellungswassers durch die poröse Thonmasse auf der Platte zurückgeblieben wäre, dies anzunehmen, liegt, solange die Existenz eines solchen Körpers nicht auf anderem Wege bewiesen ist, kein Grund vor. Vielmehr wird wohl folgende Erwägung zu dem richtigen Schlusse führen: Nach Lehmann's Vorschrift bringt man die mit dem gleichen Volumen Wasser verdünnte Milch in vollem Zusammenhang in einer $2 \mathrm{~mm}$. dicken Schicht auf die Thonplatte; es soll dann das Serum, in dem also Albumin- und Extractivstoffe gelöst sich vorfinden, von dem porösen Thon aufgesaugt werden. Es ist nun doch wohl selbstverständlich, dass in einer so viscösen Flüssigkeit, wie die Milch sie, auch nach Verdünnung mit der gleichen Menge Wasser, darstellt, hierbei das Albumin oder auch Extractivstoffe theilweise mechanisch von dem Caseinfettgemisch festgehalten werden, also eine quantitative Trennung nicht stattfindet. Die Verhältnisse liegen hier genau so wie beim Filtriren. Aus einem Niederschlage, den man mit der Lösung, in der er sich befindet, auf ein Filter bringt, tropfen die gelösten Bestandtheile freiwillig auch nicht vollständig $a b$, sondern müssen erst durch mehr oder weniger sorgfältiges Waschen daraus entfernt werden. Wenn nun die Milchschicht auf der Thonplatte auch nur $2 \mathrm{~mm}$. dick ist, so können und müssen doch in dieser relativ immerhin noch ziemlich starken Schicht mechanisch noch so viele Theile löslichen Albumin- und Extractivstoffes 
festgehalten werden, dass dadurch die hohen Zahlen der Lehmann'schen Methode bedingt werden. Will man die Möglichkeit, dass mechanisch lösliches Eiweiss zurückgehalten wird, verringern, indem man z. B. die Milchschicht noch dünner aufträgt, wie ich es in einem Versuche probirte, so stellt sich wiederum die Schwierigkeit heraus, dass man die Caseinlamellen, nachdem das Serum aufgesaugt ist, schlecht abheben kann und ein quantitatives Arbeiten unmöglich ist.

Betrachten wir nun, von der Voraussetzung ausgehend, dass Lehmann bei seinen Versuchen ebenso wie ich auf der Thonplatte Casein, Globulin und Reste löslicher Stickstoffsubstanz gehabt habe, seine Zahlen (Annalen etc.), so können wir auch aus diesen schon eine Bestätigung meiner Behauptung entnehmen.

Er hat seine Resultate den nach Hoppe-Seyler erhaltenen gegenüber gestellt und stets mehr Stickstoff erhalten. Seine Begründung für diese Thatsache habe ich oben angeführt. Da ich oben bewiesen habe, dass die Abscheidung des Caseins mit Kalialaun ebenso quantitativ verläuft, wie die mit Essigsäure und Kohlensäure, so kann ich da, wo mir die Bestimmungen mit Essigsäure fehlen, die Resultate mit Kalialaun den nach Lehmann erhaltenen gegenüber stellen.

Lehmann führt in seiner Arbeit für die Höhe des Caseinstickstoffs folgende Belegbeispiele an:

Thontellerbestimmung $\quad 0,488 \% \mathrm{~N} \quad 0,460 \% \mathrm{~N} \quad 0,477 \% \mathrm{~N} \quad 0,397 \% \mathrm{~N}$ Hoppe-Seyler ... $0,447 \%, 0,396 \%, 0,379 \%, 0,352 \%$, Differenz ....-0,041\%N-0,064\%N-0,098\% $\mathrm{N}-0,045 \% \mathrm{~N}$

Meine Versuche ergaben folgendes Ergebniss:

\begin{tabular}{|c|c|c|c|}
\hline Lehmann & & Hoppe-Seyler resp. Sehlossmann & Differenz \\
\hline $0,4311 \%$ & & $0,3445 \% \mathrm{~N}$ & $-0,0866 \%$ \\
\hline $0,4075 \%$ & 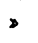 & $0,3635 \%$, & $-0,0440 \%$ \\
\hline $0,4053 \%$ & $>$ & $0,3625 \%$ & $-0,0428 \%$ \\
\hline $0,5114 \%$ & ๖ & $0,4580 \%$ & $-0,0534 \%$ \\
\hline $0,4393 \%$ & , & $0,3930 \%$ & $-0,0463 \%$ \\
\hline $0,4467 \%$ & > & $0,3769 \%$ & $-0,0698 \%$ \\
\hline $0,4372 \%$ & > & $0,3836 \%$ > & $-0,0536 \%$ \\
\hline
\end{tabular}

Die Differenzen der Lehmann'schen Beispiele, im Mittel $0,062 \% \mathrm{~N}$, bewegen sich, wie ein Vergleich zeigt, in derselben 
Höhe, wie bei meinen Zahlen, im Mittel 0,056\% $\mathrm{N}$, sind also, wie ein Blick auf die vergleichende Zusammenstellung der Lehmann'schen und $\mathrm{MgSO}_{4}$-Methode lehrt (Seite 505), falls er diese beiden verglichen hätte, auch höher, als die mit letzterer Methode erhaltenen Zahlen. Der Globulingehalt hatte nach meinen direkten Bestimmungen im Mittel eine Höhe von 0,0457\% $\mathrm{N}$, erklärt also allein das Mehr der Thontelleranalyse nicht, und die Annahme, es werde auch noch mechanisch lösliche Stickstoffsubstanz auf dem Thon zurückgehalten, ist in Folge dessen nicht von der Hand zu weisen. $\mathrm{Zu}$ dieser Folgerung berechtigen nicht nur meine eigenen Zahlen, sondern schon Lehmann's Beispiele lassen denselben Schluss zu. Der Versuch Lehmann's, an dem Thontellerrückstand die Eigenschaften und Zusammensetzung des unveränderten und reinen Caseins zu studiren, muss demnach zu falschen Folgerungen geführt haben, da er niemals reines Casein, sondern stets ein Gemenge von Casein, Globulin und löslichen, stickstoffhaltigen Substanzen analysirt hat. Ausserdem wird sein Präparat auch noch durch stickstofffreie Bestandtheile, z. B. Milchzucker verunreinigt gewesen sein.

Hiermit ist die Reihe der in der Litteratur beschriebenen Caseinbestimmungen noch nicht erschöpft; es sind z. B. noch das Chlorbaryum und Chlorcalcium als Fällungsmittel für Casein angegeben, ${ }^{1}$ ) aber diese beiden Salze fälllen auch das Albumin. Sebelien ${ }^{2}$ ) hat sich, und vor ihm bereits Hammarsten, ${ }^{3}$ ) des Kochsalzes bedient, um das Casein aus der Milch auszuscheiden und im Filtrat das Globulin mit $\mathrm{MgSO}_{4}$ zu fällen. Das Kochsalz scheidet angeblich zwar das Casein vollständig $a b$, fällt aber auch etwas Globulin, so dass die Trennung keine vollkommene ist. Aus diesem Grunde habe ich nur einige Bestimmungen mit Kochsalz in Substanz ausgeführt. So fand ich zum Beispiel:

1) Hoppe-Seyler, Zeitschr. f. physiol. Chem., Bd. IX, S. 162.

2) Hoppe-Seyler, Zeitschr. f. physiol. Chem., Bd. IX, S. 466.

3) Hoppe-Seyler, Zeitschr. f. physiol. Chem., Bd. VII, S. 250. 
1.

\begin{tabular}{|c|c|c|c|c|}
\hline & Kochsalz & Kalialaun & Magnesiumsulfat & Gerbsäure \\
\hline as & $0,4429 \% \mathrm{~N}$ & $0,4097 \% \mathrm{~N}$ & $0,4385 \% \mathrm{~N}$ & - \\
\hline Albumin- $\mathrm{N}$ & $0,0908 \%$ & $0,1195 \%$ > & $0,0886 \%$ & - \\
\hline imma: & $0,5337 \% \mathrm{~N}$ & $0,5292 \% \mathrm{~N}$ & $0,5271 \% \mathrm{~N}$ & $0,5337 \%$ \\
\hline
\end{tabular}

2.

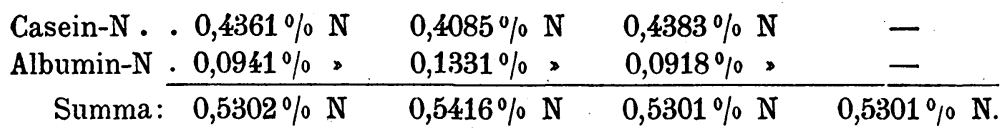

3.

Casein-N . . 0,4443\% N $0,4082 \% \mathrm{~N} \quad 0,4420 \% \mathrm{~N} \quad-$ Albumin- $\mathrm{N} .0,0902 \%$, $0,1331 \%$ > $0,0992 \%$

Summa: $0,5345 \% \mathrm{~N} \quad 0,5413 \% \mathrm{~N} \quad 0,5412 \% \mathrm{~N} \quad 0,5412 \% \mathrm{~N}$.

In diesen angeführten Beispielen liefert Kochsalz bedeutend höhere Zahlen als Kalialaun; aus der vorzüglichen Uebereinstimmung mit der $\mathrm{MgSO}_{4}$-Methode könnte man aber den Schluss ziehen, dass das Kochsalz, ebenso wie das $\mathrm{Mg} \mathrm{SO}_{4}$ das Globulin quantitativ und nicht nur theilweise fälle. $\mathrm{Zu}$ dieser Behauptung sind jedoch die analytischen Daten nicht zahlreich genug.

Von den hier besprochenen Trennungsmethoden für Casein und Albumin haben sich nach Alledem die Hoppe-Seyler'sche (Essigsäure und $\mathrm{CO}_{2}$-Strom) und Schlossmann'sche Bestimmungsweise (Kalialaun) als die brauchbarsten erwiesen. Wenn sie auch in ihren Ergebnissen gleiche Genauigkeit zeigen, so wird man doch der letzteren den Vorzug geben, da man einmal eine zeitraubende Operation (Einleiten von Kohlensäure) weniger vorzunehmen braucht, ferner mit geringeren Flüssigkeitsmengen arbeitet und endlich auch nicht Gefahr läuft, durch im Ueberschuss angewandtes Fällungsmittel Theile des gebildeten Caseinniederschlages in Lösung $\mathbf{z u}$ bringen. Das $\mathrm{MgSO}_{4}$ fällt, in der Gestalt eines halbflüssigen Krystallbreies angewandt, ausser dem Casein noch das in der Milch stets vorkommende Globulin. Da diese Methode in Folge des dabei verwendeten hohen Salzgehaltes und des schwer vor sich gehenden Filtrirens des Niederschlages eine sehr langwierige ist, wird man sich ihrer nur nothgedrungen, wenn es sich darum handelt, das Albumin ohne Globulin zu isoliren, 
bedienen. Die Lehmann'sche Darstellungsweise und Isolirung des Caseins mittelst poröser Thonplatten ist zu verwerfen, da kein reines Casein, sondern ein Gemisch von Casein, Albumin und löslichem Eiweiss auf dem Thon zurückgehalten wird. Auch erfordert die Ausführung derselben so viele technische Fertigkeiten und ausserdem Zeit, dass sie selbst bei Lieferung guter Resultate für Serienuntersuchungen sich nicht eignen würde.

So habe ich denn zu meinen im dritten Theile der Arbeit beschriebenen Versuchen für die Bestimmung der Gesammteiweisskörper mich der Almén'schen Gerbsäuremischung, für die Trennung des Caseins und Albumins der Schlossmann'schen Kalialaunlösung bedient, die sich denn auch bei der grossen Zahl der ausgeführten Bestimmungen durchaus bewährt haben.

\section{Theil.}

Untersuchung der Eiweisskörper der Milch zweier Kühe im Laufe einer Lactation.

Die Kuhmilch ist als physiologisches Produkt eines lebenden Organismus von dem augenblicklichen Zustande und Befinden dieses Organismus und von sämmtlichen Einflüssen, die auf ihn einwirken, sowohl was Qualität, als auch was Quantität anbetrifft, in hohem Maasse abhängig. Der Bestandtheil der Kuhmilch, über den die meisten Untersuchungen angestellt sind, und dessen Vorkommen und Menge am häufigsten studirt sind, ist das Fett und zwar aus dem wohlbegreiflichen Grunde, weil es in der Ernährung des Menschen eine ausserordentlich wichtige Rolle spielt. Ueber die Eiweisskörper liegen so zahlreiche Untersuchungen, speciell welchen Schwankungen sie unterworfen sind, ob das Verhältniss von Casein zu Albumin u. s. w. während der Dauer der Lactation annähernd dasselbe bleibt u. s. w., nicht vor. Der Grund dafür wird wohl zum Theil auch darin zu suchen sein, dass es für die Bestimmung, namentlich Trennung derselben, keine Methoden gibt, die sich in so kurzer Zeit ausführen lassen, wie die mannigfachen Schnellmethoden der Fettuntersuchungen. Nachdem ich nun in dem ersten Theil dieser Arbeit die Brauchbarkeit und die Vorzüge einiger Eiweissreagentien kennen gelernt hatte, stellte 
ich mir die Aufgabe, die Höhe der Gesammteiweisskörper und der einzelnen Eiweissstoffe im Laufe einer ganzen Lactation $z u$ verfolgen, die Abnahme oder Zunahme, die Regelmässigkeit bezw. Unregelmässigkeit des Abund Zunehmens kennen zu lernen. Hauptsache war es aber nicht, die etwaigen Schwankungen der einzelnen Eiweisskörper, wie sie durch Störungen des Normalbefindens der Thiere hervorgerufen werden können, Krankheit, Brunst, Wechsel der Fütterung etc. festzustellen, sondern bei möglichst normalem Zustande.

Um ein völlig zutreffendes Bild von diesen Verhältnissen zu gewinnen, müsste man, streng genommen, die Milch vom ersten Augenblicke ihrer Absonderung nach der Geburt des Kalbes bis dahin, wo die Drüsen ihre Thätigkeit wieder einstellen, Gemelk für Gemelk einzeln untersuchen. Diesen Idealzustand durchzuführen, dazu wird es wohl in allen Fällen an Zeit und Arbeitskräften zur Bewältigung des Materials fehlen, und man - wird sich damit begnügen müssen, in gewissen, nicht zu weit bemessenen Zwischenräumen die Milch zu untersuchen, in der Voraussetzung, dass die Milch in der Zwischenzeit keine erheblich andere Zusammensetzung gehabt habe. Ich bin folgendermaassen dabei zu Werk gegangen:

Die Kühe, denen die untersuchte Milch entstammte, befanden sich im Hausthiergarten des landwirthschaftlichen Instituts hiesiger Universität und wurden mir von dem Direktor desselben, Geheimrath Prof. Dr. Kühn, bereitwilligst zur Disposition gestellt. Sie wurden zweimal täglich, Morgens und Abends $5 \mathrm{Uhr}$, gemolken; jede Woche wurde an einem Tage die Tagesmilch untersucht. Da nun die Milch je nach der Vollständigkeit des Ausmelkens eine verschiedene Zusammensetzung zeigt, so habe ich, um sicher zu gehen, dass das Ausmelken ein vollständiges sei, dasselbe stets unter eigener Aufsicht von einem erfahrenen und geübten Manne besorgen lassen und die Entnahme aus dem Melkgefäss nach mehrmaligem, gründlichen Durchmischen selbst ausgeführt. Weil naturgemäss die Milch verschiedener Thiere grosse $\mathrm{Ab}$ weichungen zeigen kann, je nach Alter, Rasse, Zucht etc., so konnte ich mich mit der Untersuchung der Milch einer 
einzigen Kụh nicht begnügen. Meine ursprüngliche Absicht, mehrere Kühe für diese Versuche heranzuziehen, war leider nicht durchführbar, weil dann die Zahl der auszuführenden Analysen zu sehr angewachsen wäre, und ich musste mich deshalb damit zufrieden geben, nur von 2 Kühen regelmässig Probe zu nehmen. An dem zur Probenahme bestimmten Tage wurde das Gewicht der einzelnen Gemelke festgestellt und aliquote Theile des Morgen- und Abendgemelkes beider Thiere zu je einer Probe vereinigt, so dass man also den Durchschnitt der Tagesmilch hatte, und diese wurde dann der Analyse unterworfen. Die Untersuchung erstreckte sich auf Feststellung der Gewichtsmenge, des specifischen Gewichtes, Fettgehaltes (nach Gerber), der Trockensubstanz, des Gesammtstickstoffs, Eiweissstickstoffs, Casein-, Albumin-, Extractivstickstoffes und in einigen Fällen des Aschengehaltes. Bei der Bestimmung der stickstoffhaltigen Stoffe wurde, da auch hier, wie im ersten Theile, nicht die Gewichtsanalyse, sondern die Kjeldahl'sche Stickstoffmethode angewandt wurde, nur der Stickstoffgehalt ermittelt; den wirklichen Gehalt an Eiweisssubstanz erhält man durch Multiplication des Stickstoffgehaltes mit dem Factor 6,37, entsprechend 15,7\% Stickstoff im Casein. Zur Berechnung des Albumins aus dem Stickstoff müsste man eigentlich einen anderen Factor anwenden, da der Stickstoffgehalt des Albumins von dem des Caseins etwas abweicht; die Unterschiede sind aber so gering, dass man ruhig für beide den einheitlichen Factor 6,37 als richtig ansehen kann. Naturgemäss hatten meine Untersuchungen mit dem Colostrum, d. h. dem ersten Abscheidungsprodukte der Drüsenzellen nach der Geburt des Kalbes einzusetzen. Da das Colostrum von gewöhnlicher Milch ausserordentlich verschieden ist, und die Ansichten verschiedener Forscher von einander wesentlich abweichen, so will ich zunächst einige Angaben über die in der Litteratur befindlichen Beschreibungen des Colostrums, so weit sie sich auf die Eiweissstoffe beziehen, hier anführen. Grotenfeld ${ }^{1}$ )

1) Handledung i. mejerihnshallning, Stockholm 1881, Seite 32, citirt nach Hoppe-Seyler, Zeitschr. für physiol. Chemie, Bd. XIII, S. 172. 
behauptet, Casein komme im Colostrum überhaupt nicht vor, sondern die ganze Eiweisssubstanz bestehe nur aus Albumin. Andere Forscher haben Casein und Albumin gefunden und zwar in sehr verschiedenen Mengen. König führt als Mittel verschiedener von einander. stark abweichender Analysen $\left.{ }^{1}\right)$ 4,65\% Casein, 13,62\% Albumin an, Fleischmann ${ }^{2}$ ) 7,3\% Casein, 7,5\% Albumin, Engling ${ }^{3}$ ) 2,64-7,14\% Casein, 11,18 bis 20,21\% Albumin, Hansen und Schrodt $\left.{ }^{4}\right) 7,57 \%$ Casein, $5,45 \%$ Albumin. Sebelien ${ }^{5}$ ) constatirte ausserdem noch, dass das Globulin einen wesentlichen Bestandtheil des Colostrums ausmache und gibt folgende Zahlen an, die Analysen von Colostrum erster und zweiter Melkung entstammen. (Da ich oben den Casein- und Albumingehalt angeführt habe, so habe ich der Gleichmässigkeit halber Sebelien's Zahlen - er gibt den Stickstoffgehalt an - mit dem Factor 6,37 multiplicirt):

$3,40-4,57 \%$ Casein, 0,637-10,27\% Globulin, $1,59-2,00 \%$ Albumin.

Sebelien fand ausserdem, abgesehen von zwei Fällen, bei denen wahrscheinlich Fehler sich gehäuft haben, an nicht eiweissartigen, stickstofthaltigen Stoffen 0,086\% Stickstoff. Thiemann ${ }^{6}$ ) fand in einigen Fällen überhaupt kein Albumin, oder nur einen geringen Antheil, und behauptet, die Höhe an Eiweiss im Colostrum werde durch das Zunehmen des sonst nur in kleinen Mengen vorkommenden Globulins verursacht. Seine Analysen von Colostrum ersten Gemelkes zeigen folgende Schwankungen im Gehalt der einzelnen Eiweissstoffe. (Seine Zahlen wurden auch mit 6,37 multiplicirt):

2,78-5,35\% Casein, 2,35-17,51\% Globulin, $0,0-0,25 \%$ Albumin.

1) König, Nahrungs- und Genussmittel, 2. Auflage, Bd. II, S. 257.

2) Fleischmann, Lehrbuch der Milchwirthschaft 1898, S. 47.

3) Petersen, Forschungen auf dem Gebiete der Viehhaltung u. s. w., Bd. I, S. 92. 1878.

4) Landwirthschaftliche Versuchsstationen, Bd. XXXI, S. 74. 1885.

5) Hoppe-Seyler, Zeitschr. für physiol. Chemie, Bd. XIII, S. 173.

6) Hoppe-Seyler, Zeitschr. für physiol. Chemie, Bd. XXV, S. 363. 
Die Angaben über die einzelnen Eiweissstoffe gehen, wie wir sehen, weit aus einander, nur darin scheinen alle einig zu sein, dass die Summe des Eiweisses eine ausserordentliche Höhe erreicht. Die Differenzen sind theils auf die zur Analysirung angewandten Methoden, theils darauf, dass Colostrum verschiedener Melkungen mit einander verglichen wurden, zurückzuführen. Endlich muss ja ein solches Abscheidungsprodukt, wie das Colostrum es vorstellt, bei verschiedenen Thieren verschiedene Zusammensetzung zeigen.

Da das Colostrum, namentlich des ersten Gemelkes, eine äusserst schleimige und zähflüssige Masse ist, so konnte es so nicht der Analyse unterworfen werden, ich verdünnte es deshalb mit zwei Gewichtstheilen Wasser und verwandte diese verdünnte Flüssigkeit zur Untersuchung. Das nach Entfernung des Caseins mit Gerbsäure fällbare Eiweiss wurde darauf hin, ob es Albumin oder Globulin sei, oder ein Gemisch von beiden, wie in normaler Milch, nicht untersucht, und ich führe es deshalb analog wie in der Milch als Albumin auf. Bevor ich zur Besprechung der Analysenergebnisse komme, schicke ich noch einige Angaben über die die Milch liefernden Thiere, Rasse, Fütterung u. s. w. voraus.

Kuh 643 war von reiner friesischer Abstammung, ungefähr 9 Jahre alt und hatte zum sechsten Male gekalbt. Sie war als Kuh für Kindermilch aufgestellt und erhielt während der ganzen Dauer dieser Untersuchungen dasselbe Futter und zwar berechnet für $1000 \mathscr{\&}$ Lebendgewicht: ${ }^{1}$ )

16 46. Luzerneheu,

8 . Gerstenstroh,

8 . Hafer,

1 . Leinsamen,

2 , Weizengrieskleie.

In dieser Ration sind enthalten:

30,08 के. Trockensubstanz,

2,093 , wirklich verdauliches Protein,

0,795 , Nichtprotein,

0,877 , verdauliches Fett,

9,642 * verdauliche stickstofffreie Extractstoffe,

3,586 verdauliche Holzfaser.

1) Die Zahlen dieser Futterrationen verdanke ich der Güte des Herrn Geheimrath Prof. Dr. Jul. Kühn. 
Es kommen also auf 2,093 $\ddot{8}$ stickstoffhaltige Bestandtheile 13,306 $\mathscr{\not}$ stickstofffreie, die mit der 2,4 fachen Fettmenge einem Nährstoffverhältniss von 1:7,36 entsprechen. Von dieser Ration wurde während der ganzen Zeit nicht abgegangen.

Die andere Kuh 636 war ein Kreuzungsthier zwischen Zebu-Dittmarscher-Simmenthaler Kühen, ungefähr 4 Jahre alt und hatte zum zweiten Male gekalbt. Die Fütterung war keine gleichmässige, sondern wurde zweimal gewechselt. Von October 1900 bis 25. Februar 1901 bestand ihre Ration aus (pro $1000 \ddot{t}$ Lebendgewicht):

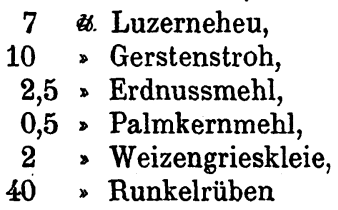

40 - Runkelrüben

und enthielt:

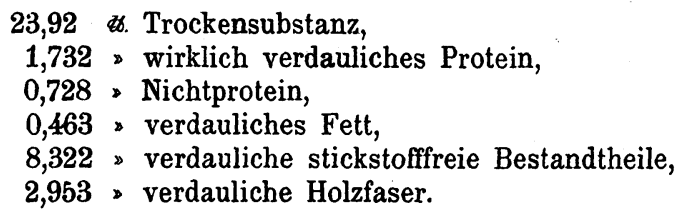

Dies entspricht, unter'Berücksichtigung der durch die Beifütterung von Hackfrüchten sich ergebenden Depression, einem Nährstoffverhältniss von $1: 7,23$. An Stelle der $40 \not{b}$ Runkelrüben traten dann vom 25. Februar bis 5. März 190120 ஜ Kartoffeln, die übrigen Theile blieben dieselben. Die Nährstoffzusammensetzung war folgende:

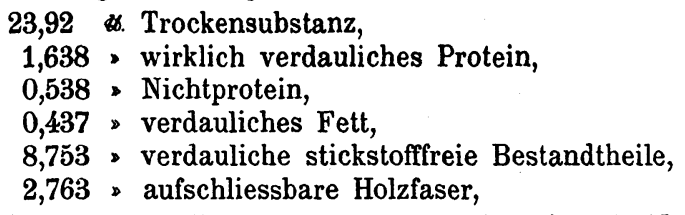

mit einem Nährstoffverhältniss von $1: 7,66$. Am 5. März wurde die Ration wieder etwas geändert und in folgender Zusammensetzung gegeben bis zum 1. Mai 1901:

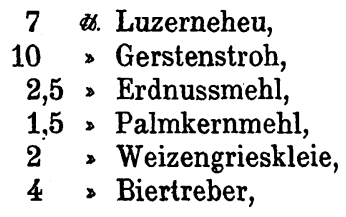


darin waren:

$$
\begin{aligned}
23,440 & \text { tr. Trockensubstanz, } \\
2,589 & \text { wirklich verdauliches Protein, } \\
0,451 & \text { Nichtprotein, } \\
0,668 & \text { verdauliches Fett, } \\
6,668 & \text { verdauliche stickstofffreie Bestandtheile, } \\
3,309 & \text { aufschliessbare Holzfaser }
\end{aligned}
$$

enthalten, mit einem Nährstoffverhältniss von $1: 4,39$. Vom Mai ab wurde dann wieder die Kartoffeln enthaltende Ration gereicht.

Die Kuh 643 kalbte am 30. September 1900; leider konnte ich meine Untersuchungen erst am 6. October beginnen, so dass also das Colostrum dieser Kuh nicht untersucht wurde. Um aber auch über die Zusammensetzung des Colostrums orientirt $\mathrm{zu}$ sein, habe ich von anderen Kühen Colostrum entnommen und untersucht. Selbstverständlich kann man, wenn das Colostrum einer Kuh bekannt ist, daraus keinen Schluss auf die genaue Zusammensetzung eines anderen machen, sondern nur behaupten, dass dasselbe ähnlich sich verhalten werde.

Von Kuh 673 (Ostfriese) wurden sechs aufeinanderfolgende Gemelke des Colostrums untersucht. Unmittelbar nach der Geburt des Kalbes wurde ein kleiner Theil des Colostrums abgemolken, aber, weil blutig, nicht verwandt. Das erste zur

\begin{tabular}{|c|c|c|c|c|c|c|c|}
\hline Datum & der Probenahme & $\begin{array}{c}\text { Speci- } \\
\text { fisches } \\
\text { Gewicht } \\
\% \\
\end{array}$ & $\begin{array}{l}\text { Fett } \\
\%\end{array}$ & $\begin{array}{c}\text { Trocken- } \\
\text { substanz } \\
\%\end{array}$ & $\begin{array}{c}\text { Ge- } \\
\text { sammt } \\
\text { stick- } \\
\text { stoff } \\
\%\end{array}$ & \begin{tabular}{|c|} 
Eiweiss- \\
stick- \\
stoff \\
$\%$ \\
\end{tabular} & $\begin{array}{c}\text { Eiweiss } \\
\%\end{array}$ \\
\hline 1. Gemelk & 26. XI. 00 Abends & 1,0715 & 4,15 & 26,95 & 2,8960 & 2,8397 & 18,0890 \\
\hline 2. & 27. XI. 00 Morgens & 1,0669 & 6,00 & 27,40 & 2,7288 & 2,6 & 30 \\
\hline 3. & 27. XI. 00 Mittags & 1,$0 ; 10$ & - & 27,62 & 2,8110 & 2,6670 & 16,9887 \\
\hline 4. & 27. XI. 00 Abends & 1,0625 & - & 26,11 & 2,5937 & 2,5494 & 16,2397 \\
\hline 5. & 28. XI. 00 Morgens & 1,0486 & - & 21,10 & 1,8347 & 1,7794 & 11,3348 \\
\hline 6. & 28. XI. 00 Mittags & 1,0475 & 6,80 & 21,50 & 1,7077 & 1,5571 & 9,9187 \\
\hline \multicolumn{2}{|c|}{ Späteres Gemelk vom 5. XII. 00} & 1,0332 & 3,85 & 13,38 & 0,6148 & 0,5781 & 3,6825 \\
\hline
\end{tabular}
Untersuchung gelangende Gemelk wurde eine Stunde nach dem Kalben gewonnen.

Die Zusammensetzung dieses Colostrums wird durch folgende Zahlen veranschaulicht:

\section{Colostrum Kuh 673.}




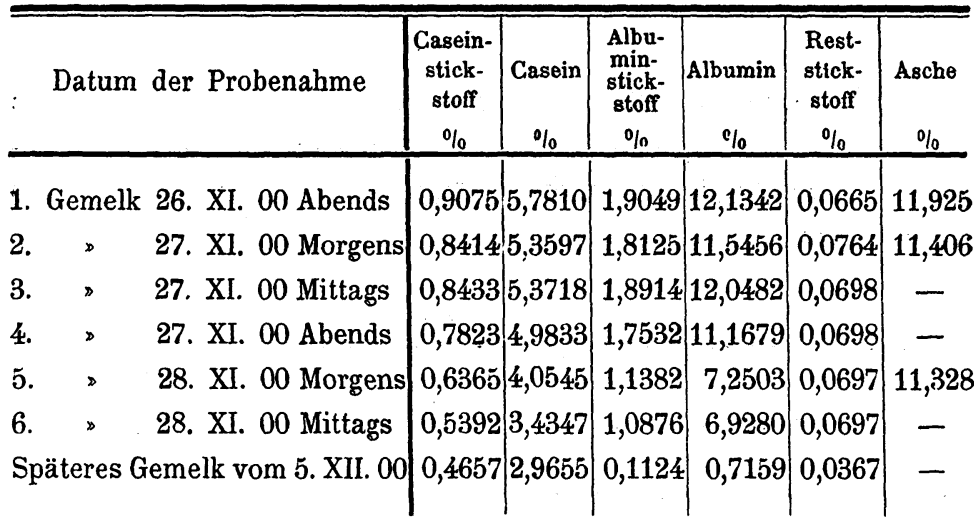

\section{Kuh 674.}

Die Kuh 674 kalbte am 23. Februar 1901 Abends. Zur Untersuchung kamen die ersten beiden Gemelke, dann an den folgenden Tagen nur immer das Frühgemelk, also thatsächlich das 1., 2., 5. und 8. überhaupt gewonnene Gemelk.

Colostrum.

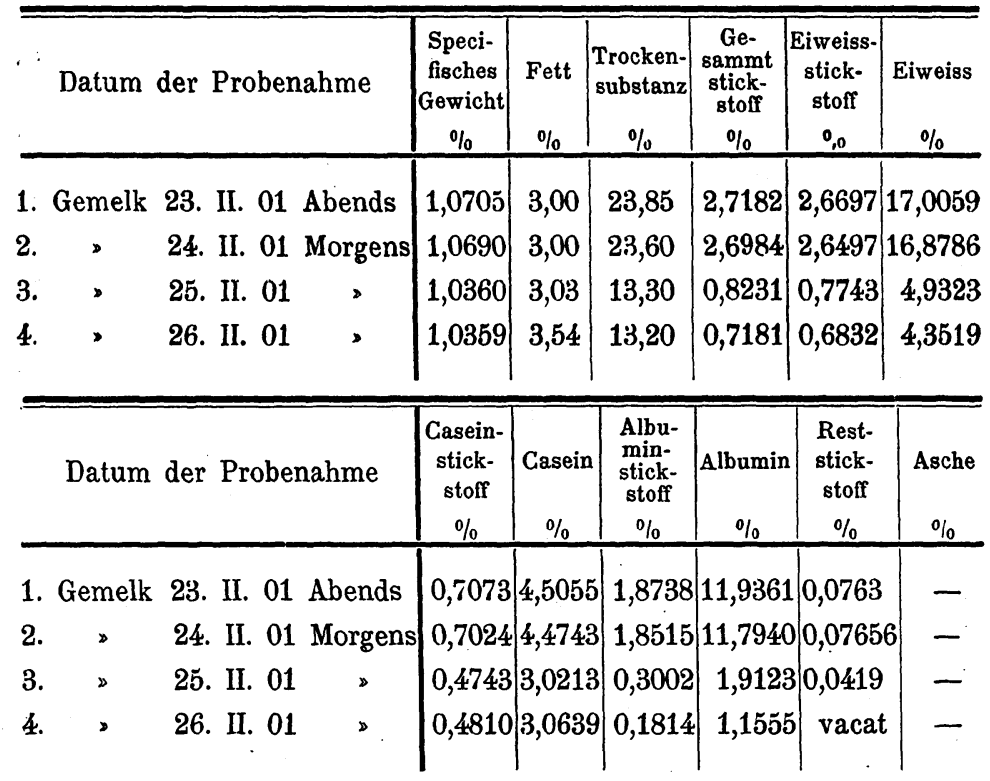




\section{Kuh 636.}

Die Kuh 636 kalbte am 25. Januar 1901; vom Colostrum wurden die ersten neun Gemelke, und zwar Abend- und Frühgemelk untersucht. Mittags wurde nur ein wenig für das Kalb abgemolken und nicht untersucht.

\section{Colostrum.}

\begin{tabular}{|c|c|c|c|c|c|c|c|}
\hline Dat & der Prober & 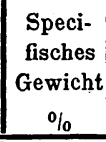 & $\left|\begin{array}{c|}\text { Fett } \\
\%\end{array}\right|$ & $\begin{array}{c}\text { Trocken- } \\
\text { substanz } \\
\%\end{array}$ & \begin{tabular}{|c|} 
Ge- \\
sammt \\
stick- \\
stoff \\
$\%$
\end{tabular} & \begin{tabular}{|c} 
Eiweiss- \\
stick- \\
stoff \\
$\%$ \\
\end{tabular} & $\begin{array}{c}\text { Eiweiss } \\
\%\end{array}$ \\
\hline Gemelk & 25. I. 01 Mittags & 1,0785 & 0,15 & 27,35 & 3,2088 & 3,1200 & 19,8744 \\
\hline$\bowtie$ & 25. I. 01 Abends & 1,0375 & 3,23 & 13,98 & 0,8756 & 0,7935 & 5,0546 \\
\hline 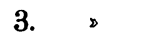 & 26. I. 01 Morgens & 1,0359 & 5,18 & 15,30 & 0,7620 &, 7071 & 4,5042 \\
\hline , & 26. I. 01 Abends & 1,0353 & 4,51 & 14,60 & 0,7278 &, 6591 & 4,1985 \\
\hline$\triangleright$ & 27. I. 01 Morgens & 1,0347 & 一 & 14,15 & 0,6735 & 0,6307 & 4,0176 \\
\hline$\triangleright$ & 27. I. 01 Abends & 1,0339 & 5,50 & 14,65 & 0,6604 & 0,6086 & 3,8761 \\
\hline 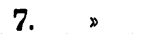 & 28. I. 01 Morgens & 1,0333 & 5,20 & 15,10 & 0,6361 & 0,5910 & 3,7647 \\
\hline ๖ & 28. I. 01 Abends & 1,0342 & 5,50 & 15,00 & 0,6634 & 0,6114 & 3,8946 \\
\hline$\triangleright$ & 29. I. 01 Morgens & 41 & 5,38 & 14,80 & 0,6280 & 31 & 3,7 \\
\hline 10. u. 11. & Gemelk 29./5 & 1,0334 & 4,90 & 14,10 & 0,6073 & 0,5586 & 3,5583 \\
\hline Datu & der & \begin{tabular}{|c|}
$\begin{array}{c}\text { Casein- } \\
\text { stick- } \\
\text { stoff } \\
0,0\end{array}$ \\
\end{tabular} & $\begin{array}{c}\text { Casein } \\
\% \\
\end{array}$ & $\begin{array}{c}\text { Albu- } \\
\text { min- } \\
\text { stick- } \\
\text { stoff } \\
\% \\
\end{array}$ & $\begin{array}{c}\text { Albumin } \\
\%\end{array}$ & $\begin{array}{c}\begin{array}{c}\text { Rest- } \\
\text { stick- } \\
\text { stoff } \\
\%\end{array} \\
\end{array}$ & $\begin{array}{c}\text { Asche } \\
\% \\
\end{array}$ \\
\hline emelk & 25. I. $01 \mathrm{Mit}$ & 0,9558 & 34 & 2,1710 & 13 & 0,0927 & 10,8240 \\
\hline , & 25. I. 01 Abends & 0,5 & 3,2678 & 0,2941 & 34 & 0,0796 & 0,9694 \\
\hline 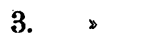 & 26. I. $01 \mathrm{Mo}$ & 217 & 3239 & 85 & 1370 & 30 & 56 \\
\hline$\triangleright$ & 26. I. 01 Abends & 0,5356 & 3,4118 & 0,3502 & 2,2308 & 0,0666 & 0,9240 \\
\hline s & 27. I. 01 Morgens & 0 & 3,4245 & 0,0918 & 0,5848 & 37 & - \\
\hline$\triangleright$ & 27. I. $01 \mathrm{Abc}$ & 49 & 62 & 34 & 68 & 10 & 一 \\
\hline$»$ & 28. I. 01 Morgens & 0,4759 & 3,0315 & 0,1050 & 0,6689 & 0,0438 & - \\
\hline 8. & 28. I. 01 Abends & 0,5072 & 3,2309 & 0,1098 & 0,6994 & 0,0461 & 0,9208 \\
\hline$\triangleright$ & 29. I. 01 Morgens & 0,4826 & 3,0742 & 0,1005 & 0,6402 & 0,0 & 0,9 \\
\hline 10. & emelk 29./30. & 0,4648 & 2,9608 & 0,1004 & 0,6395 & 0,0502 & 0,9205 \\
\hline
\end{tabular}


Aus dieser Zusammenstellung geht hervor, dass das Colostrum ein im Vergleich $\mathrm{zu}$ gewöhnlicher Milch wasserarmes Secret von hohem specifischen Gewicht und hohem Trockensubstanzgehalt ist. Die Summe der Eiweisskörper erreicht eine in Milch niemals vorkommende Höhe und übertrifft diese bis um das Sechsfache. An dieser Höhe ist sowohl das Casein wie das Albumin betheiligt, in den ersten Gemelken aber namentlich das Albumin (unentschieden bleibt hierbei, ob es Albumin oder vielleicht Globulin ist), das um das Zweibis Dreifache höher ist als das Casein, während es in gewöhnlicher Milch nur den fünften bis sechsten Theil desselben ausmacht. Die Menge der Eiweissstoffe nimmt von Gemelk zu Gemelk ab, und zwar das Albumin bedeutend schneller, so dass sich allmählich das in der Milch herrschende Verhältniss wieder herstellt; dies ist nach ungefähr drei Tagen der Fall. Die stickstoffhaltigen nicht eiweissartigen Extractivstoffe sind auch in gesteigerten Mengen vertreten und können bis zu $90 \mathrm{mg}$ und höher in $100 \mathrm{ccm}$. anwachsen, das ist bis zu dem Doppelten des gewöhnlichen Betrages. Der Aschengehalt ist um einige Zehntelprocente höher als gewöhnlich, sinkt aber von Gemelk zu Gemelk, ebenso wie die Trockensubstanz und das specifische Gewicht. Der Fettgehalt ist ausserordentlichen Schwankungen unterworfen. Wenn man aus diesen drei Beispielen schon einen Schluss ziehen kann, so ist er Anfangs niedrig, bei einem Colostrum beträgt er nur $0,15 \%$ und zeigt von Gemelk zu Gemelk eine Zunahme, um beim Uebergang des Colostrums in gewöhnliche Milch seinen normalen Stand einzunehmen.

Betrachten wir nur das erste Gemelk jeden Colostrums, so finden wir im Casein- und Albumingehalt folgende Schwankungen:

$$
\begin{aligned}
& \text { Casein . . . . . } 4,50-6,09 \% \\
& \text { Albumin . . . . } 11,94-13,89 \% \text {. }
\end{aligned}
$$

In diesen Zahlen liegt eine Bestätigung der oben citirten Angaben anderer Forscher; Grotenfeld's Behauptung, Colostrum enthalte überhaupt kein Casein, steht vereinzelt da und wird auch von meinen Befunden widerlegt. 
Die Kenntniss der Verhältnisse der Eiweissstoffe, ihre Höhe, ihre Schwankungen, Ab- oder Zunahme ist aus verschiedenen Gründen, abgesehen von dem wissenschaftlichen Nutzen, sehr wünschenswerth, da die Verwerthung der Milch je nach Zusammensetzung der Eiweissstoffe eine verschiedene sein kann. Soll die Milch z. B. als Nahrungsmittel für Kinder dienen, so wird man naturgemäss diejenige Milch vorziehen, die der Frauenmilch in ihrem Verhalten am nächsten kommt. Nun unterscheiden sich Kuhmilch und Frauenmilch vor Allem durch das verschiedene Verhältniss von Casein und Albumin. Stohmann ${ }^{1}$ gibt z. B. als Verhältniss von Casein: Albumin für Kuhmilch 6:1, für Frauenmilch $1: 1$ an, Lehmann ${ }^{2}$ ) für Kuhmilch 10:1, für Frauenmilch 2,4:1. Weichen nun diese Angaben auch weit von einander ab, so steht doch fest, dass in der Frauenmilch auf ein Theil Casein bedeutend mehr Albumin kommt als in der Kuhmilch. Dieser Umstand ist wegen der grossen Verdaulichkeit des Albumins gegenüber dem Casein nicht zu unterschätzen. Man wird also für die Lieferung von Kindermilch besonders die Kühe berücksichtigen, deren Milch sich durch einen hohen Albumingehalt auszeichnet.

Eine andere Erwägung greift dagegen Platz, wenn die Milch zur Käsefabrikation verwandt wird. Dann werden die Thiere natürlich eine höhere Ausbeute sichern, deren Milch sich als caseinreich erweist. Da es nun denkbar ist, dass altmilchende Thiere einen besonders hohen Caseingehalt, frischmilchende einen hohen Albumingehalt aufweisen, oder auch umgekehrt, so ist es werthvoll, über diese Verhältnisse sich Aufschluss zu verschaffen. Die Fachlitteratur weist Analysen von Kuhmilch, die während der ganzen Lactationsperiode ausgeführt sind, in reichlicher Anzahl auf, die Eiweisskörper sind dabei aber weniger berücksichtigt worden, oder nur in ihrer Summe, nicht Casein und Albumin getrennt, angegeben. Um nun diese offenbar bestehende Lücke in etwas auszufüllen, wurde diese Arbeit, die Untersuchung

1) Stohmann, Milch und Molkereiprodukte, 1898, S. 58.

2) Archiv für Physiologie, Bd. 56, S. 577. 
besonders der Eiweisskörper während der Lactation, unternommen. Aber ein unvorhergesehener Umstand hat es mir unmöglich gemacht, die Arbeit zu Ende zu führen und das gesteckte Ziel zu erreichen. Aus bestimmten, hier nicht in Betracht kommenden Gründen konnten diesen Untersuchungen nur 12 Monate Zeit gewidmet werden. Unter normalen Verhältnissen dauert eine Lactationsperiode ca. 9-10 Monate, so dass nach Verlauf der 12 Monate die Lactationsperiode hätte beendigt sein müssen. Beide Versuchskühe rinderten bald nach Beginn der Lactation, haben aber später wiederholt umgerindert, so dass auch jetzt noch keine Trächtigkeit zu constatiren ist. Der Grund für diesen unregelmässigen Verlauf ist vermuthlich darin zu suchen, dass beide Thiere behufs Kreuzungsversuche mit einem Bullen anderer Rasse gepaart worden sind, wobei also keine Conception eingetreten ist. Meine Untersuchungen sind nun, so lange die Zeit es erlaubte, fortgesetzt worden, und ich muss mich darauf beschränken, aus dem vorhandenen Zahlenmaterial, soweit es möglich ist, Schlüsse zu ziehen, und zwar unter Zuhülfenahme auch der Zahlen, welche Untersuchungen der Milch der Kuh 636 vom Ende der vorhergehenden Lactation entstammen.

Die Milchmenge ist zu Anfang der Lactation sehr hoch und erreicht in beiden Fällen den höchsten Punkt in der dritten Woche und bleibt ungefähr einen halben Monat auf der Höhe. Dann geht der Ertrag zurück und bleibt ca. 3 Monate, abgesehen von unbedeutenden Schwankungen, constant und nimmt dann allmählich ab. Ob diese Abnahme weiterhin periodenweise erfolgt, oder ein ganz allmähliches Sinken ist, lässt sich aus den Zahlen nicht ableiten. Die Fütterung scheint auf die Milchergiebigkeit einen Einfluss auszuüben. Kuh 643, die Kindermilchkuh, die an und für sich die milchreichere ist, bleibt in Folge der sich stets gleichbleibenden Ration schliesslich mit der Menge hinter Kuh 636 zurück, die einen Wechsel in der Fütterung durch eine reichlichere Milchabscheidung lohnt und im Ertrag auch nicht so schnell ablässt. Gegen Ende der Lactation nimmt dann die Milch, wie Tabelle IV zeigt, sehr schnell $\mathrm{ab}$, bis die Secretion schliesslich völlig aufhört.

Die Trockensubstanz, im Colostrum eine Höhe von über $27 \%$ erreichend, sinkt in der Milch bald auf die Hälfte und bleibt, 
wenn sie ihren normalen Stand erreicht hat, ziemlich constant, um gegen Ende mit abnehmender Milchmenge wieder anzusteigen.

Der Fettgehalt ist in den ersten Gemelken ganz niedrig, wird dann von Gemelk zu Gemelk höher und erreicht kurze Zeit nach dem Kalben seine grösste Höhe, auf der er einige Wochen verharrt. Er sinkt dann und bleibt, von einzelnen Schwankungen abgesehen, ziemlich gleichmässig. Durch Fütterungswechsel scheint er nicht beeinflusst zu werden. An der Concentrationszunahme der Milch gegen Ende der Lactation ist der Fettgehalt durch seine Erhöhung mitbetheiligt, procentisch ist er hier bedeutend höher als jemals bei Beginn.

Die Eiweisskörper, die im Colostrum in ganz anderen Mengenverhältnissen vorkommen als in gewöhnlicher Milch, und die hauptsächlich dem Colostrum seine charakteristische Zusammensetzung verleihen, gehen einige Tage nach dem Beginn der Milchabscheidung in den normalen Zustand über. Das Verhältniss zwischen Casein und Albumin und den Extractivstoffen bleibt im Verlauf der Lactation kein ganz constantes, lässt sich aber ungefähr durch die Zahlen 4-5:1:0,5 ausdrücken. Die Summe der Eiweissstoffe nimmt allmählich ab, um sich gegen Ende stark zu erhöhen, und zwar wächst das Albumin schneller als das Casein. Im letzten Gemelk von Kuh 636 der vorhergehenden Lactation verhält sich Casein zu Albumin zu Extractivstoffen wie $2: 1: 0,2$. Das Verhältniss zwischen Casein und Albumin wird also ein immer engeres, während das der Extractivstoffe zu den Eiweissstoffen das übliche bleibt.

Weitere Schlüsse sind mit Sicherheit aus dem vorhandenen Material bis jetzt nicht gut zu ziehen. $\mathrm{Da}$ aber die Arbeit von anderer Seite fortgesetzt werden wird, so wird ein endgültiges Urtheil gefällt werden können, wenn die Lactationsperiode bei beiden Kühen ihr Ende erreicht hat.

Zum Schluss erfülle ich die angenehme Pflicht, Herrn Geheimrath Professor Dr. Maercker, in dessen Laboratorium diese Arbeit entstanden ist, und Herrn Geheimrath Professor Dr. Kühn für bereitwillige Ueberlassung des Versuchsmaterials meinen Dank auszusprechen. 
Tabelle I.

\begin{tabular}{c|c|c|c|c}
\hline \hline \multirow{2}{*}{ Fällungsmittel } & $\begin{array}{c}\text { Gesammt- } \\
\text { eiweiss- } \\
\text { stickstoff } \\
\%\end{array}$ & $\begin{array}{c}\text { Extractiv- } \\
\text { stickstoff }\end{array}$ & $\begin{array}{c}\text { Summe von } \\
\text { Eiweiss- } \\
\text { Extractiv- } \\
\text { stickstoff } \\
\text { \% }\end{array}$ & $\begin{array}{c}\text { Ge- } \\
\text { sammt- } \\
\text { stickstoff } \\
\text { dire k t } \\
\%\end{array}$ \\
\hline
\end{tabular}

1.

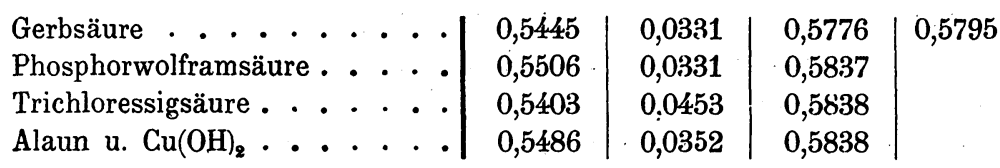

2.

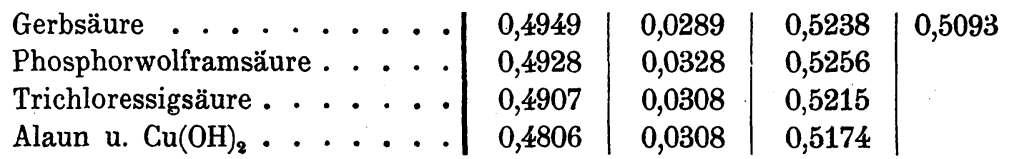

3.

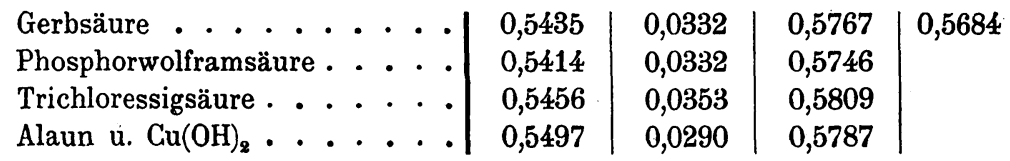

4.

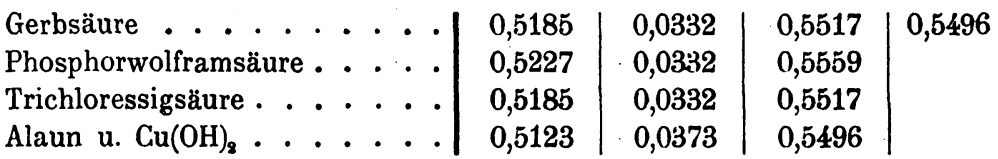

5.

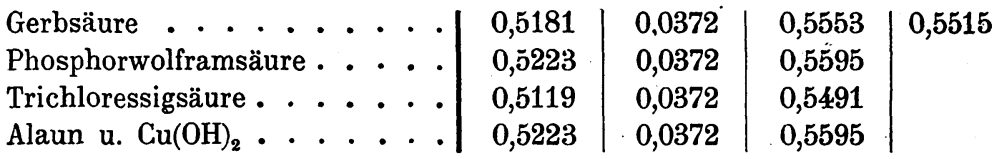

6.

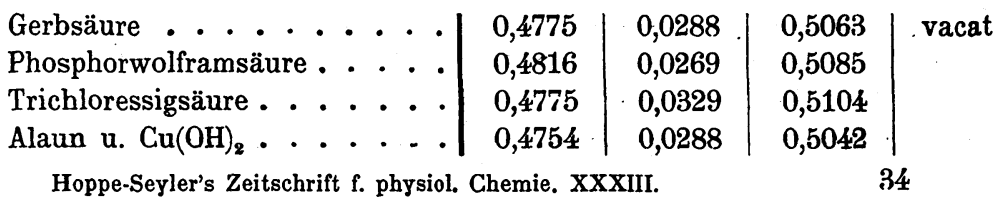


Tabelle I (Fortsetzung).

\begin{tabular}{l|c|c|c|c}
\hline Fällungsmittel & $\begin{array}{c}\text { Gesammt- } \\
\text { eiweiss- } \\
\text { stickstoff }\end{array}$ & $\begin{array}{c}\text { Extractiv- } \\
\text { stickstoff }\end{array}$ & $\begin{array}{c}\text { Summe von } \\
\text { Eiweiss- } \\
\text { u. Extractiv- } \\
\text { stickstoff } \\
\%\end{array}$ & $\begin{array}{c}\text { Ge- } \\
\text { sammt- } \\
\text { stickstoff } \\
\text { direk t } \\
\%\end{array}$ \\
\hline & & $\%$ & $\%$ &
\end{tabular}

7.

\begin{tabular}{|c|c|c|c|}
\hline Gerbsäure & 0,4990 & 0,0371 & 0,5361 \\
\hline Phosphorwolframsäure . & 0,4969 & 0,0339 & 0,5308 \\
\hline Trichloressigsäure . . & 0,4948 & 0,0359 & 0,5307 \\
\hline Alaun u. $\mathrm{Cu}(\mathrm{OH})_{2}$. & 0,4947 & 0,0359 & 0,5306 \\
\hline
\end{tabular}

8.

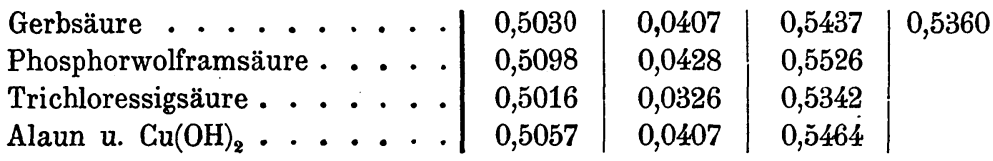

9.

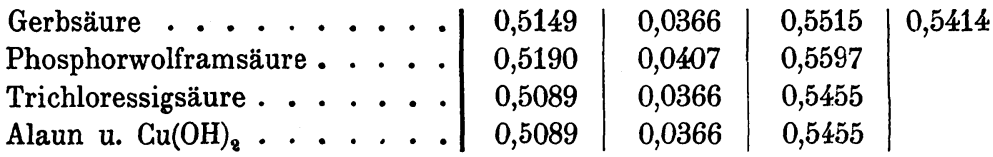

10.

\begin{tabular}{|c|c|c|c|}
\hline Gerbsäure & 0,5113 & 0,0368 & $0, \tilde{0} 841$ \\
\hline hosphorwolframsäure & 0,5154 & 0,0411 & 0,5565 \\
\hline ssigsäur & $0,50 ؟$ & 0,0431 & 0,55 \\
\hline Alaun & 0,5154 & 0,0452 & 0,5606 \\
\hline
\end{tabular}

11.

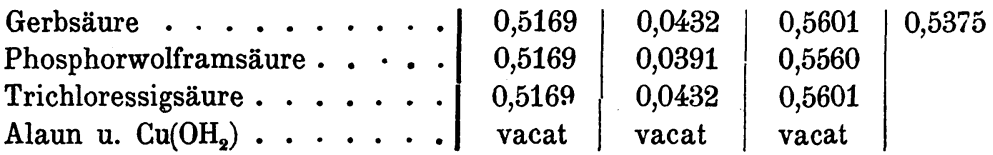

12.

Gerbsäure ........

\begin{tabular}{l|l|l|l}
0,5413 & 0,0389 & 0,5802 & 0,5598 \\
0,5393 & 0,0369 & 0,5762 & \\
0,5454 & 0,0410 & 0,5965 & \\
0,5372 & 0,0369 & 0,5741 &
\end{tabular}

\begin{tabular}{ll|l|l|l} 
Trichloressigsäure $\ldots \ldots .$. & 0,5454 & 0,0410 & 0,5965 \\
Alaun u. $\mathrm{Cu}(\mathrm{OH})_{2} \ldots \ldots .$. & $\ldots, 5372$ & 0,0369 & 0,5741
\end{tabular} 
Tabelle I (Fortsetzung).

\begin{tabular}{c|c|c|c|c|c}
\hline \hline Fällungsmittel & $\begin{array}{c}\text { Gesammt- } \\
\text { eiweiss- } \\
\text { stickstoff } \\
0 \%\end{array}$ & $\begin{array}{c}\text { Extractiv- } \\
\text { stickstoff }\end{array}$ & $\begin{array}{c}\text { Summe von } \\
\text { Eiweiss- } \\
\text { Extractiv- } \\
\text { stickstoff } \\
\%\end{array}$ & $\begin{array}{c}\text { Ge- } \\
\text { sammt- } \\
\text { stickstoff } \\
\text { direk t } \\
\%\end{array}$ \\
\hline
\end{tabular}

13.

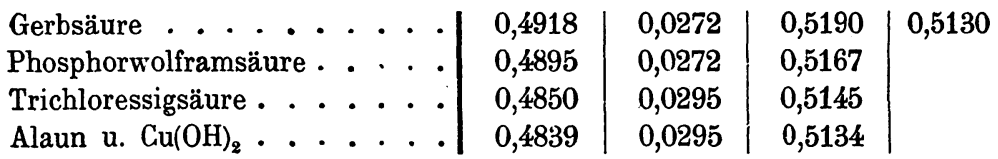

14.

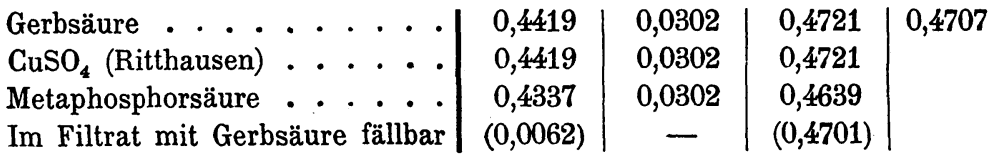

15.

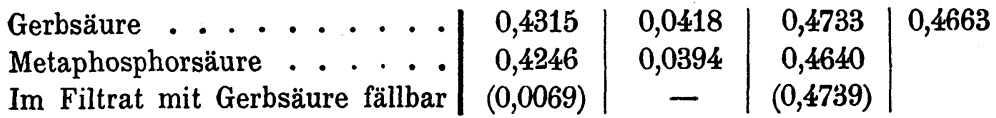

16.

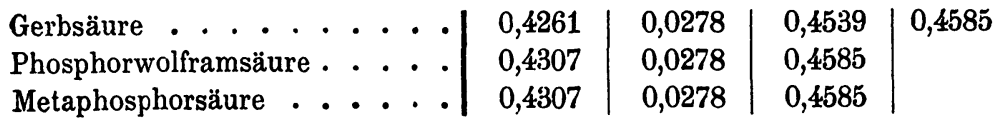

17.

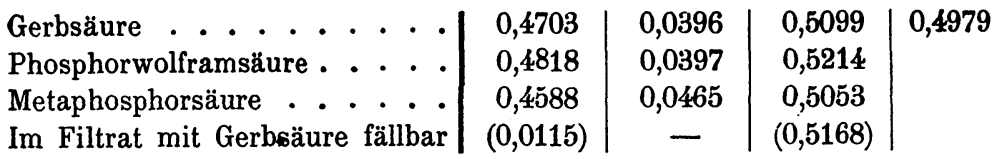

18.

\begin{tabular}{llllll|l|l|l|l} 
Gerbsäure.$\cdot$. &. &. &. & 0,5981 & 0,0467 & 0,6448 & 0,6292 \\
$\mathrm{CuSO}_{4}$ (Ritthausen) &. &. &. & 0,5981 & 0,0489 & 0,6470 &
\end{tabular}

19.

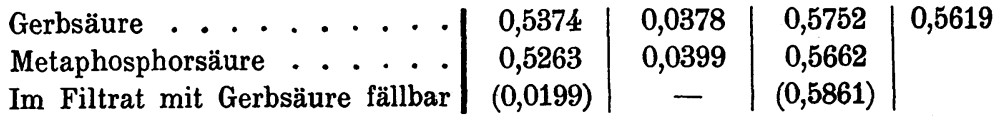


Tabelle I (Fortsetzung).

\begin{tabular}{c|c|c|c|c}
\hline \hline Fällungsmittel & $\begin{array}{c}\text { Gesammt- } \\
\text { eiweiss- } \\
\text { stickstoff } \\
0 \%\end{array}$ & $\begin{array}{c}\text { Extractiv- } \\
\text { stickstoff }\end{array}$ & $\begin{array}{c}\text { Summe von } \\
\text { Eiweiss- } \\
\text { uxtractiv- } \\
\text { stickstoff } \\
\%\end{array}$ & $\begin{array}{c}\text { Ge- } \\
\text { sammt- } \\
\text { stickstoff } \\
\text { direk t } \\
\%\end{array}$ \\
\hline
\end{tabular}

20.

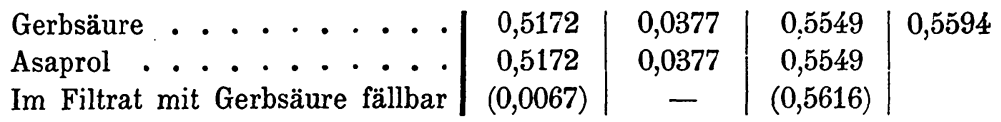

21.

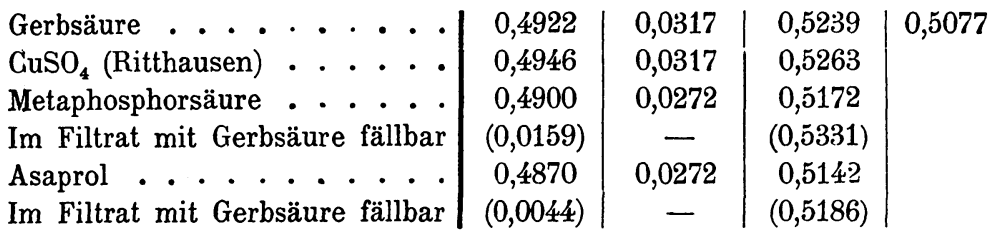

22.

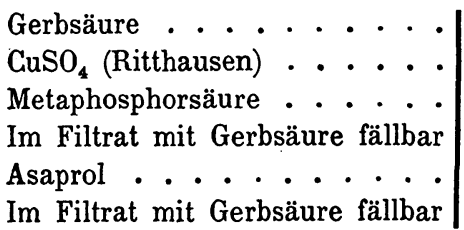

\begin{tabular}{c|c|c|c}
0,4902 & 0,0409 & 0,5311 & 0,5174 \\
0,4925 & 0,0454 & 0,5379 & \\
0,4857 & 0,0341 & 0,5298 & \\
- & - & - & \\
0,4902 & 0,0363 & 0,5265 & \\
$(0,0113)$ & - & - &
\end{tabular}

23.

Gerbsäure .........

Phosphorwolframsäure . . . .

Metaphosphorsäure . . . . .

Im Filtrat mit Gerbsäure fällbar

Asaprol . . . . . . . .

Im Filtrat mit Gerbsäure fällbar

\begin{tabular}{c|c|c|c}
0,5021 & 0,0351 & 0,5372 & 0,5328 \\
0,5043 & 0,0351 & 0,5394 & \\
0,4911 & 0,0351 & 0,5262 & \\
$(0,0109)$ & - & - & \\
0,4955 & 0,0351 & 0,5306 & \\
$(0,0088)$ & - & - &
\end{tabular}

24.

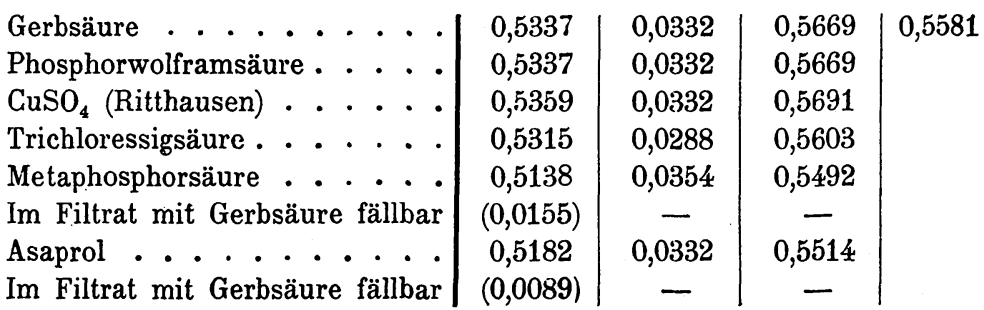


Tabelle II.

\begin{tabular}{c|c|c|c|c|c|c}
\hline \hline Fällungsmittel & $\begin{array}{c}\text { Casein- } \\
\text { stickstoff }\end{array}$ & $\begin{array}{c}\text { Albumin- } \\
\text { stickstoff }\end{array}$ & $\begin{array}{c}\text { Summe } \\
\text { von } \\
\text { Casein a. } \\
\text { Albumin- } \\
\text { stickstoff } \\
\%\end{array}$ & $\begin{array}{c}\text { Eiweiss- } \\
\text { stickstoff. } \\
\text { (Gerb- } \\
\text { säure) }\end{array}$ & $\begin{array}{c}\text { Extractiv- } \\
\text { stickstoff }\end{array}$ & $\begin{array}{c}\text { Gesammt- } \\
\text { stickstoff } \\
\text { direkt }\end{array}$ \\
\hline & $\%$ & $\%$ & $\%$ & $\%$ \\
\hline
\end{tabular}

1.

\begin{tabular}{llll|c|c|c|c|c|c} 
Kalialaun & $\cdot$ & $\cdot$ & $\cdot$ & 0,3456 & 0,1235 & 0,4691 & 0,4918 & - & 0,5130 \\
Magnesiumsulfat & $\cdot$ & $\cdot$ & 0,3989 & 0,0895 & 0,4884 & - & - & -
\end{tabular}

2.

\begin{tabular}{ll|l|l|l|c|c|c} 
Kalialaun . . • • • • • & 0,3544 & 0,1147 & 0,4691 & 0,5658 & 0,0293 & 0,4793 \\
Essigsäure ohne Kohlens. & 0,3285 & 0,1204 & 0,4489 & - & - & -
\end{tabular}

3.

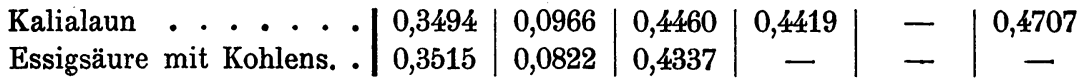

4.

Kalialaun . . . . $\mid 0,3445$

Magnesiumsulfat . . 0,4083

Lehmann . . . . . 0,4311

\begin{tabular}{c|c|c|c|c}
0,1004 & 0,4449 & 0,4859 & 0,0388 & 0,5133 \\
0,0753 & 0,4836 & - & - & - \\
- & - & - & - & -
\end{tabular}

5.

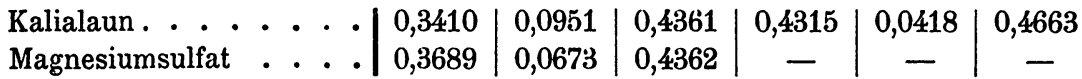

6.

Kalialaun . • • • • • $|0,3612|$

Essigsäure u. Kohlensäure 0,3635

Lehmann . . . . . $\mid 0,4075$

\begin{tabular}{l|l|l|l|l|l|l|}
0,0764 & 0,4376 & 0,4261 & 0,0278 & 0,4585
\end{tabular} \begin{tabular}{c|c|c|c|c}
0,0672 & 0,4307 & - & - & - \\
- & - & - & - & -
\end{tabular}

7.

Kalialaun . . . . • $\mid 0,3625$

Magnesiumsulfat . . . 0,3946

Lehmann . . . . . . 0,4053

\begin{tabular}{c|c|c|c|c}
0,1192 & 0,4817 & 0,4703 & 0,0396 & 0,4970 \\
0,1170 & 0,5116 & - & - & - \\
- & - & - & - & -
\end{tabular}

8.

\begin{tabular}{c|c|c|c|c|c|c} 
Kalialaun. . . . & 0,4791 & 0,1913 & 0,6704 & 0,6699 & 0,0534 & 0,7141 \\
- & 0,0512 & - & - & - & -
\end{tabular}

9.

Kalialaun. . . • • • 0,4513

Essigsäure u. Kohlensäure 0,45080

Magnesiumsulfat . . . 0,4824

Lehmann . . . . . 0,5114

\begin{tabular}{c|c|c|c|c}
0,1422 & 0,5935 & 0,5981 & 0,0467 & 0,6292 \\
0,1378 & 0,5958 & - & - & - \\
0,1156 & 0,5980 & - & - & - \\
- & - & - & - & -
\end{tabular} 
Tabelle II (Fortsetzung).

\begin{tabular}{c|c|c|c|c|c|c}
\hline \hline F ällungsmittel & $\begin{array}{c}\text { Casein- } \\
\text { stickstoff }\end{array}$ & $\begin{array}{c}\text { Albumin- } \\
\text { stickstoff }\end{array}$ & $\begin{array}{c}\text { Summe } \\
\text { von } \\
\text { Casein u. } \\
\text { Albumin- } \\
\text { stickstoff } \\
\%\end{array}$ & $\begin{array}{c}\text { Eiweiss- } \\
\text { stickstoff. } \\
\text { (Gerb- } \\
\text { säure) }\end{array}$ & $\begin{array}{c}\text { Extractiv- } \\
\text { stickstoff }\end{array}$ & $\begin{array}{c}\text { Gesammt- } \\
\text { stickstoff } \\
\text { direkt }\end{array}$ \\
\hline & $\%$ & $\%$ & $\%$ & $\%$ \\
\hline
\end{tabular}

10.

\begin{tabular}{ll|l|} 
Kalialaun. . . . . . . & 0,3930 \\
Magnesiumsulfat & $\ldots$ & 0,4352 \\
Lehmann . . . . . . . & 0,4393
\end{tabular}

\begin{tabular}{|c|c|c|c|c}
0,1354 & 0,5284 & 0,5374 & 0,0378 & 0,5619 \\
0,0977 & 0,5329 & - & - & - \\
- & - & - & - & -
\end{tabular}

11.

\begin{tabular}{lll|l} 
Kalialaun. $\ldots \ldots, 3795$ \\
Magnesiumsulfat & $\cdots$ & $\cdots$ & 0,4150
\end{tabular} $\mid$\begin{tabular}{c|c|c|c|c}
0,1398 & 0,5193 & 0,5172 & 0,0377 & 0,5594 \\
0,0488 & - & - & - & -
\end{tabular}

12.

\begin{tabular}{l|c|c} 
Kalialaun. . . . . . & 0,3912 \\
& & - \\
Essigsäure u. Kohlensäure & 0,3899 \\
Magnesiumsulfat . . . & 0,4254 \\
Lehmann . . . . . & 0,4749
\end{tabular}

\begin{tabular}{|c|c|c|c|c}
0,1285 & 0,5207 & 0,5185 & 0,0332 & $0, \check{0} 495$ \\
0,0288 & - & - & - & - \\
$($ Globulin) & - & - & - & - \\
0,1307 & 0,5206 & - & - & - \\
0,1063 & 0,5317 & - & - & - \\
- & - & - & - & -
\end{tabular}

13.

Kalialaun. . . . . . 0,3680

Essigsäure $u$. Kohlensäure 0,3769

Magnesiumsulfat . . . 0,4123

Lehmann . . . . . . 0,4467

\begin{tabular}{|c|c|c|c|c}
0,1108 & 0,4788 & 0,4922 & 0,0317 & 0,0077 \\
0,1087 & 0,4856 & - & - & - \\
0,0929 & 0,5052 & - & - & - \\
- & - & - & - & -
\end{tabular}

14.

\begin{tabular}{l|c|c} 
Kalialaun. . . . . . & 0,3836 \\
Essigsäure u. Kohlensäure & 0,3836 \\
Magnesiumsulfat . . . & 0,4040 \\
Lehmann . . . . . & 0,4372
\end{tabular}

\begin{tabular}{|c|c|c|c|c}
0,1294 & 0,5130 & 0,4902 & 0,0409 & 0,5174 \\
0,0454 & - & - & - & - \\
(Globulin) & - & - & - & - \\
0,1112 & 0,4948 & - & - & - \\
0,0931 & 0,4971 & - & - & - \\
- & - & - & - & -
\end{tabular}

15.

Kalialaun. . . . . . 00,3859

Essigsäure $u$. Kohlensäure 0,3859

Magnesiumsulfat . . . 0,4297

Lehmann . . . . . . 0,4179

$\mid$\begin{tabular}{c|c|c|c|c}
0,1162 & 0,4921 & 0,5021 & 0,0351 & 0,5328 \\
0,1162 & 0,5021 & - & - & - \\
0,0753 & 0,5050 & - & - & \\
- & - & - & - & -
\end{tabular} 
Tabelle II (Fortsetzung).

\begin{tabular}{l|c|c|c|c|c|c}
\hline \hline Fällungsmittel & $\begin{array}{c}\text { Casein- } \\
\text { stickstoff }\end{array}$ & $\begin{array}{c}\text { Albumin- } \\
\text { stickstoff }\end{array}$ & $\begin{array}{c}\text { Summe } \\
\text { von } \\
\text { Casein u. } \\
\text { Albumin- } \\
\text { stickstoff } \\
\text { stickstoff. } \\
\text { (Gerb- } \\
\text { säure) }\end{array}$ & $\begin{array}{c}\text { Eiweiss- } \\
\text { Extractiv- } \\
\text { stickstoff }\end{array}$ & $\begin{array}{c}\text { Gesammt- } \\
\text { stickstoff } \\
\text { direkt }\end{array}$ \\
\hline & $\%$ & $\%$ & $\%$ & $\%$ \\
\hline
\end{tabular}

16.

\begin{tabular}{l|c|c|c|c|c|c} 
Kalilaun . . . . . . & 0,3922 & 0,1094 & 0,5016 & 0,5062 & 0,0410 & 0,5382 \\
Essisäure u. Kohlensäure & 0,3922 & 0,1140 & 0,5062 & - & - & - \\
Mąesiumsulfat . . . & 0,4287 & - & - & - & - & -
\end{tabular}

17.

\begin{tabular}{ll|c|c|c|c|c|c} 
Kalilaun. . . . . . . & 0,4097 & 0,1195 & 0,5292 & 0,5337 & 0,0332 & 0,5581 \\
Esssä̈ure u. Kohlensäure & 0,3875 & 0,1373 & 0,5248 & - & - & - \\
Mąesiumsulfat . . . . & 0,4385 & 0,0886 & 0,5279 & - & - & - \\
Lemann . . . . . . . . & 0,4579 & - & - & - & - & - \\
Koosalz . . . . . . . . & 0,4429 & 0,0908 & 0,5337 & - & - & -
\end{tabular}

18.

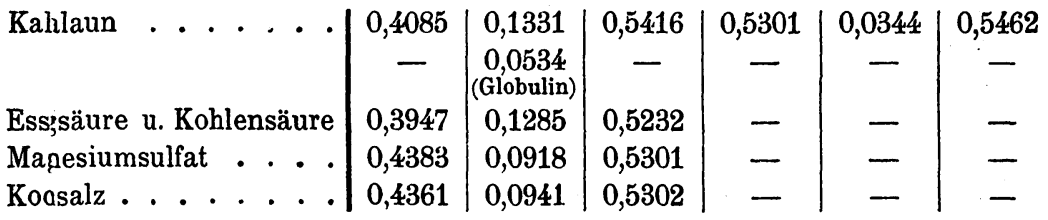

19.

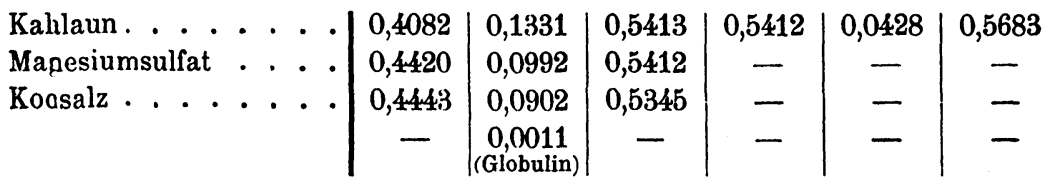

20.

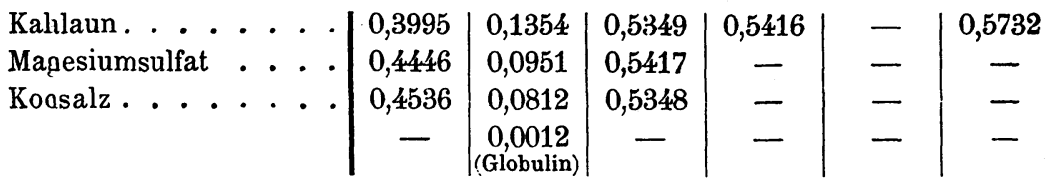

21.

\begin{tabular}{llll|l|c|c|c|c|c} 
Kahlaun & $\ldots$ & $\ldots$ & 0,3862 & 0,1226 & 0,5088 & 0,5088 & 0,0307 & 0,5435 \\
Mąesiumsulfat & $\ldots$ & $\ldots$ & 0,4288 & - & - & - & - & -
\end{tabular} 
$\therefore$ Tabelle

Untersuchungsergebnisse: der

$\mathrm{Kuh}$

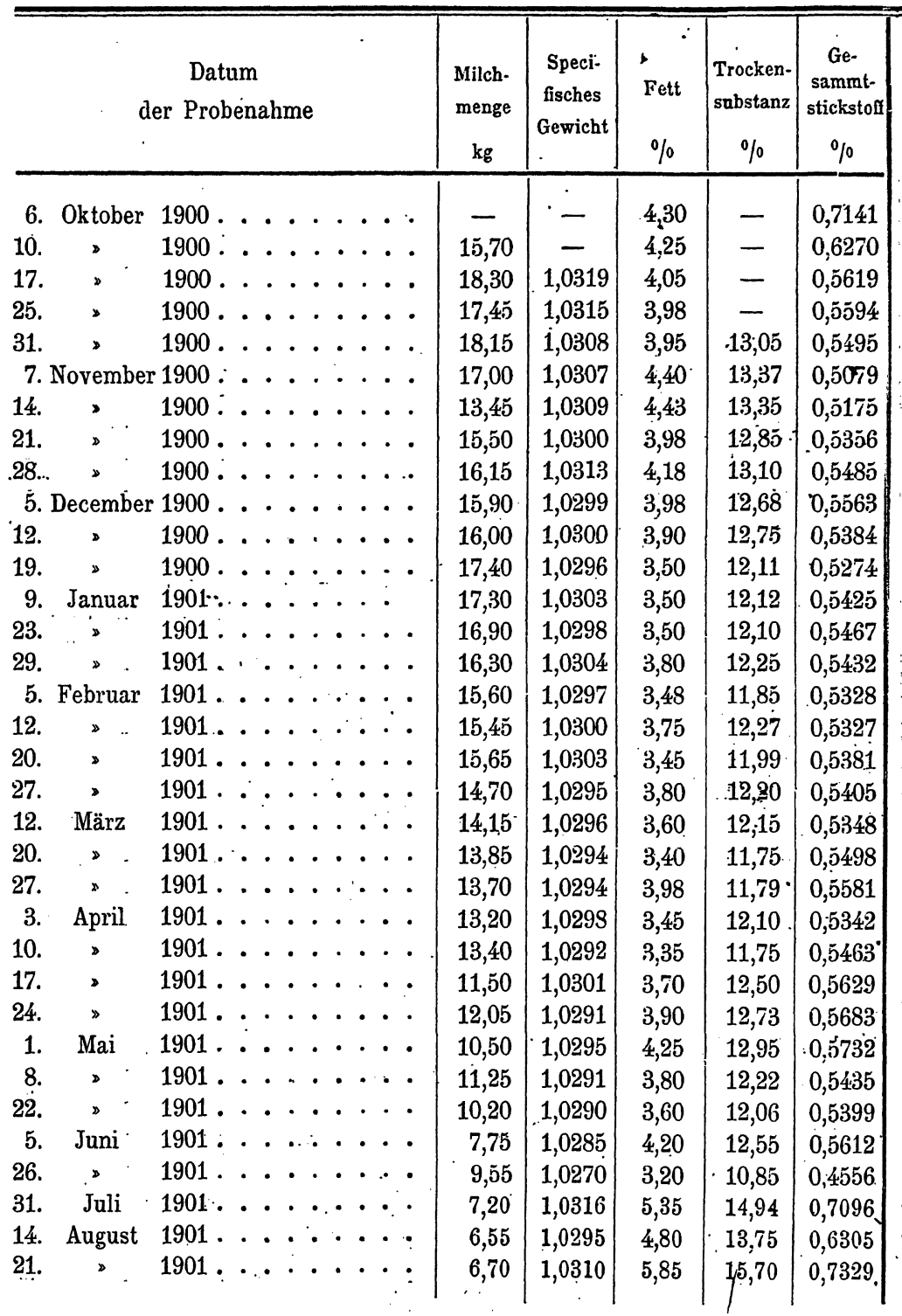


III.

Milch im Laufe der Lactation.

643 .

\begin{tabular}{|c|c|c|c|c|c|c|c|c|}
\hline $\begin{array}{c}\text { Ge- } \\
\text { sammt. } \\
\text { stickstoff } \\
\times 6,37 \\
\times \% \\
\% \%\end{array}$ & $\begin{array}{c}\text { Eiweiss- } \\
\text { stickstoff } \\
\%\end{array}$ & Eiweiss & $\begin{array}{c}\text { Casein- } \\
\text { stickstoff } \\
\% \\
\%\end{array}$ & Casein & $\begin{array}{c}\text { Albumin- } \\
\text { stickstoff } \\
\% \\
\%\end{array}$ & Albumin & $\begin{array}{c}\text { Extractiv- } \\
\text { stickstoff } \\
\%\end{array}$ & Asche \\
\hline 4,5488 & 0,6327 & 4,0303 & 0,4792 & 3,0525 & 0,1913 & 1,2186 & 0,05334 & - \\
\hline 3,9939 & 0,5981 & $.3,8099$ & 0,4514 & 2,8754 & 0,1423 & 0,9065 & 0,0489 & - \\
\hline 3,5793 & 0,5375 & 3,4239 & $0,3931$. & 2,5040 & 0,1333 & 0,8491 & 0,0377 & - \\
\hline 3,5634 & 0,5172 & 3,2946 & 0,3796 & 2,4181 & 0,1398 & 0,8905 & 0,0377 & 0,7980 \\
\hline 3,5003 & 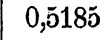 & 3,3028 & 0,3922 & 2,4983 & 0,1285 & 0,8185 & 0,0332 & 0,8100 \\
\hline$\cdot 3,2353$ & 0,4924 & 3,1366 & $0 ; 3682$ & 2,3454 & 0,1109 & 0,7064 & 0,0317 & 0,8300 \\
\hline 3,2965 & $.0,4903$ & 3,1232 & 0,3836 & 2,4435 & 0,1294 & 0,8243 & 0,0406 & 0,8232 \\
\hline 3,4118 & $0,5.129$ & 3,2672 & 0,3859 & 2,4582 & 0,1248 & 0,7949 & 0,0363 & - \\
\hline $.3,4939$ & 0,5192 & 3,3073 & 0,3877 & 2,4696 & 0,1269 & 0,8084 & 0,0369 & 0,8133 \\
\hline 3,5436 & $0,52 \xi 0$ & 3,3379 & 0,3924 & 2,4996 & 0,1339 & 0,8529 & 0,0392 & - \\
\hline 3,4296 & 0,5130 & 3,2678 & 0,3790 & 2,4142 & 0,1340 & 0,8536 & 0,0369 & 0,8406 \\
\hline 3,3595 & 0,5021 & $3,1.984$ & 0,3685 & 2,3473 & 0,1221 & 0,7778 & - & 0,8279 \\
\hline $3 ; 4557$. & 0,5155 & 3,2837 & 0,3917 & 2,4951 & 0,1192 & 0,7593 & 0,0338 & 0,9182 \\
\hline 3,4818 & 0,52086 & 3,3672 & 0,4088 & 2,6041 & 0,1242 & 0,7912 & 0,0294 & 0,8843 \\
\hline 3,4602 & 0,5094 & 3,2449 & 0,3804 & 2,4231 & 0,1246 & 0,7937 & 0,0415 & - \\
\hline 3,3939 & $0, \breve{0021}$ & 3,1984 & 0,3858 & 2,4575 & 0,1162 & 0,7402 & 0,0351 & - \\
\hline 3,3933 & 0,4976 & 3,1697 & $-0,3814$ & 2,4295 & $.0,1164$ & 0,7415 & $\mid 0,0388$ & - \\
\hline 3,4277 & 0,5062 & 3,2245 & |0,3922 & 2,4983 & 0,1094 & 0,6969 & 0,0410 & 0,7591 \\
\hline 3,4429 & $0,510 \Xi$ & 3,2519 & 0,3854 & 2,40049 & 0,1127 & 0,7179 & 0,0345 & - \\
\hline$\cdot 3,4067$ & 0,5072 & $3,2309$. & | 0,3809 & 2,4263 & 0,1279 & 0,8147 & 0,0419 & 0,8119 \\
\hline 3,5022 & 0,5161 & 3,2493 & 0,3643 & 2,3206 & 0,1524 & 9708 & 0,0287 & - \\
\hline 3,55551 & 0,5337 & 3,3996 & 0,4097 & 2,6098 & 0,1196 & 0,7619 & 0,0332 & $\overline{-}$ \\
\hline 3,4029 & 0,5011 & 3,1920 & $0 ; 3973$ & 2,5308 & 0,1190 & 0,7580 & 0,0343 & 0,7908 \\
\hline 3,4799 & 0,5302 & 3,3774 & 0,4086 & 2,6028 & 0,1331 & 0,8478 & 0,0344 & 0,7630 \\
\hline $3,58 \overline{7} 7$ & 0,5434 & 3,4615 & 0,3924 & 2,4996 & 0,1353 & 0,8619 & 0,0361 & 0,7920 \\
\hline $3,6 \dot{201}$ & 0,5412 & 3,4474 & $0,4082^{\prime}$ & 2,6002 & 0,1421 & 0,9052 & 0,0429 & - \\
\hline$-3,6513$ & $0,0,0416^{\circ}$ & 3,4499 & 0,3995 & 2,5448 & 0,1377 & 0,8771 & 0,0406 & - \\
\hline 3,4621 & 088 & :3,2411 & 0,3816 & 2,4308 & 0,1226 & 0,7809 & $\mid 0,0278$ & - \\
\hline 3,4392 & 0,5097 & 3,2468 & 0,3939 & 2,5091 & 0,1274 & $0,811 \tilde{}$ & 0,0371 & - \\
\hline 3,5748 & 0,5278 & 3,3621 & 0,3808 & 2,4257 & $0,1425^{\circ}$ & 0,9077 & 0,0467 & - \\
\hline 2,9022 & 0,4354 & 3,7735 & 0,3394 & 2,1619 & 0,0938 & 0,5975 & 0,0223 & - \\
\hline 4,5202 & 0,6675 & 4,2519 & 0,5076 & 3,2340 & 0,1508 & 0,9606 & 0,0510 & - \\
\hline & & 3,8323 & 0,4440 & 2,8283 & 0,1421 & 0,9052 & 0,0333 & - \\
\hline 4,6686 & 0,7063 & 4,4991 & - & - & - & - & 0,0444 & - \\
\hline
\end{tabular}


T:äbelle

Untersuchungsergebnisse dér

$\mathrm{Kuh}$

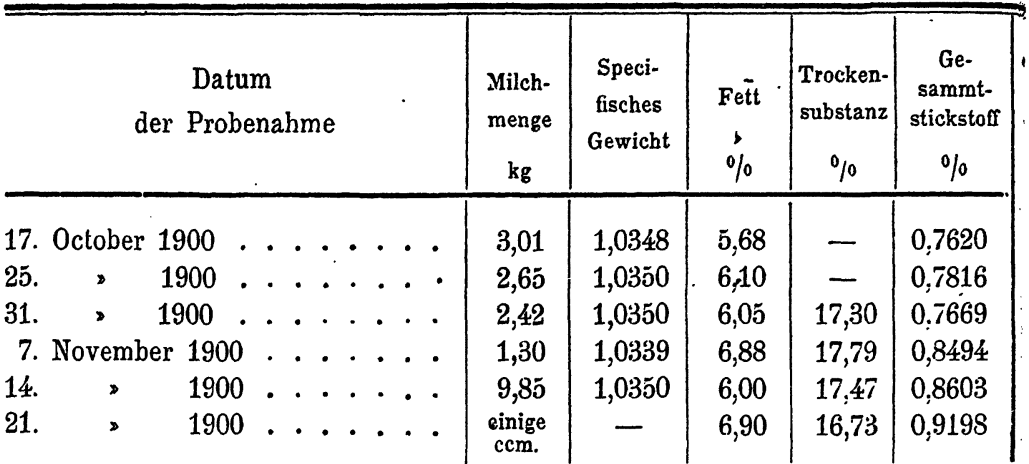

Vom 21. November 1900

1. Gemelk 25. Januar 1901 llittags . . $\mid$\begin{tabular}{c|l|l|l|l|}
- & 1,0785 & 0,15 & 27,35 & 3,2088
\end{tabular}

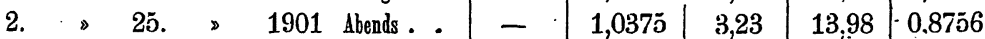

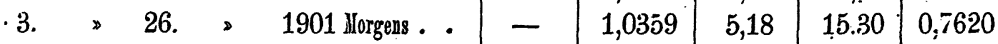

4. $>26 . \quad 1901$ Abends. . - $-1,0353$ 4,51 $14,60.9,7248$

$5 . \quad 27 .>1901$ Horgens . . $-1,0347-14,1500,6735$

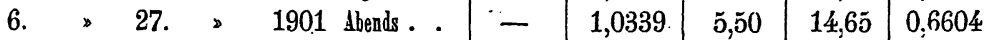

\begin{tabular}{lllll|l|l|l|l|l}
7. & $\$$ & 28. & $\#$ & 1901 Horgens . . & - & 1,0333 & 5,25 & 15,10 & 0,6361
\end{tabular}

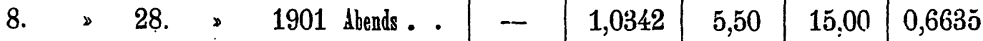

$9 .>29 . \Rightarrow 1901$ Horgens . . -

10. 11. $\$ 29 . \Rightarrow 1901 \ldots \ldots 15,45$

5. Februar $1901 \ldots \ldots 16,00$

1,0341

1,0334

1,0318

$12 .>1901 \ldots \ldots 16,85$

$20 . \quad 1901 \ldots \ldots 15,60$

1,0326

27. $\therefore 1901 \ldots . .14,60$

1,0319

12. März $1901 \ldots \ldots 13,40$

1,0316

$20 . \quad 1901 \ldots . .13,40$

1,0315

$27 . \quad 1901 \ldots . .13,90$

1,0318

3. April $1901 \ldots . .13,20$

1,0315

$10 ., 1901 \ldots . .12,10$

1,0311

1,0318

17. $\therefore 1901 \ldots \ldots 12,30$

1,0307

$24 . \quad 1901 \ldots . .11,35$

1,0305

1. Mai $1901 \ldots . .412,65$

1,0312

$8 . \gg 1901 \ldots . .13,70$

1,0319

5,38

14,80

0,6281

4,90

14,10

4,18

13,27

0,6073

3,78

13,00

0,5262

4,10

$13,5 \bar{x}$

3,90

12,75

0,4964

3,50

12,25

0,4889

0,4787

3,95

12,39

3,70

12,20

0,4602

3,35

12,00

0,4547

3,45

12,18

3,40

12,05

3,45

11,93

3,55

12,35

3,50

12,45

11,40

1,0320

3,65

12,92

3,65

12,75

5. Juni $1901 \ldots .99$

1,0319

$9, \overline{5} 5$

1,0308

3,20

12,88

0,4611

0.4583

0,4411

0,4643

0,4353

0,4758

0,4842

0,4869

31. Juli $1901 \ldots . .90$

1,0296

3,48

11,70

0,0376

0,5293

14. August $1901 \ldots . . \quad 10,20$

1,0313

3,73

12,68

0,4696

$\begin{array}{ll}9,25 & 1,0308\end{array}$

3,88

i2 2,75

0,5019

0,4891 
IV.

Milch im Laufe der Lactation.

636.

\begin{tabular}{|c|c|c|c|c|c|c|c|c|c}
\hline $\begin{array}{c}\text { Ge- } \\
\text { sammt- } \\
\text { stickstoff } \\
\times 6,37 \\
\%\end{array}$ & $\begin{array}{c}\text { Eiweiss- } \\
\text { stickstoff }\end{array}$ & Eiweiss & $\begin{array}{c}\text { Casein- } \\
\text { stickstoff }\end{array}$ & Casein & $\begin{array}{c}\text { Albumin- } \\
\text { stickstoff }\end{array}$ & Albumin & $\begin{array}{c}\text { Extractiv- } \\
\text { stickstoff }\end{array}$ & Asche \\
\hline 4,8539 & 0,7286 & 4,6412 & 0,5949 & 3,7895 & 0,1270 & 0,8089 & 0,0401 & 0,7900 \\
4,9787 & 0,7438 & 4,7380 & 0,6279 & 3,9997 & 0,1202 & 0,7657 & 0,0401 & 0,9580 \\
4,8852 & 0,7426 & 4,7304 & 0,6206 & 39532 & 0,1197 & 0,7625 & 0,0333 & - \\
5,4107 & 0,8227 & 5,2406 & 0,6759 & 4,3055 & 0,1512 & 0,9631 & 0,0364 & 0,8810 \\
5,4801 & 0,8261 & 5,2623 & 0,6755 & 4,3029 & 0,1597 & 1,0173 & 0,0411 & 0,8976 \\
5,8591 & 0,8922 & 5,6833 & 0,6209 & 3,9551 & 0,2599 & 1,6556 & 0,0483 & - \\
\end{tabular}

bis 25. Januar 1901 trocken.

\begin{tabular}{|r|r|r|r|r|r|r|r|c}
20,4401 & 3,1200 & 19,8744 & 0,9558 & 6,0884 & 2,1710 & 13,8293 & 0,0927 & 10,824 \\
5,5776 & 0,7935 & 5,0546 & 0,5130 & 2,2684 & 0,2941 & 1,8734 & 0,0796 & 0,9694 \\
4,8539 & 0,7071 & 4,5042 & 0,5276 & 3,3608 & 0,1785 & 1,1370 & 0,0660 & 0,9656 \\
$\dot{4}, 6169$ & 0,6591 & 4,1985 & 0,5356 & 3,4118 & 0,3502 & 2,2308 & 0,0666 & 0,9240 \\
4,2902 & 0,6307 & 4,0577 & 0,5376 & 3,4245 & 0,0918 & 0,5848 & 0,0437 & - \\
4,2067 & 0,6085 & 3,8761 & 0,5049 & 3,2162 & 0,0984 & 0,6268 & 0,0503 & - \\
4,0519 & 0,5910 & 0,7647 & 0,4759 & 3,0315 & 0,1050 & 0,6689 & 0,0438 & - \\
4,2265 & 0,6114 & 3,8946 & 0,5072 & 3,2309 & 0,1098 & 0,6994 & 0,0461 & 0,9208 \\
4,0009 & 0,5831 & 3,7143 & 0,4826 & 3,0742 & 0,1005 & 0,6402 & 0,0524 & 0,9429 \\
3,8685 & 0,5586 & 3,5583 & 0,4648 & 2,9608 & 0,1004 & 0,6395 & 0,0502 & 0,9205 \\
3,3519 & 0,4956 & 3,1569 & 0,4257 & 2,7117 & 0,0742 & 0,4727 & 0,0349 & - \\
3,1621 & 0,4713 & 3,0022 & 0,4007 & 2,5525 & 0,0638 & 9,4064 & 0,0342 & - \\
3,1144 & 0,4685 & 2,9843 & 0,3980 & 2,5353 & 0,0659 & 0,4198 & 0,0341 & - \\
3,0494 & 0,4415 & 2,8124 & 0,3744 & 2,3849 & 0,0641 & 0,4083 & 0,0306 & - \\
2,9316 & 0,4144 & 2,6397 & 0,3526 & 2,2461 & 0,0792 & 0,5045 & 0,0418 & 0,6744 \\
2,8964 & 0,4172 & 2,6576 & 0,3377 & 2,1511 & 0,0817 & 0,5204 & 0,0375 & - \\
2,9372 & 0,4258 & 1,7123 & 0,3640 & 2,3187 & 0,0662 & 0,4217 & 0,0397 & - \\
2,9194 & 0,4275 & 2,7232 & 0,3636 & 2,3161 & 0,0708 & 0,4509 & 0,0366 & 0,5840 \\
2,8098 & 0,4159 & 2,6493 & 0,3474 & 2,2129 & 0,0709 & 0,4516 & 0,0366 & 0,6608 \\
2,9576 & 0,4242 & 2,7022 & 0,3592 & 2,2881 & 0,0673 & 0,4287 & 0,0494 & 0,6680 \\
2,7729 & 0,3975 & 2,5321 & 0,3279 & 2,0887 & 0,0764 & 0,4867 & 0,0472 & - \\
3,0308 & 0,4421 & 2,8162 & 0,3725 & 2,3728 & 0,0696 & 0,4434 & 0,0471 & - \\
3,08444 & 0,4497 & 2,8656 & 0,3782 & 2,4091 & 0,0715 & 0,4555 & 0,0346 & - \\
3,1016 & 0,4648 & 2,9608 & 0,3899 & 2,4837 & 0,0785 & 0,5000 & 0,0296 & - \\
3,4245 & 0,5088 & 3,2411 & 0,4247 & 2,7053 & 0,0819 & 0,5217 & 0,0464 & - \\
3,3716 & 0,5071 & 3,2302 & 0,3936 & 2,5072 & 0,1023 & 0,6517 & - & - \\
2,9914 & 0,4431 & 2,8225 & 0,3549 & 2,2607 & 0,0684 & 0,4957 & 0,0397 & - \\
$.3,1971$ & 0,4753 & 3,0277 & 0,3913 & 2,4926 & 0,0685 & 0,4363 & 0,0265 & - \\
3,1156 & 0,4626 & 2,9468 & 0,4095 & - & - & - & 0,0354 & - \\
& & & & & & & & - \\
\hline
\end{tabular}


Tabell

Colostrum und einige späteri

\begin{tabular}{|c|c|c|c|c|c|c|c|}
\hline Datum de & Probenahme & & $\begin{array}{c}\text { Milch- } \\
\text { menge } \\
\mathbf{k g} \\
\end{array}$ & $\begin{array}{l}\text { Speci- } \\
\text { fisches } \\
\text { Gewicht }\end{array}$ & $\begin{array}{c}\text { Fętt } \\
\% \\
\end{array}$ & $\begin{array}{c}\text { Trocken- } \\
\text { substanz } \\
\% \\
\end{array}$ & $\begin{array}{c}\text { Ge- } \\
\text { sammt- } \\
\text { stick- } \\
\text { stoff } \\
\% \\
\end{array}$ \\
\hline 26. November & 1900 Abends & . & 1. Gemelk & 1,0715 & 4,15 & 26,95 & 2,8960 \\
\hline 27. & 1900 Morgens & - & 2. & 1,0669 & 6,00 & 27,40 & 2,7288 \\
\hline 27. & 1900 Mittags & - • & 3. & 1,0710 & - & 27,62 & $2, \dot{8110}$ \\
\hline 27. & 1900 Abends & - & 4. & 1,0625 & - & 26,11 & $2, \overline{5} 937$ \\
\hline 28. & 1900 Morgens' & - $\cdot$ & 5. & 1,0486 & - & 21,10 & 1,8347 \\
\hline 28. & 1900 Mittags & . & 6. & 1,0475 & 6,80 & 21,50 & 1,7077 \\
\hline 5. Dezember & $1900 \ldots$ & . & 11,40 & 1,0332 & 3,85 & 13,38 & 0,6148 \\
\hline .12. & $1900 \ldots$ & . . & 15,83 & 1,0320 & 3,90 & 13,30 & $.0,5361$ \\
\hline 19. & $1900 \ldots$ & 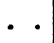 & 16,50 & 1,0313 & 3,65 & 12,70 & $\cdot 0,4995$ \\
\hline 9. Januar 190 & $01 \ldots$ & & 15,50 & 1,0311 & 3,50 & 12,30 & 0,5014 \\
\hline $23 . \quad 190$ & $01 \ldots$ & . & 13,90 & 1,0300 & 3,85 & 12,43 & 0,4971 \\
\hline 12. März 1901 & . . . . . & $\therefore$ & 11,80 & 1,0308 & 3,20 & 11,85 & 0,5181 \\
\hline
\end{tabular}

Colostrum der

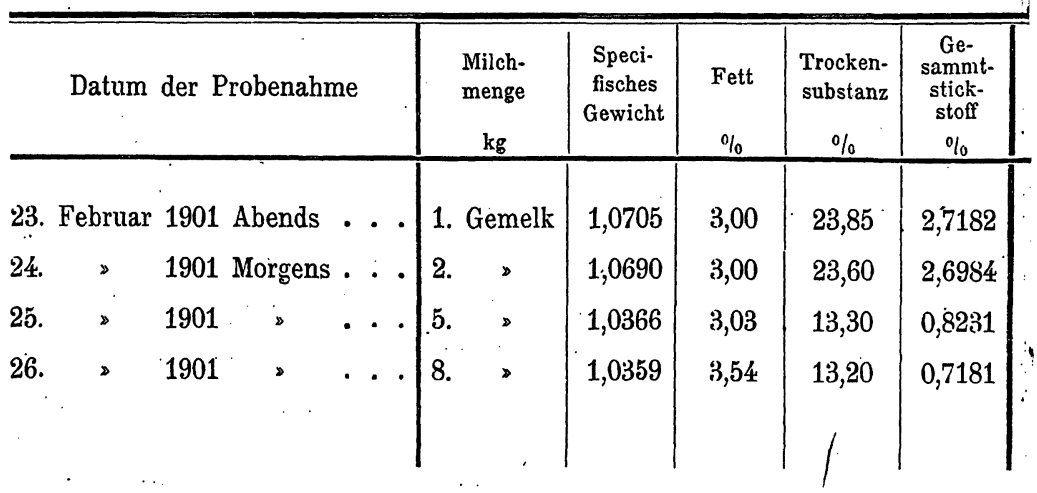


$V$.

Gemelke der Kuh 673.

\begin{tabular}{|c|c|c|c|c|c|c|c}
\hline $\begin{array}{c}\text { Gesammt- } \\
\text { stickstoff } \\
\times 6,37\end{array}$ & $\begin{array}{c}\text { Eiweiss- } \\
\text { stickstoff }\end{array}$ & Eiweiss & $\begin{array}{c}\text { Casein- } \\
\text { stickstoff }\end{array}$ & $\begin{array}{c}\text { Casein } \\
\%\end{array}$ & $\begin{array}{c}\text { Albumin- } \\
\text { stickstof }\end{array}$ & Albumin & $\begin{array}{c}\text { Extractiv- } \\
\text { stickstof } \\
\%\end{array}$ \\
\hline 18,4475 & 2,8390 & 18,0889 & 0,9075 & 5,7807 & 1,9049 & 12,1342 & 0,0665 \\
17,3825 & 2,6606 & 16,9480 & 0,8414 & 5,3597 & 1,8125 & 11,5456 & 0,0764 \\
17,9061 & 2,6670 & 16,9887 & 0,8433 & 5,3718 & 1,8914 & 12,0482 & 0,0698 \\
16,5219 & 2,5494 & 16,2397 & 0,7823 & 4,9833 & 1,7532 & 11,1679 & 0,0698 \\
11,6870 & 1,7794 & 11,3348 & 0,6365 & 4,0545 & 1,1382 & 7,2503 & 0,0697 \\
10,8780 & 1,5571 & 9,9187 & 0,5392 & 3,4347 & 1,0876 & 6,9280 & 0,0697 \\
3,9163 & 0,5781 & 3,6825 & 0,4655 & 2,9655 & 0,1124 & 0,7159 & 0,0367 \\
3,4149 & 0,5085 & 3,2391 & 0,4165 & 2,6531 & 0,0943 & 0,6009 & 0,0368 \\
3,1818 & 0,4812 & 3,0652 & 0,3941 & 2,5104 & 0,0825 & 0,5255 & - \\
3,1939 & 0,4745 & 3,0226 & 0,4003 & 2,5499 & 0,0697 & 0,4499 & 0,0293 \\
3,1665 & 0,4656 & 2,9659 & 0,3981 & 2,5358 & 0,0742 & 0,4771 & 0,0292 \\
3,3003 & 0,4769 & 3,0379 & 0,4081 & 2,5996 & 0,0683 & 0,4351 & 0,0441 \\
& & --- & &. & & & \\
& & & & & & &
\end{tabular}

Kuh 674.

\begin{tabular}{|c|c|c|c|c|c|c|c}
\hline \hline $\begin{array}{c}\text { Gesammt- } \\
\text { stickstoff } \\
\times 6,37 \\
\%\end{array}$ & $\begin{array}{c}\text { Eiweiss- } \\
\text { stickstoff } \\
\%\end{array}$ & Eiweiss & $\begin{array}{c}\text { Casein- } \\
\text { stickstoff } \\
\%\end{array}$ & $\begin{array}{c}\text { Casein } \\
\%\end{array}$ & $\begin{array}{c}\text { Albumin- } \\
\text { stickstoff } \\
\%\end{array}$ & Albumin & $\begin{array}{c}\text { Extractiv- } \\
\text { stickstoff } \\
\%\end{array}$ \\
\hline & & & 0,7073 & 5,5055 & 1,8738 & 11,9361 & 0,0763 \\
17,3149 & 2,6697 & 17,0059 & 0,703 & & \\
17,1888 & 2,6497 & 16,8786 & 0,7024 & 4,4743 & 1,8515 & 11,7940 & 0,0766 \\
5,2431 & 0,7743 & 4,9323 & 0,4743 & 3,0213 & 0,3002 & 1,9123 & 0,0419 \\
4,5743 & 0,6832 & 4,3519 & 0,4810 & 3,0639 & 0,1814 & 1,1555 & vacat \\
& & & & & & & $\ldots$
\end{tabular}

